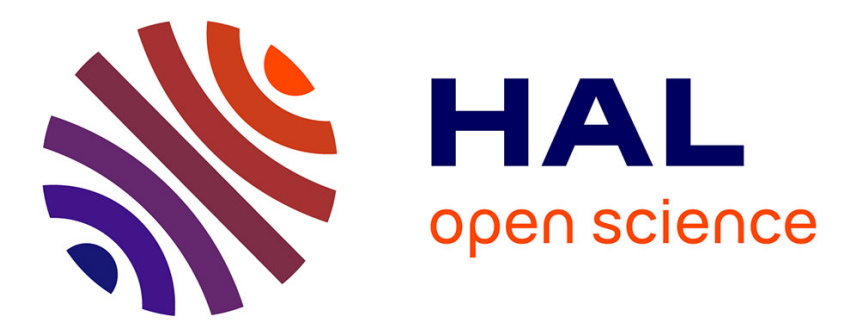

\title{
Advances in drug delivery systems based on synthetic poly(hydroxybutyrate) (co)polymers
}

Ghislaine Barouti, Cédric C. Jaffredo, Sophie M. Guillaume

\section{To cite this version:}

Ghislaine Barouti, Cédric C. Jaffredo, Sophie M. Guillaume. Advances in drug delivery systems based on synthetic poly(hydroxybutyrate) (co)polymers. Progress in Polymer Science, 2017, 73, pp.1 - 31. 10.1016/j.progpolymsci.2017.05.002 . hal-01616813

\section{HAL Id: hal-01616813 https://hal.science/hal-01616813}

Submitted on 14 Oct 2017

HAL is a multi-disciplinary open access archive for the deposit and dissemination of scientific research documents, whether they are published or not. The documents may come from teaching and research institutions in France or abroad, or from public or private research centers.
L'archive ouverte pluridisciplinaire HAL, est destinée au dépôt et à la diffusion de documents scientifiques de niveau recherche, publiés ou non, émanant des établissements d'enseignement et de recherche français ou étrangers, des laboratoires publics ou privés. 


\section{Accepted Manuscript}

Title: Advances in drug delivery systems based on synthetic poly(hydroxybutyrate) (co)polymers

Authors: Ghislaine Barouti, Cédric G. Jaffredo, Sophie M.

Guillaume

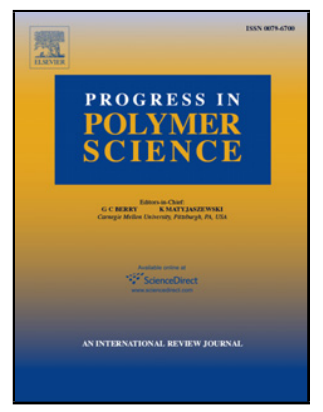

PII:

S0079-6700(16)30082-X

DOI: http://dx.doi.org/doi:10.1016/j.progpolymsci.2017.05.002

Reference: JPPS 1028

To appear in:

Progress in Polymer Science

Received date:

$12-10-2016$

Revised date:

$25-4-2017$

Accepted date:

15-5-2017

Please cite this article as: Barouti Ghislaine, Jaffredo Cédric G, Guillaume Sophie M.Advances in drug delivery systems based on synthetic poly(hydroxybutyrate) (co)polymers.Progress in Polymer Science http://dx.doi.org/10.1016/j.progpolymsci.2017.05.002

This is a PDF file of an unedited manuscript that has been accepted for publication. As a service to our customers we are providing this early version of the manuscript. The manuscript will undergo copyediting, typesetting, and review of the resulting proof before it is published in its final form. Please note that during the production process errors may be discovered which could affect the content, and all legal disclaimers that apply to the journal pertain. 


\title{
Advances in drug delivery systems based on synthetic poly(hydroxybutyrate) (co)polymers
}

Ghislaine Barouti, Cédric G. Jaffredo and Sophie M. Guillaume*

Institut des Sciences Chimiques de Rennes (ISCR), CNRS - Université de Rennes 1, Campus de Beaulieu, 263 Avenue du Général Leclerc, F-35042 Rennes Cedex, France

*Corresponding author : sophie.guillaume@univ-rennes1.fr

\begin{abstract}
Within the general context of nanomedicine, drug delivery systems based on polymers have sparked a rapidly growing interest and have arisen many efforts to tackle various diseases, among which cancer. Polyester-based nanoparticulate drug delivery systems, including polymer-drug conjugates and amphiphilic block copolymers, represent a major class with promising outcomes, especially for those derived from poly(3-hydroxybutyrate) (PHB). This review describes recent advances in drug delivery systems designed from the selfassembly of synthetic (co)polymers derived from PHB. The various strategies for the synthesis of PHB-conjugates, PHB/poly(ethylene glycol) (PEG) and other PHB-based copolymers are first summarized. Nanoparticles, micelles, microparticles, and hydrogels elaborated from these (co)polymers following various preparation methods, along with their exploitation in the encapsulation and release of various therapeutic agents, are next detailed. Finally, we discuss the synthetic challenges, drug delivery outlooks, and perspectives of PHBbased drug delivery systems. Engineered nano-scaled materials based on PHB self-assembled systems are thus anticipated to emerge as a valuable platform for original drug delivery systems.
\end{abstract}

\section{Contents}

1. Introduction

2. PHB-based (co)polymers prepared from synthetic routes 
2.1. Chemically modified bacterial PHB-based (co)polymers

2.2. PHB-based copolymers prepared from ring-opening polymerization of $\beta$-butyrolactone

3. PHB-based (co)polymers for drug delivery applications

3.1. Preparation methods and characteristics of PHB-based self-assembled systems

3.2. Encapsulation and drug release from PHB-based self-assembled systems

3.3. Targeting approaches associated with PHB-based self-assembled systems

3.4. In-vitro and in-vivo effects of PHB-based self-assembled systems

3.5. Biodegradation of PHB-based self-assembled systems

4. Concluding remarks and outlooks

Acknowledgements

References

\section{Abbreviations}

AG A33scFv Green fluorescence protein

3HB-CoA 3-Hydroxybutyryl-coenzyme A

API Active pharmaceutical ingredient

ATRP Atom transfer radical polymerization

BL $\quad \beta$-Butyrolactone

$\mathrm{BL}^{\text {allyl } \quad \text { Allyl- } \beta \text {-butyrolactone }}$

rac-BL Racemic $\beta$-butyrolactone

rac-BL ${ }^{\text {allyl }}$ Racemic allyl- $\beta$-butyrolactone

BrdU Bromodesoxyuridine

CD Cyclodextrin

CDI 1,1'-Carbonyldiimidazole

CMC Critical micelle concentration

DBTL Dibutyl tin dilaurate

DCC Dicyclohexylcarbodiimide

DCP Dicumyl peroxide

DDS Drug delivery system

$D_{\mathrm{h}} \quad$ Hydrodynamic diameter

Did Oil Dioctadecyl-3,3,3',3'-tetramethylindodicarbocyanine perchlorate

DLC Drug loading content

DLE Drug loading efficiency 
$\begin{array}{ll}\text { DLS } & \text { Dynamic light scattering } \\ Ð_{M} & \text { Dispersity, } M_{\mathrm{w}} / M_{\mathrm{n}}\end{array}$

DMAEMA 2-(Dimethylamino)ethyl methacrylate)

DMAP 4-Dimethylaminopyridine

DMTA Dynamic mechanical thermal analysis

DM- $\beta C D \quad H e p t a k i s(2,6$-di- $O$-methyl)- $\beta$-cyclodextrin

DOCA Deoxycholic acid

DOSY Diffusion ordered spectroscopy

DOX Doxorubicin

DSC Differential scanning calorimetry

EEP Ethyl ethylene phosphate

$f \quad$ Hydrophilic weight fraction

FDA U.S. Food and Drug Administration

FITC Fluorescein isothiocyanate

Fmoc Fluorenylmethyloxycarbonyl

FOL Folic acid

FRET Fluorescence resonance energy transfer

FT-IR Fourier transform infrared spectroscopy

GFP Green fluorescence protein

HB Hydroxybutyrate

HDI 1,6-Hexamethylene diisocyanate

$\mathrm{IC}_{50} \quad$ Half maximal inhibitory concentration

ICG Indocyanine green

$K \quad$ Partition equilibrium coefficient

LCST Low critical solution temperature

MALDI-ToF MS Matrix-assisted laser desorption/ionization - time of flight mass spectrometry

MCS 3-D Multicellular spheroids

MLA $\quad \beta$-Malic acid

MLA $^{\text {Be }} \quad$ Benzyl $\beta$-malolactonate

$M_{\mathrm{n}} \quad$ Number average molar mass of a polymer sample

MTT 3-(4,5-Dimethylthiazol-2-yl)-2,5-diphenyltetrazolium bromide

$M_{\mathrm{w}} \quad$ Weight average molar mass of a polymer sample

$N_{\text {agg }} \quad$ Number of aggregation

nat Natural (microbial)

Nile red 5-Benzo[ $\alpha]$ phenoxazinone

NIPAAM $N$-isopropylacrylamide

NMR Nuclear magnetic resonance

Oil Red O 1-(2,5-dimethyl-4-(2,5-dimethylphenyl) phenyldiazenyl) azonapthalen-2-ol

$p \quad p$-value

$\mathrm{P}(3 \mathrm{HB}-4 \mathrm{HB}) \quad$ Poly(3-hydroxybutyrate-co-

4-hydroxybutyrate)

$\mathrm{P}\left(\mathrm{HB}-c o-\mathrm{HB}^{\text {allyl }}\right)$ Poly(3-hydroxybutyrate-co-allylhydroxybutyrate)

$\mathrm{P}\left(\mathrm{HB}-\mathrm{co}-\mathrm{HB}^{\mathrm{diOH}}\right)$ Poly(3-hydroxybutyrate-co-dihydroxypropane-hydroxybutyrate) 
$\mathrm{P}(R)$-HB Poly $((R)$-3-hydroxybutyrate $)$

PBS Phosphate buffered saline

PCL Poly( $\varepsilon$-caprolactone)

PDMAEMA Poly(2-(dimethylamino)ethyl methacrylate)

PEEP Poly(ethyl ethylene phosphate)

PEG Poly(ethyl ethylene glycol)

PEG-COOH $\omega$-Carboxy poly(ethylene glycol)

PF-127 or Pluronic Pluronic ${ }^{\circledR}$ F-127, (polyethylene glycol)- $b$-(polypropylene glycol)- $b$ (polyethylene glycol)

PHA Poly(hydroxyalkanoate)

PHB Poly(3-hydroxybutyrate)

$\mathrm{PHB}^{\mathrm{diOH}}$ Poly(dihydroxypropanehydroxy-butyrate)

PHBHH Poly(3-hydroxybutyrate-co-3-hydroxyhexanoate)

PHBV Poly(3-hydroxybutyrate-co-3-hydroxyvalerate)

PLA Poly(lactide)

PLAGA Poly(lactic acid-co-glycolic acid)

PMLA Poly $(\beta$-malic acid)

PMLA $^{\text {Be }} \quad$ Poly(benzyl $\beta$-malolactonate)

PNIPAAM Poly( $N$-isopropyl acrylamide)

PPG Poly(propylene glycol)

PPO Poly(propylene oxide)

PVA Poly(vinyl alcohol)

RES Reticulo-endothelial system

$R_{\mathrm{g}} \quad$ Gyration radius

RGD4C Cyclic peptide (amino acid sequence: ACDCRGDCFCG)

$R_{\mathrm{h}} \quad$ Hydrodynamic radius

SLS Static light scattering

$\mathrm{Sn}(\mathrm{Oct})_{2} \quad$ Tin octoate

sPEG Star poly(ethylene glycol)

synt Synthetic

TAM Triallyl trimesate

TBD 1,5,7-Triazabicyclo[4.4.0]dec-5-ene

TEM Transmission electron microscopy

TEMPO (2,2,6,6-tetramethylpiperidin-1-yl)oxy

$T_{\mathrm{g}} \quad$ Glass transition temperature

TGA Thermal gravimetric analysis

Tm Melting temperature

Tween 80 Poly(ethylene glycol) sorbitan monooleate

XRD X-Ray diffraction

Keywords: Poly(3-hydroxybutyrate) (PHB), amphiphilic block copolymer, self-assembled systems, colloidal properties, drug delivery system (DDS), biological properties 


\section{Introduction}

Nanomedicine, the application of nanotechnology to a safer and more effective medicine, aims at developing theranostic nano-scaled materials to tackle various diseases, such as cancers, while avoiding the issues of conventional therapeutic agents [1-5]. Multifunctional nanoparticle-based drug delivery systems (DDSs) can contribute to improved water solubility and prolonged circulation half-life of drugs, reduced immunogenicity and enhanced biodistribution while controlling their release, and site-specific active targeting for a specific distribution [6-12]. While a number of engineered nanoparticle platforms derived from polymers are currently used in clinical treatments, much remains to be done to improve their performance.

Polymer-based nanoparticulate structures used in DDSs are usually derived from dendrimers, micelles, nanoparticles or nanogels, with diameters ranging from 1 to $1000 \mathrm{~nm}$ [8,13-18]. Nanocarriers can incorporate a drug through covalent bonding to the polymer, thereby resulting in a polymer-drug conjugate [11,19-22]. Alternatively, the drug can be embedded through hydrophobic interactions within an amphiphilic polymer platform. Polysaccharides, poly(aminoacid)s, polypeptides and proteins, polyesters, or poly(alkyl cyanoacrylate)s are the most widely used polymers in nanocarriers [23]. Polyester-based DDSs are the most widely developed, as the result of the biocompatibility and biodegradability of these polymers. In particular, the ubiquitous poly(lactic acid) (PLA) and poly(glycolic acid), and their copolymers poly(lactic-co-glycolic acid) (PLGA), have been extensively investigated in combination with poly(ethylene glycol) (PEG) [24,25]. The resulting amphiphilic block copolymers such as PLA- $b$-PEG and PLGA- $b$-PEG, selfassembled into nanoparticles, micelles or polymersomes featuring a hydrophobic PLA or PLGA core and an outer hydrophilic PEG corona [26-31]. Polyester-systems prepared from $\operatorname{poly}(\varepsilon$-caprolactone) [32-34] or poly(hydroxyalkanoate)s (PHAs; vide infra), often associated with PEG, similarly form nano-sized objects. PEG has thus been used as a biocompatible 
hydrophilic segment enabling the preparation of nanoparticles with controlled size. Furthermore, PEG was shown to provide "stealth", inhibiting fast recognition by the immune systems (i.e., the opsonisation) and minimizing particle aggregation [16,35-39]. However, the non-biodegradability of this polyether can impedes its application within DDSs. Moreover the immunological inertia of PEG is not demonstrated and the accumulation of PEGylated compounds in the liver has unidentified toxicological consequences over a long period of time [40].

The synthetic approaches towards these polyester-based DDSs basically consist in the ring-opening polymerization (ROP) of lactide (LA), glycolide (GA), or ( $\varepsilon$-caprolactone) (CL) from PEG-macroinitiating moieties, or alternatively in the chemical coupling of preformed PLA, PGA, PLGA, PCL, or PHA, with PEG segments. Furthermore, polyester nanoparticulate DDSs can be formed from either naturally occurring polymers such as chitosan [41] or PHAs [42-44], or from synthetic macromolecules such as PLA, PEG, PCL or PHAs. Indeed, PHAs can be advantageously both naturally (microbial PHAs) or synthetically (chemically) produced [43,45-57]. Among the numerous PHAs, the ubiquitous biocompatible and biodegradable poly(3-hydroxybutyrate) (PHB) can be obtained from bacteria as isotactic PHB, while ROP of substituted $\beta$-lactones provides a valuable entry into PHBs featuring various tunable microstructures (atactic, syndiotactic, isotactic) [58-60]. The stereoregularity of the enchainment of $\beta$-lactone units within PHB dictates its thermomechanical properties. In particular, microbial isotactic PHB is a stiff and rather brittle polymer of high crystallinity, and consequently not easily processable, thus impeding its applications such as in packaging, implantable devices, or also drug delivery applications [57,61]. Therefore, the possibility to access various PHBs with different stereochemistries from ROP opens new venues in PHBbased DDSs [62]. In addition, PHB promotes the formation of micelles with enhanced colloidal stability and high drug loading efficiency (DLE), without requiring the use of a surfactant [63-73]. Moreover, the very low critical micelle concentration (CMC) of PHB- 
based micelles is expected to impart a longer in-vivo half-life and ultimately a better efficiency compared to other polyester-based DDSs. Natural as well as synthetic PHBs have thus been associated with various hydrophilic polymers such as PEG, poly( $N$-isopropyl acrylamide) (PNIPAAM), poly(2-dimethylamino ethyl methacrylate) (PDMAEMA), or poly(ethyl ethylene phosphate) (PEEP). However, the latter hydrophilic polymers are nonbiodegradable and can be excreted by the renal system only if their molar mass is below 20000 g.mol ${ }^{-1}$. In addition, these polymers can be accumulated in the liver with unidentified toxicological outcomes over a long period of time [40].

In this review, we first introduce the synthetic strategies for the preparation of PHBbased (co)polymers next used for drug delivery applications, as summarized in Table 1. The focus is placed on synthetic PHB-based DDSs and not on natural ones. We next highlight the self-assembling properties of PHB-based systems, including nanoparticles, micelles, microparticles and hydrogels, along with their characteristics, as gathered in Table 2. Investigations of the ability of these PHB-based materials to encapsulate and subsequently release a drug, possibly through targeting approaches, are reported along with some in-vitro and in-vivo behavior (Table 3).

\section{PHB-based (co)polymers prepared from synthetic routes}

Most self-assembled systems using PHB are based on bacterial semi-crystalline poly $((R)$-3-hydroxybutyrate) $\mathrm{P}(R)$-HB [43,45-57]. Indeed, industrial production of bacterial PHB, and generally of PHAs (poly(3-hydroxybutyrate-co-4-hydroxybutyrate) (P(3HB-4HB)), poly(3-hydroxybutyrate-co-3-hydroxyvalerate) (PHBV), poly(3-hydroxybutyrate-co-3hydroxyhexanoate (PHBHH), etc.), has known a tremendous development since the early 80's [45]. PHB is now available from fermentation processes using natural microorganisms such as Ralstonia eutropha, Alcaligenes latus or Bacillus spp., or modified microorganisms such as 
Escherichia coli, fed by glucose or sucrose [74]. Nevertheless, only long-chain isotactic PHB polymers and random copolymers are obtained from this microbial strategy.

Given the aforementioned limitations of such native PHB-based materials, modified PHB-based copolymers have been developed. Enhancing PHB properties by covalent bonding to other polymers has been favored. Thus, the chemical modification of microbial isotactic PHB or the chemical synthesis of - especially amorphous - PHB from the ROP of $\beta$ butyrolactone (BL), have afforded an emerging category of self-assembled systems with tunable properties. The aim of this first section is to cover the different synthetic pathways to PHB-based (co)polymers (originating from bacterial PHB or from fully man-made ones) which have been developed for drug delivery applications. The two major approaches, namely modification of bacterial PHB and PHB obtained by ROP of BL, are overviewed. Synthetic strategies, catalytic systems and the characterization of the resulting copolymers are addressed (Table 1). Note that Table 1 only gathers the most relevant features of the PHB-based copolymers. The objective of this Table 1 being the comparative evaluation of PHB-based copolymers, it is not devised to include all the reported properties. The reader is invited to refer to the original work for other sparingly available data.

\section{Table 1.}

\subsection{Chemically modified bacterial PHB-based (co)polymers}

Historically, native PHB homopolymer, i.e,. $\mathrm{P}(R)-\mathrm{HB}$ [93-97], and bacterial copolymers such as $\mathrm{P}(3 \mathrm{HB}-\mathrm{co}-4 \mathrm{HB})$ [98-100], PHBV [101-103] or $\mathrm{PHBH}$ and derivatives [104-106], have been used for the elaboration of self-assembled systems such as DDSs, tissue engineering scaffolds and implants [107-110]. Those polymers have been chosen for their biodegradability and biocompatibility. The properties of such bacterial PHAs remain limited and their chemical modification opened the way to new (co)polymer structures of interest for 
self-assembled systems and their subsequent applications. All native PHBs discussed in this section are isotactic bacterial PHB (Table 1).

\subsubsection{Bacterial PHB homopolymers chemically modified into PHB-conjugates}

The synthesis of bacterial PHB conjugated to a targeting agent was scarcely reported in the literature. Kim and coworkers investigated the synthesis of RGD4C-PHB conjugated polymer (RGD4C = a cyclic peptide with the amino acid sequence: ACDCRGDCFCG) [76]. The strategy was based on the use of fused RGD4C-PHA synthase. In the presence of 3(R)-hydroxybutyryl-coenzyme A (3HB-CoA), the PHA synthase produced PHB through an enzymatic pathway, and the polymerization was proposed to afford a polymer chain which remained covalently bound to the PHA synthase enzyme, itself bearing the peptide, namely RGD4C-PHB. Nevertheless, no clear information was given to support this binding $[111,112]$.

This strategy was recently used by Kim and coworkers with the aim to synthesize multi-functional PHB nanoparticles for theranostic applications [75]. Tri-fused protein A33scFv-green fluorescence protein-PHA synthase (AG-PHA synthase), used as targeting, imaging and catalytic moiety in the presence of 3HB-CoA, led to the formation of AG-PHB conjugate. In both cases, no information on the characterization of the polymer conjugates was yet reported.

\subsubsection{Chemically modified bacterial PHB/PEG-based copolymers}

Bacterial PHB has often been associated with poly(ethylene glycol) (PEG) [113,114], an hydrophilic and biodegradable polyether, to form amphiphilic copolymers.

Recently, bile acid deoxycholic acid (DOCA) was conjugated to a PHB- $b$-PEG block copolymer [77]. Kulkarni, Aminabhavi and co-workers implemented a two-step route (Scheme 1). First, long-chain bacterial PHB was transesterified by PEG-OH $\left(M_{\mathrm{n}}=4000\right.$ 
g.mol ${ }^{\llbracket 1}$ ) using dibutyl tin dilaurate (DBTL) as a catalyst, to afford short-chain $\alpha, \omega$-dihydroxy telechelic PHB-b-PEG copolymer. The second step involved the coupling of this diblock copolymer diol with DOCA using both dicyclohexylcarbodiimide (DCC) and 4dimethylaminopyridine (DMAP), leading to the di-DOCA conjugated block copolymer, DOCA-PHB- $b$-PEG-DOCA, further analyzed by both ${ }^{1} \mathrm{H}$ and solid state ${ }^{13} \mathrm{C}$ NMR spectroscopy. This copolymer was next used for the formation of nanoparticles loaded with fluorescein isothiocyanate labelled insulin, for cytotoxicity evaluation (vide infra).

\section{Scheme 1.}

Recently, Kim and co-workers showed the effect of the control of the relative length of PHB/PEG blocks on the loading and the release profile of the drug from nanoparticles prepared from PHB-co-PEG diblock copolymers $\left(M_{\mathrm{n}}=5600-9900\right.$ g.mol $\left.{ }^{\natural 1}\right)$, obtained from the coupling of PHB and PEG in the presence of tin octoate [69]. The study was performed in-vitro by using Griseofulvin (antifungal drug) as hydrophobic model drug (vide infra).

The synthesis of ABA triblock copolymers using PEG (A) and PHB (B) was developed following the pioneering work of Li's group [78]. The triblock copolymer $\alpha, \omega-$ dimethoxy poly(ethylene glycol)- $b$-poly $((R)-3$-hydroxybutyrate)- $b$-poly(ethylene glycol) (PEG- $b$-PHB- $b$-PEG) was prepared according to a three-step strategy (Scheme 2) $[64,67,78]$. First, bacterial long-chain PHB was purified upon dissolution in chloroform, filtration and precipitation in petroleum ether, to afford PHB with $M_{\mathrm{n}}=87000 \mathrm{~g} \cdot \mathrm{mol}^{\natural 1}$ and $\bigoplus_{\mathrm{M}}=2.64$. The next transesterification step using diethylene glycol with DBTL as catalyst in diglyme, then gave shorter $\alpha, \omega$-dihydroxy telechelic PHB (PHB diol oligomers) with a controlled chainlength ranging from 500 to 5500 g.mol ${ }^{\square 1}$ [115]. During the latter procedure, diethylene glycol and DBTL could be replaced by ethylene glycol and tin octoate $\left(\operatorname{Sn}(\mathrm{Oct})_{2}\right)$, respectively, without affecting the overall strategy. The last step was the coupling of the PHB diol with two equivalents of mono-carboxy terminated PEG (PEG-COOH), in the presence of DCC and 
DMAP as catalyst, finally affording the PEG- $b$-PHB- $b$-PEG triblock copolymer $\left(M_{\mathrm{n}}=4500-\right.$ 13400 g.mol ${ }^{\square 1} ; \bigoplus_{\mathrm{M}}=1.04-1.21$ ) [78]. The PHB block length was modulated from 7-59wt\% by controlling the reaction time of the transesterification step, and also by the selection of PEG-COOH with different molar mass values. The presence of the two distinct repeating units in the polymer chain was confirmed by ${ }^{1} \mathrm{H}$ NMR spectroscopy, showing the characteristic signals of the PEG and PHB segments, and by differential scanning calorimetry (DSC) thermal analyses showing melting transition temperatures for PEG and PHB ( $T_{\mathrm{m}} c a$. $54{ }^{\circ} \mathrm{C}$ and $\mathrm{ca} .147^{\circ} \mathrm{C}$, respectively). Li and co-workers subsequently studied the micellization and self-aggregation behavior of such triblock copolymers (vide infra) $[64,67]$.

\section{Scheme 2.}

Pun and co-workers also reported the synthesis of PEG- $b$-PHB- $b$-PEG triblock copolymers $\left(M_{\mathrm{n}}=12700\right.$ g.mol ${ }^{\square 1} ; \bigoplus_{\mathrm{M}}=1.13$; measured by SEC using THF as eluent and PEG standards) to form polymeric micelles for the encapsulation of doxorubicin (DOX), an effective chemotherapeutic drug against a wide range of solid tumors [71]. Following the synthetic approach previously reported, the authors further used $\alpha$-amine, $\omega$-carboxylic PEG $\left(\mathrm{H}_{2} \mathrm{~N}-\mathrm{PEG}-\mathrm{COOH}\right)$ for the synthesis of fluorescein-conjugated PEG- $b$-PHB- $b$-PEG triblock copolymers (Scheme 3). The amine group of $\mathrm{H}_{2} \mathrm{~N}-\mathrm{PEG}-\mathrm{COOH}$ reacted with the isothiocyanate derivative of fluorescein, in the presence of trimethylamine as a catalyst, leading to the formation of the fluorescein-PEG-COOH via a thiourea bonding. The latter prepolymer was then reacted with the PEG-PHB-OH diblock copolymer, previously formed by esterification of PHB diol and PEG-COOH using DCC/DMAP, to ultimately give the fluorescein-conjugated PEG- $b$-PHB- $b$-PEG triblock copolymer. The copolymer was purified by ultrafiltration to remove unreacted fluorescein and then lyophilized. This copolymer enabled the evaluation of DOX-loaded PEG- $b$-PHB- $b$-PEG micelles to diffuse through tumorlike tissues (vide infra) [71].

\section{Scheme 3.}


Following studies on poly(ethylene glycol- $b$-propylene glycol- $b$-ethylene glycol) (PEG- $b$-PPG- $b$-PEG also known as Pluronic F-127; PF-127, vide infra) triblock copolymers [116], Pun and co-workers reported the use of a mixture of PF-127 $\left(\mathrm{PEG}_{100}-\mathrm{PPG}_{65}-\mathrm{PEG}_{100}\right.$; PEG $_{100}=100$ ethylene glycol repeating units) and PEG- $b$-PHB- $b$-PEG in filamentous micelles for tumor localization [79]. The PEG/PHB triblock copolymers were synthesized according to the strategy developed by Li and co-workers [78], and characterized using NMR and SEC analyses $\left(M_{\mathrm{n}}=13800 \mathrm{~g} \cdot \mathrm{mol}^{-1} ; \bigoplus_{\mathrm{M}}=1.20\right)($ Scheme 4$)$. Thus, HO-PHB- $b$-PEG (presynthesized as aforementioned) was coupled with Fmoc-PEG-COOH (Fmoc = fluorenylmethyloxycarbonyl), in the presence of both DCC and DMAP, to afford the Fmocterminated triblock copolymer. The Fmoc protecting group was then removed by piperidine, using the well-known deprotection procedure by basic cleavage [117], liberating the amine reactive group. The molecular probe Alexa Fluor 488 succinimidyl ester dye was finally coupled with the resulting PEG- $b$-PHB- $b$-PEG-NH 2 , leading to the $\alpha$-dye triblock copolymer conjugate, Alexa Fluor 488-PEG- $b$-PHB- $b$-PEG [79].

\section{Scheme 4.}

$\mathrm{Li}$ and co-workers have also studied copolymers based on PPG, PEG and native PHB segments, covalently bonded within a polyurethane polymer [80]. PHB diol $\left(M_{\mathrm{n}}=1100\right.$ g.mol ${ }^{\llbracket 1}$ ), obtained from the transesterification of bacterial PHB with ethylene glycol and

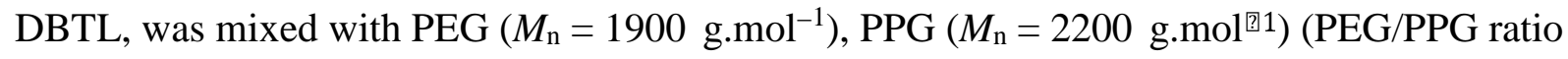
$=2: 1 ;$ PHB ratio $=3-9 \mathrm{~mol} \%$ ), and 1,6-hexamethylene diisocyanate (HDI) used as a coupling agent (Scheme 5). The poly(PEG/PPG/PHB urethane) random copolymers thus obtained showed a high molar mass $M_{\mathrm{n}}=42500-50600 \mathrm{~g} \cdot \mathrm{mol}^{-1}$ and a narrow dispersity $\bigoplus_{\mathrm{M}}=1.37-$ 1.56. ${ }^{1} \mathrm{H}$ as well as ${ }^{13} \mathrm{C}\left\{{ }^{1} \mathrm{H}\right\}$ NMR spectroscopic analyses, confirmed the presence of each repeating unit as well as the characteristic signals of urethane bonds. These copolymers were next used for the formation of gels further evaluated for their cytotoxicity and cell culture 
efficiency (vide infra). Nevertheless, a major drawback of this strategy is the use of isocyanates, which are known to be toxic [118-120].

\section{Scheme 5.}

\subsubsection{Other chemically modified bacterial PHB-based copolymers}

In order to study colloidal drug delivery systems, Pignatello, Ballistreri and coworkers synthesized copolymers from bacterial PHB $\left(M_{\mathrm{w}}=400000\right.$ g.mol $\left.{ }^{-1} ; \bigoplus_{\mathrm{M}}=2.10\right)$ or PHBV $\left(24 \mathrm{~mol} \% \mathrm{HV} ; M_{\mathrm{w}}=177000 \mathrm{~g} \cdot \mathrm{mol}^{-1} ; \bigoplus_{\mathrm{M}}=1.70\right)$, and poly( $\varepsilon$-caprolactone) (PCL) $\left(M_{\mathrm{w}}=120000 \mathrm{~g} \cdot \mathrm{mol}^{-1} ; \bigoplus_{\mathrm{M}}=1.70\right)$ [81]. The authors reported a single-step approach, for the coupling of the microbial polymer (PHB or PHBV) with PCL, by a transesterification reaction catalyzed by para-toluene sulphonic acid. Different initial ratios of pre-polymers were used, affording random copolymers $\left(M_{\mathrm{w}}=4600-25900 \mathrm{~g} \cdot \mathrm{mol}^{-1} ; \bigoplus_{\mathrm{M}}=1.31-1.72\right)$. Matrix-assisted laser desorption/ionization - time of flight mass spectrometry (MALDI-ToF MS) was used to identify terminal groups, confirming the formation of $\alpha$-hydroxy, $\omega$-toluene sulphonate PHB/PHBV-co-PCL random copolymers. Along with the PHB-co-PHB ${ }^{\text {allyl }}$ and PHB-co-PHB diol (vide infra), these later PCL copolymers are the only examples of random PHB-based copolymers used for drug delivery applications.

Previous examples have shown strategies based on the coupling of different polymer chains. Indeed, PHB diols or derivatives (vide infra), were used as macroinitiators for the polymerization of different monomers. Cheng and Wang reported the synthesis of poly(ethyl ethylene phosphate)- $b$-poly(3-hydroxybutyrate)- $b$-poly(ethyl ethylene phosphate) (PEEP- $b$ PHB- $b$-PEEP) by the ROP of ethyl ethylene phosphate (EEP), using PHB diol as a macroinitiator [82]. PHB diol $\left(M_{\mathrm{n}}=900 ; 1600\right.$ or $\left.4050 \mathrm{~g} \cdot \mathrm{mol}^{-1}\right)$, previously obtained from the transesterification of bacterial PHB with ethylene glycol and DBTL as a catalyst, was reacted with EEP in the presence of $\mathrm{Sn}(\mathrm{Oct})_{2}$ (Scheme 6) [121]. The resulting triblock copolymers $\left(M_{\mathrm{n},}=3400-15600 \mathrm{~g} \cdot \mathrm{mol}^{-1} ; \bigoplus_{\mathrm{M}}=1.47-2.23\right)$ were characterized by ${ }^{1} \mathrm{H},{ }^{13} \mathrm{C}\left\{{ }^{1} \mathrm{H}\right\}$ and 
${ }^{31} \mathrm{P}\left\{{ }^{1} \mathrm{H}\right\}$ NMR spectroscopy. In particular, the latter analysis showed a single resonance assigned to a linear phosphonate function. PEEP- $b$-PHB- $b$-PEEP were next used to form micelles, further studied for the encapsulation and the controlled delivery of Paclitaxel (an anticancer drug; vide infra).

\section{Scheme 6.}

$\mathrm{Li}$ and co-workers and Loh and co-workers studied the use of short-chain PHBs as macroinitiators for the atom transfer radical polymerization (ATRP) of different monomers, such as $N$-isopropylacrylamide (NIPAAM) [70,83] and 2-(dimethylamino)ethyl methacrylate) (DMAEMA) [73,84], respectively, according to a common strategy (Scheme 7). PHB diol, again obtained from the transesterification of bacterial PHB with diethylene glycol and catalyzed by DBTL, was reacted with 2 equivalents of 2-bromoisobutyryl bromide in the presence of triethylamine. The resulting Br-PHB-Br $\left(\mathrm{PHB}-\mathrm{diBr} ; M_{\mathrm{n}}=1700 \mathrm{~g} \cdot \mathrm{mol}^{-1} ; \bigoplus_{\mathrm{M}}=\right.$ 1.04 , or $M_{\mathrm{n}}=2100$ g.mol $\left.{ }^{-1} ; \bigoplus_{\mathrm{M}}=1.33\right)$ macroinitiator was next reacted with NIPAAM or DMAEMA, in the presence of $\mathrm{CuBr}$ and 1,1,4,7,10,10-hexamethyltriethylenetetramine, to afford the triblock copolymers PNIPAAM- $b$-PHB- $b$-PNIPAAM $\left(M_{\mathrm{n},}=3800-37700 \mathrm{~g} \cdot \mathrm{mol}^{-1}\right.$; $\left.\bigoplus_{\mathrm{M}}=1.09-1.50\right)$ [70], or PDMAEMA- $b$-PHB- $b$-PDMAEMA $\left(M_{\mathrm{n}}=5200-24000 \mathrm{~g} \cdot \mathrm{mol}^{-1}\right.$ as measured by ${ }^{1} \mathrm{H}$ NMR; $\bigoplus_{\mathrm{M}}=1.23-1.35$ ), respectively (Scheme 7) [73]. The copolymers were characterized by ${ }^{1} \mathrm{H}$ NMR and SEC (THF; vs. PEG standards) analyses. This synthetic route enabled to tune the amount of the different monomers incorporated within the copolymer, and thus to control the length of the different blocks. PNIPAAM- $b$-PHB- $b$-PNIPAAM copolymers with different ratios of NIPAAM $(\mathrm{N})$ and $\mathrm{HB}$ repeating units $\left(\mathrm{N}_{10} \mathrm{HB}_{17} \mathrm{~N}_{10}\right.$; $\mathrm{N}_{60} \mathrm{HB}_{17} \mathrm{~N}_{60} ; \mathrm{N}_{157} \mathrm{HB}_{17} \mathrm{~N}_{157} ; \mathrm{N}_{180} \mathrm{HB}_{17} \mathrm{~N}_{180}$ ) were synthesized and further investigated for their ability to form micelles, and for their thermoresponsiveness (vide infra) [80,83]. These properties were used for the encapsulation and controlled release of pyrene (a molecular probe). On the other hand, a range of PDMAEMA- $b$-PHB- $b$-PDMAEMA triblock 
copolymers with different block lengths were synthesized $\left(\mathrm{D}_{21} \mathrm{HB}_{21} \mathrm{~N}_{21} ; \mathrm{D}_{53} \mathrm{HB}_{21} \mathrm{D}_{53}\right.$; $\mathrm{D}_{110} \mathrm{HB}_{21} \mathrm{D}_{110}$ ), and further studied for their ability to form both $\mathrm{pH}$ - and thermoresponsive micelles used for the encapsulation and controlled release of DOX (vide infra) [73]. These triblock copolymers were also evaluated as nano-vectors for gene delivery [84].

\section{Scheme 7.}

Loh, Guillaume and co-workers reported the synthesis of multi-arm PHB-based triblock copolymers $\quad(\operatorname{poly}([R]-3$-hydroxybutyrate)- $b$-poly $(N$-isopropylacrylamide $)-b$ $[[$ poly(methyl ether methacrylate)- $g$-poly(ethylene glycol)]-co-[poly(methacrylate)- $g$ poly(propylene glycol)]], PHB- $b$-PNIPAAM- $b$-(PPEGMEMA-co-PPPGMA), from bacterial PHB [85]. Microbial PHB $\left(M_{\mathrm{n}}=59400 \mathrm{~g} \cdot \mathrm{mol}^{-1}\right)$ was transesterified with different alcohols, hexanol, ethylene glycol and erythritol, in the presence of DBTL as catalyst, affording linear PHB-OH and PHB-diOH and four-arm PHB-tetraOH, respectively. Those hydroxy telechelic PHB were brominated using the reported 2-bromoisobutyryl bromide-based strategy [70,83]. Thus PHB-Br $\left(M_{\mathrm{n}}=1400 \mathrm{~g} \cdot \mathrm{mol}^{-1}\right)$, linear PHB-diBr $\left(M_{\mathrm{n}}=2500 \mathrm{~g} \cdot \mathrm{mol}^{-1}\right)$ and four-arm PHBtetraBr $\left(M_{\mathrm{n}}=1700 \mathrm{~g} \cdot \mathrm{mol}^{-1}\right)$ were used as macroinitiators for the sequential ATRP of NIPAAM followed by a one-pot ATRP of PEGMEMA and PPGMA, leading to one-arm $\left(M_{\mathrm{n}}\right.$ $\left.=26300 \mathrm{~g} \cdot \mathrm{mol}^{-1} ; \bigoplus_{\mathrm{M}}=1.78\right)$, two-arm $\left(M_{\mathrm{n}}=17300-20000 \mathrm{~g} \cdot \mathrm{mol}^{-1} ; \bigoplus_{\mathrm{M}}=1.48-1.71\right)$ and four-arm $\left(M_{\mathrm{n}}=17700 \mathrm{~g} \cdot \mathrm{mol}^{-1} ; \quad \bigoplus_{\mathrm{M}}=1.88\right)$ corresponding PHB- $b$-PNIPAAM- $b-$ (PPEGMEMA-co-PPPGMA) (Scheme 8). The triblock copolymers, presenting a PHB content from 6 to $11 \mathrm{wt} \%$, were characterized by ${ }^{1} \mathrm{H},{ }^{13} \mathrm{C} \mathrm{J}$-MOD NMR, SEC, TGA, and DSC analyses. While spectroscopic analyses confirmed the composition of the copolymers, thermal analyses supported their proposed topology. The two thermal transition phenomena recorded from DSC analyses $\left(T_{\mathrm{m}}=35-38{ }^{\circ} \mathrm{C} ; 135-150{ }^{\circ} \mathrm{C}\right)$ correspond to the PPEGMEMA block and to the overlap of the melting transition of PHB with the glass transition of PNIPAAM, respectively. TGA experiments showed a two stage degradation process, with first the 
degradation of PHB and PEGMA segments in the $250-325^{\circ} \mathrm{C}$ temperature range, and second the degradation of PNIPAAM and remaining PEGMA-PEGMEMA segments in the 325-445 ${ }^{\circ} \mathrm{C}$ temperature range. Such multi-arm PHB- $b$-PNIPAAM- $b$-(PPEGMEMA-coPPPGMA) have shown good thermogelling behavior (vide infra).

\section{Scheme 8.}

\subsection{PHB-based copolymers prepared from ring-opening polymerization of $\beta$-butyrolactone}

The ring-opening polymerization (ROP) of racemic $\beta$-butyrolactone (rac-BL) is an alternative approach for the synthesis of PHB-based copolymers. While bacterial PHB is a highly crystalline thermoplastic material (isotactic PHB; $T_{\mathrm{m}}=175-180{ }^{\circ} \mathrm{C}, T_{\mathrm{g}}=9{ }^{\circ} \mathrm{C}$ ), synthetic PHB can feature different stereochemical sequences (atactic (amorphous), syndiotactic ( $T_{\mathrm{m}}$ unknown), or isotactic PHBs) depending on the catalytic system used [5860]. Also, ROP may be used to copolymerize two distinct monomers, such as in particular cyclic esters, either sequentially or simultaneously, thereby providing copolymers with different topologies like block or random copolymers, respectively (Table 1).

\subsubsection{PHB/PEG-based copolymers prepared from ring-opening polymerization of} $\beta$-butyrolactone

Similarly to microbial PHB, synthetic PHB segments have been covalently bonded to PEG blocks, seeking the advantages of the hydrophobic and hydrophilic character of PHB and PEG, respectively. The majority of PHB/PEG copolymers developed for drug delivery applications was based on triblock copolymers with PEG as the central block.

Liu, Li and co-workers "clicked" a 8-arm star PEG (sPEG) with amorphous PHB segments using the Huisgen's reaction (1,3-dipolar cycloaddition) [72]. This strategy was based on the complementary functionalization of PHB and PEG with alkyne and azide, respectively (Scheme 9). Hydroxy terminated SPEG was chlorinated in the presence of $\mathrm{SOCl}_{2}$ 
and then reacted with $\mathrm{NaN}_{3}$ leading to the azide terminated sPEG. On the other hand, anionic ROP of rac-BL was initiated by sodium adamantane carboxylate and terminated by propargyl bromide, thereby giving $\alpha$-adamantyl, $\omega$-alkynyl functionalized PHB. Both PEG and PHB were next coupled in the presence of $\mathrm{CuSO}_{4} \cdot 5 \mathrm{H}_{2} \mathrm{O}$ and sodium ascorbate to afford PHB- $b$ sPEG. This strategy resulted in the formation of diblock copolymers with an average of 6-7 functionalized PEG arms, as characterized by ${ }^{1} \mathrm{H}$ NMR, SEC (in THF; vs. PEG standards: $M_{\mathrm{n}}$ $=20600-36800$ g.mol $\left.{ }^{-1} ; \bigoplus_{M}=1.30-1.41\right)$ and DSC analyses. Those copolymers were used for the formation of adamantyl functionalized nanoparticles with a PEG core, and further supramolecularly assembled with heptakis(2,6-di- $O$-methyl)- $\beta$-cyclodextrin (DM- $\beta$-CD) taking advantage of the host-guest interaction with the adamantyl chain-end functions (vide infra).

\section{Scheme 9.}

Chen and co-workers synthesized PHB- $b$-PEG- $b$-PHB copolymers in order to form nanoparticles with a hydrophobic core $[65,66]$. The one-step synthesis involved the use of $\alpha, \omega$-dihydroxy telechelic PEG (PEG diol; $M_{\mathrm{n}}=4000 \mathrm{~g} \cdot \mathrm{mol}^{-1}$ ) as a macroinitiator in the presence of $r a c-B L$ and $\mathrm{Sn}(\mathrm{Oct})_{2}$ as a catalyst (Scheme 10). The ROP then led to a series of triblock copolymers with different ratios of the repeating units from the PEG-enriched $\mathrm{PHB}_{7}-b-\mathrm{PEG}_{91}-b-\mathrm{PHB}_{7}$ to the PHB-rich $\mathrm{PHB}_{368}-b-\mathrm{PEG}_{91}-b-\mathrm{PHB}_{368}\left(M_{\mathrm{n}},=5300-67400\right.$ g.mol ${ }^{-1} ; \bigoplus_{\mathrm{M}},=$ not reported $)$ copolymers. ${ }^{1} \mathrm{H}$ NMR studies showed the formation of $\alpha, \omega$-crotonate terminated copolymers. Copolymers were further characterized by ${ }^{13} \mathrm{C}\left\{{ }^{1} \mathrm{H}\right\}$ NMR, SEC, DSC and WAXD analyses. The range of copolymers featuring different hydrophilic/hydrophobic balance enabled a complete study of the critical micellar concentration (CMC) of those copolymers in aqueous solution, and further of the formation of nanoparticles for the encapsulation of pyrene as a drug model (vide infra).

\section{Scheme 10.}


$\mathrm{Li}$ and co-workers also studied PHB- $b$-PEG- $b$-PHB triblock copolymers [86]. The authors reported an original synthetic strategy through the anionic ROP of rac-BL initiated by a modified PEG (Scheme 11). First a di-anionic PEG macroinitiator was synthetized from PEG diol. The (2,2,6,6-tetramethylpiperidin-1-yl)oxy (TEMPO) mediated oxidation of PEG diol, in the presence of $\mathrm{NaCl}$ and $\mathrm{NaBr}$, was next carried out. The sodium carboxyl endcapped PEG thus obtained was deprotonated by $\mathrm{Na}_{2} \mathrm{CO}_{3}$ leading to the dianionic PEG macroinitiator. The anionic ROP of $r a c-\mathrm{BL}$ then proceeded and was terminated by the addition of 2-iodoethanol, ultimately affording dihydroxy telechelic PHB- $b$-PEG- $b$-PHB triblock copolymers, further characterized by ${ }^{1} \mathrm{H}$ NMR and SEC (THF; vs. PEG standards: $\left(M_{\mathrm{n},}=4500\right.$ g.mol $\left.{ }^{-1} ; \bigoplus_{\mathrm{M},}=1.07\right)$ analyses. These short copolymers were used to form supramolecular hydrogels using $\alpha$-cyclodextrin (vide infra).

\section{Scheme 11.}

Oledzka and co-workers also developed triblock PHB- $b$-PEG- $b$-PHB copolymers synthetized from the ROP of rac-BL [87]. The authors reported the synthesis and the characterization of PHB-based peptide dendrimers for drug carrier applications. The two-step synthesis of these dendrimers was performed from the third generation poly( L-lysine) dendrimer end-functionalized with arginine-6-oligomer (Scheme 12). The PHB- $b$-PEG- $b$ PHB was first synthesized by the ROP of $r a c-B L$ in the presence of different amounts of PEG $\operatorname{diol}\left(M_{\mathrm{n}}=600 \mathrm{~g} \cdot \mathrm{mol}^{-1}\right)$ macroinitiator and $\mathrm{Sn}(\mathrm{Oct})_{2}$ catalyst. The triblock copolymers thus obtained $\left(M_{\mathrm{n}}=1000-4900 \mathrm{~g} \cdot \mathrm{mol}^{-1} ; \bigoplus_{\mathrm{M}}=1.48-2.26\right)$ were analyzed by NMR $\left({ }^{1} \mathrm{H}\right.$ and $\left.{ }^{13} \mathrm{C}\left\{{ }^{1} \mathrm{H}\right\}\right)$ spectroscopy and MALDI-ToF MS. These analyses revealed the presence of crotonate end-groups onto PHB segments that remained minor in comparison to hydroxyl termini, and did not alter the following step. These triblock copolymers were coupled with the free-amine groups of the poly(L-lysine) dendrimer end-functionalized with arginine-6oligomer, in the presence of 1,1'-carbonyldiimidazole (CDI) and DMAP, leading to urethane 
covalent linkages. The PHB/PEG-based dendrimer formed were characterized by both spectroscopic ( ${ }^{1} \mathrm{H}$ and ${ }^{13} \mathrm{C}$ NMR; FT-IR) and spectrometric (MALDI-ToF) analyses. Rheological and thermal behavior was also evaluated.

\section{Scheme 12.}

\subsection{2. $\mathrm{PHB} / \mathrm{PHA}-\mathrm{based}$ copolymers prepared from ring-opening polymerization of $\beta$ -} butyrolactone

Carpentier, Thomas and co-workers developed PHB-based copolymers for the encapsulation and controlled release of $L$-leuprolide acetate (an anticancer drug) [89]. Random copolymers were synthesized from a mixture of racemic monomers ( $r a c$-BL and racemic-allyl- $\beta$-butyrolactone ( $\left.r a c-\mathrm{BL}^{\text {allyl }}\right)$ ) with $r a c-\mathrm{BL}^{\text {allyl }}=7$ or $11 \mathrm{~mol} \%$ (Scheme 13 ). The tacticity of these copolymers, as determined by ${ }^{13} \mathrm{C}\left\{{ }^{1} \mathrm{H}\right\}$ NMR analyses, was tuned according to the catalyst used. Polymerization of a racemic mixture of the monomers using the syndiospecific yttrium(III) catalyst led to syndiotactic copolymers (probability of racemic linkage $\left.P_{\mathrm{r}}=0.82-0.84\right)[122-125]$, whereas polymerization of such a mixture with the nonstereospecific $\beta$-diketiminate zinc catalyst [126] resulted in the formation of atactic copolymers. Polymerizations with the $\beta$-diketiminate zinc catalyst afforded isotactic copolymers (probability of meso linkage $P_{\mathrm{m}}=0.96-0.97$ ) when both enantio-pure monomers were used, namely $R$-BL and $R$-BL ${ }^{\text {allyl }}$. The PHB-co-PHB ${ }^{\text {allyl }}\left(M_{\mathrm{n}}=9200-61100 \mathrm{~g}^{-\mathrm{mol}^{-1}} ; \bigoplus_{\mathrm{M}}\right.$ $=1.24-1.62)$ were further chemically modified by reaction with osmium tetraoxide in the presence of $N$-methyl morpholine $N$-oxide, leading to the dihydroxy end-functionalized polyesters $\mathrm{PHB}-\mathrm{co}-\mathrm{PHB}^{\mathrm{diOH}}\left(\mathrm{PHB}^{\mathrm{diOH}}=\operatorname{poly}(\right.$ dihydroxypropanehydroxybutyrate $) ; M_{\mathrm{n}}=$ 11 200-69 600 g.mol ${ }^{-1} ; \bigoplus_{M}=1.28-1.76$ ) [88]. The synthesis of such a range of copolymers exhibiting different tacticities enabled to evaluate the impact of the microstructure on the 
encapsulation and kinetics of drug release (vide infra). The major drawback of this strategy remains the use of highly sensitive catalysts, that require use with the rigorous exclusion of air and moisture.

\section{Scheme 13.}

Finally, Barouti, Guillaume and co-workers developed the synthesis of poly(hydroxybutyrate)- $b$-pol( $\beta$-malic acid) (PHB- $b$-PMLA) amphiphilic copolymers for the formation of nanoparticles, further evaluated as nanovectors [91]. The synthesis was realized by optimization of a previously reported three-step strategy (Scheme 14) [90]. First, the ROP of rac-BL was carried out in the presence of 1,5,7-triazabicyclo[4.4.0]dec-5-ene (TBD) as an organic catalyst, affording TDB-PHB-crotonate $[127,128]$. This polymer was next able to initiate the ROP of benzyl $\beta$-malolactonate $\left(\operatorname{MLA}^{\mathrm{Be}}\right)[90,129]$. The growth of the PMLA ${ }^{\mathrm{Be}}$ segment gave the PHB- $b$-PMLA ${ }^{\text {Be }}$ hydrophobic diblock copolymer $\left(M_{\mathrm{n}}=8200-18800\right.$ g.mol $\left.{ }^{-1} ; \bigoplus_{M}=1.16-1.28\right)$. At this stage, the copolymers were fully characterized $\left({ }^{1} \mathrm{H},{ }^{13} \mathrm{C}\left\{{ }^{1} \mathrm{H}\right\}\right.$ and DOSY NMR, SEC, DSC, TGA, contact angle). The last step involved the deprotection of pendant benzyl functionalities of the $\mathrm{MLA}^{\mathrm{Be}}$ units by hydrogenolysis [129]. The cleavage of the benzylic group was carried out in the presence of $\mathrm{Pd} / \mathrm{C}$ catalyst, under $\mathrm{H}_{2}$ atmosphere, affording carboxylic pending functions. Amphiphilic PHB-b-PMLA copolymers were thus isolated with various hydrophilic weight fractions (MLA $=10-82 \mathrm{wt} \%$ ) and molar mass values, which were determined by ${ }^{1} \mathrm{H}$ NMR, $\left(M_{\mathrm{n}}=8100-0200 \mathrm{~g} \cdot \mathrm{mol}^{-1}\right)$. Thermal and micellization behavior was also evaluated. DSC showed a single glass transition $\left(T_{\mathrm{g}}=-6\right.$ to $\left.+19{ }^{\circ} \mathrm{C}\right)$ ranging between the $T_{\mathrm{g}}$ of both polymers $\left(T_{\mathrm{g}, \text { PHB }}=-2{ }^{\circ} \mathrm{C} ; T_{\mathrm{g}, \text { PMLA }}=+12{ }^{\circ} \mathrm{C}\right)$. TGA experiments confirmed the theoretical wt $\%$ of each block. Finally, water contact angles $\left(100^{\circ}\right.$ to $<20^{\circ}$ ) were found to decrease with the increase of the PMLA block length, in agreement with the increase of the hydrophilicity of the copolymers.

\section{Scheme 14.}


For applications based on self-assembled systems, triblock copolymers, are interesting due to the possibility to form stable DDSs with low CMC values. Nonetheless, the synthesis of triblock copolymers is often more complicated than that of the corresponding diblock copolymers. Barouti and Guillaume developed a strategy for the synthesis of the corresponding PMLA ${ }^{\mathrm{Be}}-b$-PHB- $b$-PMLA ${ }^{\text {Be }}$ triblock copolymers $\left(M_{\mathrm{n}}=3300-11500\right.$ g.mol ${ }^{-1}$; $\bigoplus_{\mathrm{M}},=1.30-1.41$; measured by ${ }^{1} \mathrm{H}$ NMR and SEC (THF vs. polystyrene standards, respectively) [92], from the ROP of rac-MLA ${ }^{\mathrm{Be}}$ using PHB diol macroinitiator[130] in the presence of neodymium triflate $\left(\mathrm{NdOTf}_{3}\right)$ as catalysts [91]. The characteristic signals of $\mathrm{MLA}^{\mathrm{Be}}$ and $\mathrm{HB}$ units in the purified samples were observed in both ${ }^{1} \mathrm{H}$ and ${ }^{13} \mathrm{C}\left\{{ }^{1} \mathrm{H}\right\} \mathrm{NMR}$ spectra. DOSY NMR measurements confirmed the presence of a single macromolecular species in the sample, and that the triblock copolymer was not contaminated by homopolymer. DSC experiments revealed a glass transition temperature for each segments $\left(T_{\mathrm{g}}\right.$ $=1$ and $26^{\circ} \mathrm{C}$ for PHB and PMLA ${ }^{\mathrm{Be}}$ segment, respectively). Finally, the corresponding amphiphilic PMLA- $b$-PHB- $b$-PMLA $\left(M_{\mathrm{n}}=2800-7100 \mathrm{~g} \cdot \mathrm{mol}^{-1}\right.$; measured by ${ }^{1} \mathrm{H}$ NMR $)$ triblock copolymers were obtained through hydrogenolysis of $\mathrm{PMLA}^{\mathrm{Be}}-b-\mathrm{PHB}-b-\mathrm{PMLA}^{\mathrm{Be}}$, in presence of activated palladium. The amphiphilic copolymers were similarly characterized by ${ }^{1} \mathrm{H},{ }^{13} \mathrm{C}\left\{{ }^{1} \mathrm{H}\right\}$ and DOSY NMR spectroscopy, DSC and TGA analyses, which fully supported the formation of these well-defined triblock copolymers. The relevance of the hydrophilic weight fraction of the copolymer in its chemical composition-architecture-solution behavior relationship was highlighted. Noteworthy, these copolymers represent, the first examples of PHA-PHB-PHA triblock copolymers.

\section{PHB-based (co)polymers for drug delivery applications}

\subsection{Preparation methods and characteristics of PHB-based self-assembled systems}

PHB-based self-assembled systems have been developed from both natural and synthetic PHB segments and involve from nanoscale to macroscale: nanoparticles, micelles, 
microparticles and gels. The preparation methods and characteristics of these self-assembled systems are discussed in this section.

\subsubsection{Preparation methods and characteristics of PHB-based nanoparticles}

Polymer-based nanoparticles have been widely studied in the past few decades to encapsulate anti-cancer molecules in order to increase their bioavailability and to avoid some severe side effects [3,131-134]. Currently, nanoparticles are usually made of poly(lactide) (PLA) [3,23,29,131], poly(lactic-co-glycolic acid) (PLGA) [3,131,135-137], poly(alkyl cyanoacrylate) $[138-140]$ and poly( $\varepsilon$-caprolactone) (PCL) $[3,33,34]$ that are biocompatible and biodegradable copolymers. Among various available nanomaterials, PHB-based nanoparticles are promising drug delivery systems (DDSs). Indeed, the high hydrophobicity of this polyester results in the formation of stable nanoparticles with longer biodegradation times compared with other biodegradable PLA-, PLGA- or PCL-based particles [65]. Moreover, the synthesis of PHB by ROP of $\beta$-butyrolactone enables control of the tacticity of PHB (atactic, syndiotactic or isotactic [58-60]), providing a viable route to control the physico-chemical properties of PHB-based self-assembled systems, whereas microbial production only gives highly crystalline (isotactic) PHB. Both PHB homopolymers, as well as PHB-based block copolymers, are used to form nano-drug carriers in aqueous solutions (Table 2).

\section{Table 2.}

\subsubsection{Preparation methods and characteristics of nanoparticles derived from PHB homopolymers}

PHB homopolymers used as drug carriers are mainly naturally produced ones [43]. However, the present review aims to address synthetic PHB-based systems used for drug delivery applications. Therefore, only PHB homopolymers which are chemically modified after their microbial production are discussed in this section. Such PHB conjugates feature a 
PHB moiety covalently bonded to various molecules of interest such as targeting ligands $[76,141]$ or fluorescent probes [75] (Table 2).

The microbial synthesis of PHB facilitates the control of some physico-chemical characteristics of the nanoparticles such as the hydrodynamic diameter $\left(D_{\mathrm{h}}\right)$. Indeed, the precise control of the size of the nano-object is an important issue for the design of circulating DDSs [145]. After intravenous administration, small particles $\left(D_{\mathrm{h}}<20 \mathrm{~nm}\right)$ are eliminated by renal excretion and larger particles can be rapidly taken up by the mononuclear phagocyte system cells present in the liver, the spleen and the bone marrow. Nanoparticles of 150 to 300 $\mathrm{nm}$ are thus mainly found in the liver and the spleen. Also, it is generally admitted that the "ideal" size requirements for self-assembled systems developed for cancer treatments are between 70 and $200 \mathrm{~nm}[84,146-148]$.

In the case of nanoparticles made of $\mathrm{A} 33 \mathrm{scFv}$ green fluorescence protein-natural PHB conjugate (AG-PHB), the $D_{\mathrm{h}}$ values were tuned by the enzyme/(3-hydroxybutyryl-coenzyme A (3HB-CoA)) substrate ratio used during the polymerization[75]. Kim and co-workers thus reported the formation of AG-PHB nanoparticles with an average diameter ranging from 70 to $550 \mathrm{~nm}$, as evaluated by dynamic light scattering (DLS), upon modulating the enzyme concentration, while maintaining the same $(3 \mathrm{HB}-\mathrm{CoA})$ substrate loading. $D_{\mathrm{h}}$ was found to decrease with higher concentrations of enzyme as the length of the AG-PHB was inversely proportional to the concentration of the enzyme [75].

The formulation method implemented also plays a key role on the control of the physico-chemical properties of the self-assembled systems [149,150]. Nanoparticles are commonly obtained by nanoprecipitation, emulsion techniques (single or double), or electrospraying methods [3]. Several parameters such as the choice of the solvent, the use and the nature of the surfactant, the organic/aqueous solvent volume ratio, the mixing rate and time, do significantly affect the nanoparticles characteristics and in particular their size [15,151-153]. For example, nanoparticles derived from folic acid (FOL)-PHB with $D_{\mathrm{h}}$ ranging 
from 44 to $1132 \mathrm{~nm}$ (DLS) were obtained by modifying the sonication time during the double emulsion-solvent evaporation process from 30 to $5 \mathrm{~min}$, respectively, without modifying their shape as assessed by scanning electron microscopy (SEM) of the nanoparticles [141]. As mentioned above, the use of a surfactant also significantly modifies the nanoparticles characteristics such as their size, shape, and stability. Poly(vinyl alcohol) (PVA), one of the most commonly used surfactant with excellent emulsifying and stabilizing properties, enabled to significantly reduce the size of these nanoparticles based on FOL-PHB. Indeed, $D_{\mathrm{h}}$ ranging from 142 to $208 \mathrm{~nm}$ (DLS) were then obtained with PVA concentrations ranging from 0.15 to $0.005 \%(w / v)$, respectively [141].

Furthermore, it is important to note that $D_{\mathrm{h}}$ can be significantly affected by the grafting of a targeting molecule since the hydrophilic/hydrophobic balance of the final material is then changed. Kim and co-workers reported the preparation of PHB-based nanoparticles with a $D_{\mathrm{h}}$ of $209 \mathrm{~nm}$ by an oil-in-water emulsion-solvent evaporation process without the use of any surfactant. The diameter of the recovered nanoparticles was increased by $c a .46 \mathrm{~nm}$ after grafting RGD4C as a targeting peptide, and an increase of the size distribution of the nanoparticles was also observed, as assessed by DLS analysis (Figure 1) [76]. The grafting of the peptide thus increased the hydrophilic character of the polymer, then resulting in the formation of core-shell particles with higher $D_{\mathrm{h}}$ (Figure 1).

\section{Figure 1.}

\subsubsection{Preparation methods and characteristics of nanoparticles derived from PHB- based copolymers}

The covalent association of a hydrophilic block with a hydrophobic PHB block and the control of the block lengths facilitate precise control of the physico-chemical properties of the resulting nanoparticles. While the use of natural PHB homopolymer as a drug carrier has been extensively studied, the control of the physico-chemical properties remains nonetheless quite limited in these reports. In this regard, the use of (synthetic) PHB-based copolymers 
provides a viable route for the elaboration of highly tunable drug carriers. Indeed, the control of the hydrophilic weight fraction $(f)$ of PHB-based amphiphilic block copolymers affords self-assembled systems tunable in terms of size, encapsulation efficiency, stability, and degradation time.

Upon nanoprecipitation of PHB-b-PMLA copolymers in phosphate buffered saline (PBS) solution, spherical self-assembled systems exhibiting $D_{\mathrm{h}}$ ranging from 17 to $180 \mathrm{~nm}$ with a narrow size distribution were obtained, as assessed by DLS and transmission electronic microscopy (TEM). The most hydrophobic copolymers $(f=10 \%)$ were found to form particles with the largest $D_{\mathrm{h}}$, while copolymers with $f$ up to $65 \%$ afforded self-assembled systems with $D_{\mathrm{h}}=17 \mathrm{~nm}[91]$.

Furthermore, as shown by Kulkarni, Aminabhavi and co-workers, the use of PHB enabled the formation of small particles $\left(D_{\mathrm{h}}<20 \mathrm{~nm}\right)$ [77] with a highly compact hydrophobic core compared to PLA-, PLGA- and PCL-based particles [3]. Indeed, PHB- $b$ PEG copolymers conjugated with deoxylic acid (DOCA) enabled to form ultra-small nanoparticles with a $D_{\mathrm{h}}$ of $10 \mathrm{~nm}$, as assessed by DLS and high resolution TEM. These particles were obtained by a modified solvent diffusion and solvent evaporation method, and stabilized with poly(ethylene glycol) sorbitan monooleate (Tween 80) surfactant at a concentration of $1 \%(w / w)$ [77]. The size of the recovered nanoparticles was rationalized by the compartmentalization of the aqueous phase within the particles.

While amphiphilic block copolymers enable to prepare nanoparticles, they are also often used to form nano-carriers with micellar structures, as discussed in the following section.

\subsubsection{Preparation methods and characteristics of PHB-based micelles}

Amphiphilic block copolymers are found to form aggregates in aqueous medium by the association of their hydrophobic blocks [154]. These self-assembled systems are often called micelles. It is important to note that micelles refer to the self-assembly of a block 
copolymer in a dynamic equilibrium, while nanoparticles are kinetically frozen [155]. The self-assembly of block copolymers is less straightforward than that of small surfactants where the exchange of molecules and dynamic equilibria are often favored. The distinction between nanoparticles and micelles in literature reports is not always possible as dynamic exchanges are simply not systematically assessed or are not evaluated on a sufficient time scale [154].

Several studies have reported the use of PLA-, PGA- or poly(propylene oxide) PPObased copolymers for the preparation of micelles for drug delivery applications [156-158]. The major drawback of these latter systems is that the critical micelle concentration (CMC) of the copolymer is highly dependent on the hydrophobic block length. In addition, the molecular weight and the number of aggregation $\left(N_{\mathrm{agg}}\right)$ of these self-assembled systems vary with the temperature without any precise control, which thus makes these systems highly dependent on the surrounding conditions, and therefore not very stable $[157,159]$. All these observations suggested that, the use of a more hydrophobic polymer such as PHB can promote the development of micelles with more suitable characteristics (Table 2).

\subsubsection{Preparation methods and characteristics of PHB/PEG-based micelles}

The association of PEG as hydrophilic block with PHB leads to the development of interesting polymeric self-assembled systems. The presence of PEG on the surface of particles leads to neutrally charged objects which help to inhibit electrostatic interactions of plasma components with polymer-based self-assembled systems [3]. Indeed, PEG is a biocompatible polymer which increases the half-life of the drug carrier in the organism as discussed thereafter in the section "Targeting approaches associated with PHB-based self-assembled systems".

Kim and co-workers reported the formation of micelles based on PHB-co-PEG with diameter ranging from 61 to $109 \mathrm{~nm}$ as assessed by atomic force microscopy (AFM). The increase of the hydrophilic weight fraction $f$ from 13 to $50 \%$ influenced the self-assembly mechanism by affecting the hydrophobic interactions which induced an increase of the 
particle size as often observed with PEGylated self-assembled systems[69]. These micelles were then used for the sustained release of Griseofulvin.

$\mathrm{Li}$ and co-workers and Pun and co-workers both reported the conception of promising micelles resulting from the self-assembly of PEG- $b$-PHB- $b$-PEG triblock copolymers [64,67,78]. Copolymers with PHB molar mass ranging from $M_{\mathrm{n}} 470$ to $3800 \mathrm{~g} \cdot \mathrm{mol}^{-1}$ and with a constant PEG block length of $M_{\mathrm{n}} 4750$ g. $\mathrm{mol}^{-1}$ (PEG $\left.{ }_{5000}\right)$ were found to form spherically shaped micelles with a $D_{\mathrm{h}}$ ranging from 27 to $48 \mathrm{~nm}$, as assessed by TEM analysis [64]. Conversely, the length of the PEG segments was varied from $M_{\mathrm{n}} 3600$ (i.e., two extreme blocks of 1800 g.mol ${ }^{-1}$ each) to 9500 g.mol ${ }^{-1}$ (i.e., two extreme blocks of 4750 g.mol ${ }^{-1}$ each) while maintaining the central PHB block with $M_{\mathrm{n}} 800 \mathrm{~g} \cdot \mathrm{mol}^{-1}$, thus resulting in a $D_{\mathrm{h}}$ value decreasing from 40 to $26 \mathrm{~nm}$ and from 86 to $64 \mathrm{~nm}$, as measured by TEM and DLS respectively [67]. The change in the hydrophilic weight fraction $(f)$ thus affected the hydrophobic interactions and the size of the self-assembled systems. In addition, SLS analyses showed that the gyration radius $\left(R_{\mathrm{g}}\right), D_{\mathrm{h}}$ and $N_{\mathrm{agg}}$ were not significantly modified when the polymer concentration was varied from 1.4 to $11 \mathrm{mg} \cdot \mathrm{mL}^{-1}$ [67]. These observations suggested that a diluted concentration regime was reached without interference from the neighboring micelles. Remarkably, the molecular weight and $N_{\text {agg }}$ of the particles remained constant in the temperature range going from 10 to $50^{\circ} \mathrm{C}$. Only, $D_{\mathrm{h}}$ decreased with the temperature due to dehydration of the hydrophilic block [64]. The self-assembled structures formed with PHB as highly hydrophobic block led to stable self-assemblies. It is noteworthy that the $\mathrm{CMC}$ value of this triblock copolymer $\left(\mathrm{CMC}\right.$ of $\mathrm{PEG}_{5000}-b-\mathrm{PHB}_{3800}-b-\mathrm{PEG}_{5000}=$ 1.3.10 ${ }^{-5}$ g.mL $\mathrm{mL}^{-1}$ ) determined from the fluorescence excitation spectra of pyrene, was around 10 times smaller than that of analogous PEG-based triblock copolymers with PLGA as central hydrophobic block with comparable block length $\left(\mathrm{CMC}=1.2-1.4 \cdot 10^{-4} \mathrm{~g} \cdot \mathrm{mL}^{-1}\right)[64,157]$. Moreover, the CMC was also found to be non-sensitive to temperature from 23 to $45^{\circ} \mathrm{C}$ (Figure 2) [64]. 


\section{Figure 2.}

These PEG- $b$-PHB- $b$-PEG-based micelles revealed successful DDSs toward 3-D multicellular spheroids (MCS) as in-vitro cells model and towards a tumor in a murine xenograft model [71]. In order to enhance and tune the physico-chemical properties of these micelles, Pun and co-workers reported the formulation of PEG- $b$-PHB- $b$-PEG micelles mixed with PEG- $b$-PPO- $b$-PEG (Pluronic, PF-127) copolymers [79]. These self-assembled systems were shown to form thermosensitive filamentous micelles (Figure 3). Such micelles were quite unexpected because the PEG- $b$-PHB- $b$-PEG and PF-127 exhibited hydrophilic weight fractions of $f=80$ and $70 \%$, respectively. Indeed, amphiphilic copolymers with such a high $f$ value usually form spherically shaped micelles due to a large surface area available $[160,161]$. The alternative filamentous morphology resulted from interactions between the two copolymers, as assessed by the transfer of energy between PEG- $b$-PHB- $b$-PEG is conjugated with a "donor" molecular probe, and F-127 is conjugated with an "acceptor" molecular probe, as evidenced by fluorescence resonance energy transfer. These observations confirmed the spatial proximity and the localization of both copolymers in the same micellar structure. The interest in mixing PHB-based triblock with Pluronic was that stable micelles with $D_{\mathrm{h}}$ below $20 \mathrm{~nm}$ (i.e., $5 \mathrm{~nm}$ ) were formed at $37^{\circ} \mathrm{C}$. The morphology of the formed micelles significantly improved the passive tumor penetration as compared with the spherical micelles based on PEG- $b$-PHB- $b$-PEG alone [79]. All these studies suggested that linear block copolymers containing both PHB and PEG blocks were able to form interesting self-assembled systems in an aqueous medium.

\section{Figure 3.}

The macromolecular architecture of a polymer can lead to the formation of peculiar structures resulting from the arrangement of the polymer chains relatively to one another. For example, micelles with "flower" like structures were obtained with the "reverse" triblock PHB- $b$-PEG- $b$-PHB copolymers [65]. Indeed, such micelles were prepared by the 
precipitation-solvent evaporation technique without the use of any surfactant. Micelles with sizes varying from $D_{\mathrm{h}}=20$ to $127 \mathrm{~nm}$ were thus formed upon increasing the PHB block length [65]. Noteworthy, $D_{\mathrm{h}}$ was more affected by changing the hydrophilic weight fraction of the "reverse" copolymer than of the PEG- $b$-PHB- $b$-PEG based micelles $[64,65,67]$. Moreover, the CMC values of these copolymers $\left(\mathrm{CMC}=3.3-14.4 .10^{-6} \mathrm{~g} \cdot \mathrm{mL}^{-1}\right)$ were much lower than those of the "reverse" triblock structure $\left(\mathrm{CMC}=1.3 \cdot 10^{-5}-1.1 .10^{-3} \mathrm{~g} \cdot \mathrm{mL}^{-1}\right)[64]$.

The concentrations of copolymers used for the preparation of self-assembled systems are always much higher than the CMC, permitting dilution of the systems in the organism without reaching a concentration lower than the $\mathrm{CMC}$ value. It is thus important to determine the optimal polymer concentration below which all the characteristics of the micelles remain constant. This concentration corresponds to the one at which micelles are diluted enough not to interact with one another. At this concentration, the measured parameters such as the micelles' radius and molecular weight are close to the real values. For example, micelles derived from the most hydrophilic PHB- $b$-PEG- $b$-PHB copolymers were not affected by dilutions below a concentration of the triblock copolymer of $6 \mathrm{mg} \cdot \mathrm{mL}^{-1}$, while a slight increase of the diameter was observed upon dilution of the most hydrophobic copolymers [65]. This was rationalized by the aggregation of particles. This phenomenon is nonetheless surprising and remains to be further confirmed by SLS measurements. The molecular weight values of the nanoparticles would then provide interesting information to confirm this hypothesis.

The formation of original and stable micelles can be induced by restricted polymer chains mobility during the formulation process thanks to the use of non-linear block copolymers [160,161]. Indeed, Liu and co-workers, and Li and co-workers reported the use of star-shaped copolymers consisting of multiple adamantyl end-capped PHB anchored to a central star-shaped PEG (average of 6 or 7 arms; sPEG) block as potential DDS (Figure 4). SLS measurements revealed the formation of self-assembled systems with a very high $N_{\text {agg }}$ 
(1030-6314) and a high molecular weight $\left(30-185.10^{3}\right.$ g.mol $\left.{ }^{-1}\right)$ corresponding to "nanogellike large micelles". The star-shaped structure of the adamantyl-PHB- $b$-sPEG conjugate copolymer led to the formation of original and stable structures considered as micellar objects with $D_{\mathrm{h}}$ 154-264 nm [72] much higher than those obtained with PEG- $b$-PHB- $b$-PEG linear copolymers (64-86 nm) as assessed by SLS measurements [67]. Furthermore, the structure of these self-assembled objects was then modified upon addition of a highly hydrophilic derivative of $\beta$-cyclodextrin, namely heptakis(2,6-di- $O$-methyl)- $\beta$-cyclodextrin (DM- $\beta$-CD). Nano-sized vesicles with diameters ranging from 200 to $500 \mathrm{~nm}$ were thus obtained due to polymer/CD host/guest interactions [72]. The organization of the self-assembled systems was thus modified by the cyclodextrin which induced other supramolecular interactions. This study showed that the relationship between the polymer architecture and the resulting nanostructure is not straightforward. All these results underlined the potential of these copolymers as carriers for the co-delivery of both hydrophilic and hydrophobic drugs in nanogel-like structures or in vesicles.

\section{Figure 4.}

As illustrated in this section, PEG is often used as hydrophilic block. However, the weaknesses of PEG are not always addressed. Indeed, after exposure to PEG, the serum of healthy blood donors was found to often contain anti-PEG immunoglobulins, thus showing that PEG is not immunologically inert. In addition, the clearance times of PEGylated compounds resulted in the accumulation in the liver of high molecular weight compounds, with unidentified toxicological consequences over a long period of time [40].

\subsubsection{Preparation methods and characteristics of PHB-based stimuli-responsive micelles}

The recent interest in stimuli-responsive polymers [162-164] and the unique properties of micelles containing a PHB core promoted the development of PHB-based stimuliresponsive drug carriers $[57,165,166]$. Indeed, thermo- or pH-responsive copolymers enable 
to tune the physico-chemical properties of the micelles and also to modify the drug release profile [167-171].

Poly( $N$-isopropyl acrylamide) (PNIPAAM) (low critical solution temperature (LCST) $\left.=32-34{ }^{\circ} \mathrm{C}\right)[172,173]$, poly $($ propylene glycol $)(\mathrm{PPG})\left(\mathrm{LCST}=15-45^{\circ} \mathrm{C}\right)[80]$, and poly $(2-$ (dimethylamino)ethyl methacrylate) (PDMAEMA) $\left(\mathrm{LCST}=50-52^{\circ} \mathrm{C}\right)[174]$, are hydrophilic polymers under their LCST and induce the collapse of their self-assemblies upon reaching their LCST. Amphiphilic copolymers containing such hydrophilic blocks form micelles at temperatures lower than the corresponding LCST, and induce the release of the drug when increasing the temperature above the LCST due to the collapse of the micelles [172]. Li and co-workers reported the formation of thermoresponsive micelles based on PNIPAAM- $b$-PHB$b$-PNIPAAM $\left(D_{\mathrm{h}}=287-844 \mathrm{~nm}\right)$ dissolution in aqueous solutions at $25{ }^{\circ} \mathrm{C}$. The hydrophobicity of the PNIPAAM segments increased with the temperature resulting in the collapse of the corona, thus reducing the size of the micelles $\left(D_{\mathrm{h}}=140-550 \mathrm{~nm}\right.$, DLS $)$ and their polydispersity above $35^{\circ} \mathrm{C}$ (Figure 5) [70]. The CMC of these PNIPAAM- $b$-PHB- $b$ PNIPAAM systems $\left(\mathrm{CMC}=1.5-41.10^{-6} \mathrm{~g} \cdot \mathrm{mL}^{-1}\right)$ was lower than that of other PNIPAAMbased copolymers such as PNIPAAM- $b$-PCL- $b$-PNIPAAM $[175,176]\left(\mathrm{CMC}=1.5-5 \mathrm{~g} \cdot \mathrm{mL}^{-1}\right)$ or PCL- $b$-PNIPAAM- $b$-PCL $\left(\mathrm{CMC}=34-42.10^{-6}\right.$ g.mL $\left.{ }^{-1}\right)$ [177], thus supporting the formation of enhanced systems in the case of the former PHB copolymers, thanks to the high hydrophobicity of the PHB segment.

\section{Figure 5.}

In addition, the micellization process is entropy driven, thus making it strongly dependent on the hydrophilic/hydrophobic balance of the copolymer [80,157]. Also, it is generally admitted that the micellization process is favored by a high hydrophobic content as it is mainly driven by hydrophobic interactions [178]. In this regard, $\mathrm{Li}$ and coworkers reported that the micellization entropies of poly(PEG/PPG/PHB urethane) copolymers became less positive with longer PHB blocks. The hydrophilic weight fraction $(f)$ of the 
copolymer is a key parameter to tune the size, the structure and the morphology during the formation of the particles, up to the dissociation of the self-assembled systems. Indeed, the morphology of the gels obtained after the collapse of poly(PEG/PPG/PHB urethane) copolymers-based micelles was found to depend on $f$. Thus, worm-like structures resulted from copolymers exhibiting a PHB content of 2 and 5\% (w/w), while copolymers with a PHB content of $8.1 \%(w / w)$ led to lamellar structures, as assessed by AFM images. Finally, these thermoresponsive copolymers formed slightly viscous micellar solutions in the temperature range of $5-15^{\circ} \mathrm{C}$, and then gels with various morphologies at $20-50{ }^{\circ} \mathrm{C}$, while the structures collapsed at $50{ }^{\circ} \mathrm{C}[80]$.

Stimuli-responsive polymers constitute a smart strategy to deliver a molecule nearby tumoral cells. For example, the close surrounding of tumoral cells is more acidic $(\mathrm{pH}=6.5)$ than that of blood (physiological $\mathrm{pH}=7.4$ ) due to the increased glucose uptake, the reduced rate of oxidative phosphorylation, the poor blood supply and the decreased lymphatic drainage [179]. Therefore, the use of $\mathrm{pH}$-responsive copolymers is extremely attractive $[165,166,178,179]$. Indeed, the decrease of the size of micelles in acidic medium enables the transport of the drug at physiological $\mathrm{pH}$, and subsequently its fast release in the close proximity of tumoral cells, thereby protecting normal cells. $\mathrm{pH}$ - and thermoresponsive micelles derived from PDMAEMA- $b$-PHB- $b$-PDMAEMA copolymers were prepared by the solvent evaporation method [73]. These copolymers exhibited a LCST in the range of 29$36{ }^{\circ} \mathrm{C}$. A similar behavior was observed with micelles based on PNIPAAM- $b$-PHB- $b$ PNIPAAM copolymers. Furthermore, the change of $\mathrm{pH}$ significantly modified the $D_{\mathrm{h}}$ of the micelles. Indeed, at $\mathrm{pH} 7.4$ and at $20^{\circ} \mathrm{C}$, two populations of particles with $D_{\mathrm{h}}$ of $10-20 \mathrm{~nm}$ and aggregates with $D_{\mathrm{h}}$ of 500-600 nm were observed, while at $\mathrm{pH} 2$ and $20{ }^{\circ} \mathrm{C}$ the size of the second population's objects was decreased down to $100-200 \mathrm{~nm}$. Due to the thermoresponsive behavior of the copolymer, an increase of the temperature up to $40{ }^{\circ} \mathrm{C}$ at $\mathrm{pH}$ 7 resulted in a single population with a $D_{\mathrm{h}}$ of $700 \mathrm{~nm}$ as assessed by DLS [73]. It appeared 
that the large size (> $200 \mathrm{~nm}$ ) of the micelles in physiological conditions made them non-ideal drug carriers for systemic injections.

\subsubsection{Preparation methods and characteristics of micelles derived from other PHB-}

\section{based copolymers}

Other hydrophilic blocks have been associated with PHB. Thus, PHB centered poly(ethyl ethylene phosphate) (PEEP) triblock copolymers, PEEP- $b$-PHB- $b$-PEEP, were used to form by dialysis, micelles with $D_{\mathrm{h}}$ ranging from 30 to $70 \mathrm{~nm}$ as determined by TEM analysis [82]. The CMC (measured by pyrene fluorescence) of these systems (3.6-7.0.10-6 g.mL $\left.{ }^{-1}\right)$ [82] was lower than that of the PEG- $b$-PHB- $b$-PEG copolymers $\left(1.3 .10^{-5}-1.1 .10^{-3}\right.$ g.mL $L^{-1}$ ) [64]. These results highlighted the fair potential of PHB-based triblock copolymers as diversified self-assembled systems for drug delivery applications, thanks again to the high hydrophobicity of the PHB block.

Besides PHB-based systems self-assembled into nanoparticles and micelles, microparticles have also been considered for drug delivery applications as discussed in the following section.

\subsubsection{Preparation methods and characteristics of PHB-based microparticles}

Microparticles are commonly defined as particle with diameter ranging from 1 to 1000 $\mu \mathrm{m}$ [180]. Therefore, their use is not recommended for systemic injection due to their too large size, as discussed above. Nonetheless, microparticles remain useful for other parenteral administrations [3]. PHB-based microparticles derived from random copolymers have thus been used for drug delivery applications with the objective to enhance the bioavailability of the drug, and to avoid the side effects due to the high cytotoxicity of active ingredients used in anti-cancer therapies (Table 2).

Microparticles were formed from the same polymers as the ones used for the elaboration of nanoparticles, yet upon changing some parameters during the formation of the 
self-assembled systems. Indeed, both microparticles and nanoparticles based on P(HB-co-CL) were prepared by the solvent evaporation method, simply upon changing the stirring method. Nanoparticles with $D_{\mathrm{h}}$ around $500 \mathrm{~nm}$ were obtained by using a high stirring rate (24000 rpm; with an Ultraturax), while larger microparticles of $2.5-3.0 \mu \mathrm{m}$ were recovered upon stirring more slowly (500 rpm; with a magnetic stirrer), as evidenced by DLS [81]. Nanoparticles exhibited more negative Zeta potential values than larger particles, due to their larger surface area and higher propensity to hydrolysis. The Zeta potential values are indeed typically good indicators of the colloidal stability of a system. The choice and the optimization of the formation of the particles are thus fundamental to get the desired particles in terms of size, shape and porosity.

In addition, the chemical structure of the polymer plays a key role in the formation and the structuration of the self-assembled systems. The use of $\mathrm{P}(\mathrm{HB}-\mathrm{co}-\mathrm{HV}-\mathrm{co}-\mathrm{CL})$ enabled the formation of smaller particles $\left(D_{\mathrm{h}} 200-300 \mathrm{~nm}\right)$ than the ones formed with $\mathrm{P}(\mathrm{HB}-\mathrm{co}-\mathrm{CL})$ [81]. This resulted from the change of the crystalline nature of the copolymer. The HB/HV/CL terpolymers were amorphous, while HB-enriched $\mathrm{P}(\mathrm{HB}-\mathrm{co}-\mathrm{CL})$ copolymers were highly crystalline. Indeed, amorphous polymers generally lead to the formation of smaller particles than crystalline copolymers, as the result of the higher mobility of the polymer chains during the preparation of self-assembled systems.

Noteworthy, the microstructure (i.e., tacticity) of the copolymer highly impacts the physico-chemical properties of the resulting self-assembled system, in particular the drug release and degradation profile [181-183]. $\mathrm{P}\left(\mathrm{HB}-\mathrm{co}-\mathrm{HB}^{\mathrm{R}}{ }_{11 \%}\right)$ (with $\mathrm{R}=$ allyl or diOH, molar ratio (\%)) with tunable tacticity (atactic, syndiotactic or isotactic), were used to form, by solvent precipitation or coprecipitation, L-Leuprolide-loaded microparticles with a $D_{\mathrm{h}}$ ranging from 10 to $100 \mu \mathrm{m}$, as assessed by SEM images [89]. The size of the particles were not significantly affected by the functionalization of the polymer (i.e., allyl or diOH). The drug loading efficiency (DLE) and the drug release profile were then highly dependent on the 
crystallinity and on the functionality of the copolymer, regardless of the formulation process, as discussed in the section below.

\subsubsection{Preparation methods and characteristics of PHB-based hydrogels}

Hydrogels are three-dimensionally cross-linked hydrophilic polymer networks, which can absorb and retain a considerable amount of water without dissolution. When the polymer network is bearing functional groups, exposure of the hydrogels to some chemical, biochemical, or physical stimuli induces changes in its swelling. This response of the hydrogels is mainly governed and tuned by the hydrogel composition, the cross-linking type (chemical or physical) and the degree of cross-linking. There are numerous applications of hydrogels including in particular vehicles for drug delivery, scaffolds for tissue engineering, actuators for optics and fluidics, and model extracellular matrices for biological studies [184190]. However, PHB-based hydrogels used as DDS remain quite rare in comparison to the PHB-based nanoparticles, micelles or microparticles.

The reactive extrusion modification of an additive-free PHB $\left(1400 \mathrm{~kg} \cdot \mathrm{mol}^{-1}, \bigoplus_{\mathrm{M}}=7\right)$ in the melt state using a dicumyl peroxide/triallyl trimesate (DCP/TAM) afforded high degrees of PHB branching and/or crosslinking depending on the amounts of DCP and TAM [142]. Dynamic oscillatory rheological properties of TAM(PHB- $b$-DCP- $b$-PHB) $)_{3}$, as well as extensional viscosities showed that with added amounts of DCP $(0.2$ and $0.3 \mathrm{wt} \%)$ and TAM (up to $1 \mathrm{wt} \%$ ), a gel fraction of up to $65 \mathrm{wt} \%$ was obtained and the viscosity of PHB increased by about two orders of magnitude from unmodified PHB to DCP/TAM-modified PHB, thus suggesting that TAM was a very effective branching/crosslinking agent for PHB. PHB with enhanced melt strength was thus produced for the first time. The crosslinking, resulting from the incorporation of TAM, thus substantially improved the thermal stability. Indeed, the TAM-modified samples exhibited a significant increase $\left(>15^{\circ} \mathrm{C}\right)$ in the crystallization temperature of $\mathrm{PHB}$, thus supporting a nucleating effect, supplemented by a decrease of crystal spherulite sizes, as observed by DSC and microscopy, respectively. Also, the solid- 
state storage modulus measured by dynamic mechanical thermal analysis (DMTA) was higher $(65 \%)$ in formulations featuring high gel contents, whereas the glass transition temperature $\left(T_{\mathrm{g}}\right)$ of the cured formulations was slightly lower. No further studies from this modified PHB have been reported so far.

Well-defined low molar mass $\left(M_{\mathrm{n}, \mathrm{SEC}}=4500 \mathrm{~g} \cdot \mathrm{mol}^{-1}, \bigoplus_{\mathrm{M}}=1.07\right)$ amphiphilic triblock copolymers reported by $\mathrm{Li}$ and co-workers, and featuring two relatively short $(12,24$ or 30 repeating units) atactic $\mathrm{PHB}$ segments sandwiching a middle $\mathrm{PEG}_{68}$ block ( $\mathrm{PHB}_{12,24,30-\mathrm{PEG}_{68}-}$ $\mathrm{PHB}_{12,24,30}$ ) formed strong hydrogels with $\alpha$-cyclodextrin (CD) molecules, the latter preferentially covering the PEG segment $[86,143]$. X-Ray diffraction (XRD) measurements indicated that the hydrogels based on PHB-PEG-PHB had less crystalline columnar $\alpha-C D$, thus leading to physical crosslinking. In comparison to hydrogels obtained from PEG of similar molar mass, the hydrogels based on the triblock copolymer/ $\alpha-\mathrm{CD}$ also demonstrated better elastic responses over the investigated frequency range. Indeed, the host-guest interactions between the polymer and the macrocycle led to the formation of strong supramolecular self-assembled structures. The hydrophobically associative nature of PHB-

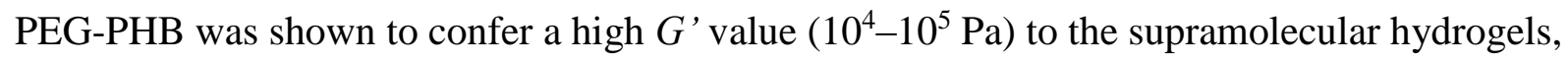
along with a high yield stress value $\left(>10^{2} \mathrm{~Pa}\right)$ and a fast structural recovery after yielding, as evidenced by CMC and DLS measurements. The hydrophobic interactions lead to the formation of extended and strong hydrogel networks, similar to hydrogels formulated with high molar mass PEG. However, no application was therein presented.

Li and coworkers have developed biodegradable thermogelling copolymers from poly(ester ether urethane)s, namely poly(PHB/PPG/PEG urethane)s [80,144]. An increase of the temperature of aqueous solutions of the copolymers from 4 to $80{ }^{\circ} \mathrm{C}$ induced a sol-gel-sol transition (Figure 6). Also, aqueous solutions of the copolymers featured a very low critical gelation concentration ranging from 2 to $5 \mathrm{wt} \%$. Based on these results, an associated micelle packing mechanism was proposed for the sol-gel transition of the copolymer gels. Further 
insights into the thermogelling behavior of the aqueous polymer solutions by variable temperature ${ }^{1} \mathrm{H}$ and ${ }^{13} \mathrm{C}$ NMR spectroscopy showed a broadening of the signals indicative of the reduced motion of the polymer segments upon gelation. The formation of the gel was proposed to result from the aggregation of micelle clusters, while a higher PHB content increased the size of the micelle cluster. Cytotoxicity and cells attachment were next studied (vide infra).

\section{Figure 6.}

Other thermoresponsive copolymers with various macromolecular architectures were used to form original self-assembled systems as described by Guillaume, Loh and co-workers [85]. Linear and star-shaped (poly([R]-3-hydroxybutyrate)- $b$-poly( $N$-isopropylacrylamide)- $b$ $[[\operatorname{poly}($ methyl ether methacrylate)-g-poly(ethylene glycol)]-co-[poly(methacrylate)- $g$ poly(propylene glycol)] $] \quad$ (PHB- $b$-PNIPAAM- $b$-(PPEGMEMA-co-PPPGMA))-based copolymers formed micellar solutions and gels, respectively. The mechanical properties of the gels varied according to the number of arms of the copolymers (from two to four arms). Copolymers with four arms exhibited interesting characteristics with high storage modulus (up to $460 \mathrm{~Pa}$ ). The formed supramolecular structures were then used as biocompatible DDS of doxorubicin.

\subsection{Encapsulation and drug release from PHB-based self-assembled systems}

Drug delivery systems are developed to encapsulate an active pharmaceutical ingredient (API) (a drug, a gene or a functional agent; yet these latter two are beyond the scope of the present review), and to achieve its controlled release at the targeted site. Several parameters such as drug loading content (DLC) and drug loading efficiency (DLE) indicate the efficiency of the system to encapsulate a molecule. The drug release refers to how the molecule is moved from the inner polymeric matrix to the outer surface and then to the surrounding medium. These phenomena are mainly explained by a diffusion mechanism through water-filled pores and through the polymeric matrix $[3,131,191]$. These mechanisms 
are governed by the Brownian motion of molecules and by the osmotic pressure gradient. In addition, the surface erosion of the polymeric matrix induces a further porosity which can promote the API release. Another kind of erosion called "bulk erosion" can result from the large hydration of the polymer and generally leads to the hydrolysis of the polymeric matrix and the dissolution of the self-assembled system [3,131,191]. Most often, a zero-order kinetics, that is a constant and continuous release of the drug at a defined concentration, is targeted. Nevertheless, the undesirable burst effect corresponding to a fast and short release of the drug is most commonly observed $[3,131,191]$. Classically, drug delivery profiles obtained from polymeric self-assembled systems are divided in three phases: the first one corresponding to the burst effect, is followed by a slow release explained by the slow drug diffusion through water-filled pores and through the polymeric matrix, and finally by a third phase with a fast release corresponding to the polymer matrix erosion [3,192]. In some particular cases for which a pulsatile drug release is preferred, the burst release is voluntary triggered [193,194]. To date, some strategies have been established to avoid the burst effect such as the coating of particles or the homogenous repartition of the encapsulated API $[3,131]$. The kinetic profile is then highly depending on the physico-chemical properties of the self-assembled system. The encapsulation and drug release from PHB-based self-assembled systems reported in the literature involve nanoparticles, micelles microparticles as well as gels (Table 3).

\subsubsection{Encapsulation and drug release from PHB-based nanoparticles}

Nanoparticles based on PHB homopolymer have been used to encapsulate hydrophobic drugs with excellent DLE due to the absence of hydrophilic group in the PHB (hydrophobic) main chain. FOL-PHB conjugate-based nanoparticles encapsulated arsenic trioxide used to target colon cancer with a DLE of $c a .94 \%$ [141]. The potential electrostatic interactions between the electronegative oxygen of the ester carbonyl group of PHB repeating units with the electropositive arsenic metal ion, and the hydrophobic interactions between 
PHB and arsenic trioxide, enabled to reach such a high DLE. Moreover, a typical sustained release of the drug was observed mainly due to the drug diffusion and to the copolymer erosion, as often observed. Indeed, $13 \%$ of arsenic trioxide was first released within $30 \mathrm{~min}$ due to the "burst effect", and then $40 \%$ was released in $48 \mathrm{~h} \mathrm{[141].}$

Several studies reported the encapsulation of fluorescent molecules such as 9-diethylamino-5-benzo[ $\alpha]$ phenoxazinone (Nile red), 1,1'-dioctadecyl-3,3,3',3'tetramethylindodicarbocyanine perchlorate (Did Oil), calcein, or fluorescein isothiocyanate labeled insulin into PHB-based copolymers, permitting visualization of the particles by several imaging techniques after cells internalization[75-77,81,91].

\subsubsection{Encapsulation and drug release from PHB-based micelles}

Core-shell PHB-based micelles have been commonly used to encapsulate hydrophobic molecules into their inner core. Several parameters such as the crystallinity of the core, the partition equilibrium coefficient $(K)$, the architecture of the copolymer and the surrounding conditions determine the DLE of a molecule in a polymeric matrix.

\subsubsection{Encapsulation and drug release from PHB/PEG-based micelles}

Triblock copolymers formed core-shell micelles with different structures depending on the macromolecular topology. Both PHB- $b$-PEG- $b$-PHB and the "reverse" PEG- $b$-PHB- $b-$ PEG based self-assembled systems successfully encapsulated hydrophobic molecules. Both the DLE (14-61\%) and DLC (1.4-6.7 mg. $\left.\mathrm{g}^{-1}\right)$ of pyrene-encapsulated into micelles based on PHB- $b$-PEG- $b$-PHB was increased with longer PHB blocks [65]. Micelles formed from the "reverse" triblock structures (PEG- $b$-PHB- $b$-PEG) gave a DOX DLE of 64\% [71]. Also, the DLE of these latter self-assembled systems was reduced in the presence of added Pluronic due to the higher crystallinity of the micelles core [79]. Indeed, as aforementioned, the crystallinity of a polymer plays a key role for the encapsulation of a molecule. A high degree of crystallinity of a low molar mass polymer decreases the ability to encapsulate a drug due to 
the poor mobility of the polymer chains which makes the incorporation of the drug more difficult, as evidenced with PHB- $b$-PEG- $b$-PHB/pyrene [65,195]. Nevertheless, the crystallinity has less impact on the DLE and the drug release rate when high molar mass polymers with a high porosity are used [195]. Therefore, one major drawback of naturally produced isotactic PHB is its too high crystallinity.

\subsubsection{Encapsulation and drug release from other PHB-based micelles}

As aforementioned, the DLE of a polymeric system is strongly dependent on the partition equilibrium coefficient $(K)$ of the encapsulated molecule. Hydrophobic molecules such as pyrene are well-encapsulated by PHB-based copolymers thanks to the high hydrophobicity of the PHB segment(s). The $K$ values of pyrene in the aqueous PNIPAAM- $b$ PHB- $b$-PNIPAAM micelles-based solution $\left(1.64-20.42 .10^{5}\right.$, inversely correlated to $f=41-$ 96\%) [80] were higher than the ones of PNIPAAM- $b$-PCL- $b$-PNIPAAM micelles-based solution $\left(3.1 .10^{4}-2.46 .10^{5}\right.$, inversely correlated to $\left.f=65-86 \%\right)$ [196], thus highlighting the higher hydrophobicity of PHB compared to PCL. The $K$ values thus obviously increased with the length of the hydrophobic block.

In addition, DLE and drug release rate also depend on the surrounding conditions. Indeed, the hydrophobicity of the copolymers is tuned by modulating the $\mathrm{pH}$. Micelles based on PDMAEMA- $b$-PHB- $b$-PDMAEMA (DLE: $31-38 \%$ ) released DOX much faster at $\mathrm{pH} 5$ than at $\mathrm{pH} \mathrm{7,} \mathrm{as} \mathrm{the} \mathrm{result} \mathrm{of} \mathrm{the} \mathrm{decrease} \mathrm{of} \mathrm{the} \mathrm{size} \mathrm{of} \mathrm{the} \mathrm{micelles} \mathrm{and} \mathrm{of} \mathrm{a} \mathrm{larger} \mathrm{surface}$ area exposed to the buffer. In addition, the thermoresponsive behavior of the copolymer impacted the drug release rate. Indeed, a prolonged release of DOX was observed during 20 days at $\mathrm{pH} 7$ and at $20{ }^{\circ} \mathrm{C}$, while decreasing down to 13 days at $\mathrm{pH} 7$ and $40{ }^{\circ} \mathrm{C}$. Interestingly, the decrease of the temperature from $37{ }^{\circ} \mathrm{C}$ to $20^{\circ} \mathrm{C}$ reversely slowed down the release rate. (Figure 7) [73].

\section{Figure 7.}


Noteworthy, micelles based on PDMAEMA- $b$-PHB- $b$-PDMAEMA were not destroyed above the copolymer LCST as opposed to PNIPAAM-based micelles (PNIPAAM$b$-PCL- $b$-PNIPAAM and PNIPAAM- $b$-PMMA)[177,197], thus making these former methacrylate triblock copolymers valuable as double stimuli-responsive DDSs.

Other triblock copolymers such as PEEP- $b$-PHB- $b$-PEEP were used to encapsulate Paclitaxel (DLE $=1-46 \%$ ) as a hydrophobic drug model. Up to $70 \%$ of the loaded drug was released in $25 \mathrm{~d}$. In addition, the DLE decreased upon lowering the hydrophilic weight fraction because the stability of the self-assembled system was reduced [82].

\subsubsection{Encapsulation and drug release from PHB-based microparticles}

Microparticles are used to encapsulate either hydrophilic or hydrophobic molecules depending on the physico-chemical characteristics of the copolymer used and of the formulation method. Pignatello, Ballistreri and co-workers reported the encapsulation of calcein, an hydrophilic molecule, by P(HB-co-CL)-based microparticles with a DLE of $100 \%$. On the contrary, the encapsulation of a hydrophobic molecule such as 1-(2,5-dimethyl-4-(2,5dimethylphenyl) phenyldiazenyl) azonapthalen-2-ol (Oil Red O) probe gave lower DLE. The highest Oil Red O-DLE (up to 57\%) was obtained for the copolymer exhibiting the highest content of HB. This was suggested to arise from the possible formation of lipophilic microdomains resulting from the presence of numerous HB units in the polymer chains. It thus appeared that $\mathrm{P}(\mathrm{HB}-\mathrm{co}-\mathrm{CL})$ copolymer was more appropriate to encapsulate hydrophilic molecules. The prolonged release of calcein at $37{ }^{\circ} \mathrm{C}$ was preceded by a burst phase due to the high adsorption of the drug on the hydrophilic outer layer of the particle, while the release profile of Oil Red O displayed a linear release kinetic during $72 \mathrm{~h}$ without any burst effect. Assessing the adsorption of the hydrophilic probe on the particle outer layer by Zeta potential measurements, revealed that the negative surface charge increased after the encapsulation of calcein (from 20 to $-27 \mathrm{mV}$ ), while it remained constant after the encapsulation of Oil Red O [81]. 
The synthesis of PHB from the ROP of $\beta$-butyrolactone associated with the precise control of its microstructure, clearly illustrated the effect of the crystallinity on DLE and drug release rate. Indeed, $\mathrm{P}\left(\mathrm{HB}-\mathrm{co}-\mathrm{HB}^{\text {allyl }}{ }_{11 \%}\right)$ based microparticles with various tacticities were used for the encapsulation and the prolonged release of L-Leuprolide. While atactic PHBbased microparticles released more than $80 \%$ of encapsulated L-Leuprolide in $3 \mathrm{~d}$, only $3 \%$ were released within $2 \mathrm{~d}$ followed by a regular slow release recorded up to $20 \mathrm{~d}$ with isotactic PHB-based microparticles. The slow release observed with highly crystalline PHB-based microparticles was rationalized by the better stability of the microparticles and the potential formation of hetero-stereocomplexes between the isotactic PHB and L-Leuprolide [89]. The functionality of the copolymer also significantly affected the release of L-Leuprolide. P(HB$c o-\mathrm{HB}^{\mathrm{diOH}}{ }_{11 \%}$ ) showed a faster and more linear release profile without reaching a plateau; this was explained by the more hydrophilic character of the copolymer compared to the allyl functionalized one.

In summary, different molecules with various hydrophilic/lipophilic balances were successfully encapsulated by PHB-based self-assembled systems. The DLE and the release rate were imparted by the polymer chemical structure, crystallinity and surrounding conditions.

\subsection{Targeting approaches associated with PHB-based self-assembled systems}

The circulation time of a drug carrier in the organism is increased by the control of different parameters such as the size, shape, surface charge, flexibility of the particle and the chemical composition of the polymeric matrix [198-200]. The effect of the chemical functionality(ies) available at the surface of the particles on their half-life has also been widely studied during the past few years $[198,200]$. Most commonly, PEG-based amphiphilic block copolymers have been used to increase the in-vivo circulation time of the drug carrier. Indeed, PEG helps to prevent the adhesion at the surface of the particles of the opsonins 
through steric and hydration effects [192]. Although PEGylation generally increases the size of nanoparticles which in turn can induce a higher phagocytic activity, a longer circulatory retention time and a lower uptake by the liver and the reticulo-endothelial system (RES), are commonly reported [200]. This PEG-based approach significantly improved the therapeutic approaches since other conventional carriers (i.e., first generation non-PEG nanovectors without any targeting agent) are eliminated too rapidly by the RES (within seconds or minutes) after intravenous injection [201-203].

More recently, the conjugation of a targeting ligand to the polymeric carrier has been reported as a more efficient strategy to enhance the bioavailability of the API, and to reduce the severe side effects due to the high toxicity of API combined with the lack of selectivity [200]. However, examples of conjugated PHB-based vectors remain nowadays very limited. Ligands such as the single-chain variable fragment antibody $\mathrm{A} 33 \mathrm{scFv}$ specific to colon cancer, or the green fluorescence protein (GFP) useful for imaging, were covalently bonded to PHB during the enzymatic synthesis of the polymer [75]. The uptake of A33scFv-GFP-PHBbased nanoparticles by colon cancer cells took place through specific interactions between the anti-body and the A33 antigen. Such an approach remains however limited because the identification of a precise targeted receptor is not always obvious.

Another approach consisted in the conjugation to the polymer of a molecule involved in DNA synthesis such as folates (FOLs); FOLs are required in high quantity by dividing cells. For example, $90 \%$ of ovarian carcinomas over-express FOL receptors [204]. Binod and co-workers reported the formation of nanoparticles based on FOL-PHB conjugate for the targeting of fibrosarcoma L929 cells. These nanoparticles were rapidly internalized by carcinoma cells as "nano-Trojan horses" and the cytotoxicity towards targeted cells was significantly increased compared to non-functionalized nanoparticles, as assessed by fluorescence microscopy imaging [141]. 
An alternative method consists in using a specific peptide to produce protein-polymer hybrid particles. Proteins do form a layer at the surface of particles facilitating stabilization of the self-assembled systems. For example, nanoparticles based on RGD4C-PHB conjugates revealed efficient regarding MDA-MB 231 human breast cancer cells as assessed by the monitoring of cells' adhesion and cells' uptake by fluorescence imaging [76]. Moreover, some substrates like bile salts (DOCA) facilitated the cellular uptake by disrupting the tight junctions. Kulkarni and Aminabhavi and co-workers reported the rapid cellular uptake of nanoparticles based on DOCA-PHB- $b$-PEG conjugate by HT-29 human colon cells. Monitoring the cellular uptake by fluorescence microscopy showed the highest fluorescence rate after $3 \mathrm{~h}$ of incubation [77]. However, internalization of non-conjugated PHB- $b$-PEGbased nanoparticles by HT-29 human colon cell line was not reported, thus making difficult to clearly evidence the benefit of DOCA grafting.

\subsection{In-vitro and in-vivo effects of PHB-based self-assembled systems}

Prior to any drug delivery application, the in-vitro and in-vivo biocompatibility of synthetic PHB-based systems such as nanoparticles, micelles, microparticles and gels must be evaluated.

\subsubsection{In-vitro biocompatibility of PHB-based self-assembled systems}

Despite the inherent biocompatibility of PHB, chemical modification of natural PHB into PHB conjugates or PHB copolymers, and the chemical synthesis of PHB copolymers, may affect the organization of cells through different known phenomena, such as interactions with the phospholipid bilayers during the internalization, interactions with proteins during their assembling process, or also interactions with DNA [205]. For these reasons, numerous tests such as in particular the 3-(4,5-dimethylthiazol-2-yl)-2,5-diphenyltetrazolium bromide (MTT) assays, have been carried out on several cell lines in order to evaluate the in-vitro cytotoxicity. Most often, the viability of cells incubated with the polymeric self-assembled 
system is reduced, thus reflecting either mild or acute cytotoxicity. The half maximal inhibitory concentration $\left(\mathrm{IC}_{50}\right)$ which corresponds to the concentration at which $50 \%$ of the incubated cells are killed, is often determined.

Generally, PHB homopolymers associated with a surfactant approved by the U.S. Food and Drug Administration (FDA) induce a very mild cytotoxicity. Indeed, PHB nanoparticles stabilized with PVA reduced the cell viability of HEK293T cells by less than $1 \%$ as assessed by MTT assays. Also, the encapsulation of arsenic trioxide as well as the grafting of FOL induced an inhibition of cell viability up to $4 \%$ and $10 \%$, respectively [141]. These higher cytotoxicities were most likely induced by the grafting of the targeting agent and by the encapsulation of a cytotoxic drug, respectively.

An important consideration in assessing cell viability is that the comparison of the $\mathrm{IC}_{50}$ values remains difficult as these are strongly dependent on the nature of the investigated cell lines. Indeed, several cell lines such as human and murine fibroblasts, human mesenchymal stem cells, rabbit bone marrow cells, human osteogenic sarcoma cells, human epithelial cells, and human endothelial cells, are all suitable models for in-vitro tests such as the cell viability measurements and the cellular uptake of nano- or micro-drug carriers [205]. The cytotoxicity of most particles based on PHB copolymers evaluated by MTT assays on various cell lines, often showed a lower induced cytotoxicity as assessed by the high $\mathrm{IC}_{50}$ values compared with values commonly reported for polymeric nanoparticles $\left(50-500 \mu \mathrm{g} \cdot \mathrm{mL}^{-1}\right)[205,206]$. Indeed, the $\mathrm{IC}_{50}$ of nanoparticles based on PEEP- $b$-PEG- $b$-PEEP evaluated on HEK293 cells were higher than $1 \mathrm{mg} \cdot \mathrm{mL}^{-1}$ [82]. It was also reported that PNIPAAM- $b$-PHB- $b$-PNIPAAM based micelles did not induced a significant cytotoxicity on L929 cells in the concentration range of $2-500 \mathrm{mg} \cdot \mathrm{mL}^{-1}[70]$.

Likewise, the cytotoxicity of amphiphilic PMLA- $b$-PHB copolymers was evaluated by MTT assays on SK-MEL-28 melanoma cells and HepaRG hepatoma cells [91]. The $\mathrm{IC}_{50}$ was determined as $175 \mu \mathrm{g} \cdot \mathrm{mL}^{-1}$, thus indicating a mild cytotoxicity in the range of $\mathrm{IC}_{50}$ values of 
polymeric nanoparticles just mentioned above $\left(50-500 \mu \mathrm{g} \cdot \mathrm{mL}^{-1}\right)[205,206]$. Interestingly, the levels of DNA replication and apoptosis were evaluated on proliferating HepaRG cells, respectively (Figure 8). These results revealed that the proliferation rate of cells was decreased as the incorporation of bromodesoxyuridine (BrdU), a labeled nucleoside involved in cells proliferation, was slightly decreased, thus indicative of a cytostatic effect. Nevertheless, no death of cells was induced as the caspase activity remained equal to that of the negative control [91].

\section{Figure 8.}

The cytotoxicity is impacted by the physical state of the self-assembled system. It is thus essential to verify that any change made on stimuli-responsive polymers does not induce any cytotoxicity. Interestingly, poly(PEG/PPG/PHB urethane)s did not induce any significant cytotoxicity on L929 fibroblast mouse cells in the range of 3-100 $\mu \mathrm{g} \cdot \mathrm{mL}^{-1}$ despite the change of state from solution to gels above $12.5 \mathrm{mg} \cdot \mathrm{mL}^{-1}$, as evaluated by MTT assays [80]. The $\mathrm{IC}_{50}$ of particles based on PDMAEMA- $b$-PHB- $b$-PDMAEMA was found to depend on the temperature and the $\mathrm{pH}$ conditions. The $\mathrm{IC}_{50}$ was decreased from 27 to $17 \mu \mathrm{g} \cdot \mathrm{mL}^{-1}$ by decreasing the temperature from 37 to $20^{\circ} \mathrm{C}$. The $\mathrm{IC}_{50}$ was also modified by the surrounding as the $\mathrm{pH}$ conditioned the DOX release rate.

Interestingly, spheroids are 3-D cell cultures that are efficient models providing drug accumulation and diffusion mechanisms transposable to solid tumors [71,207-210]. These model cells were used to evaluate the cytotoxicity and the efficiency of PEG- $b$-PHB- $b$-PEG micelles as DDSs. The penetration of DOX in these cells was enhanced by the self-assembled systems. Indeed, the penetration of DOX in the core of the 3-D-spheroids was observed within $30 \mathrm{~min}$, while, in the same period of time, the free drug was only able to penetrate the first outer layers, as assessed by fluorescence measurements. Moreover, it was reported that free DOX mixed with drug-free micelles had the same behavior as DOX alone, thus evincing the real necessity to encapsulate the drug during the formulation process for a better 
efficiency (Figure 9) [71]. The cytotoxicity of DOX loaded micelles was next determined through the $\mathrm{IC}_{50}\left(24 \mu \mathrm{g} \cdot \mathrm{mL}^{-1}\right)$ evaluated by MTT assays. Furthermore, the growth inhibition tests evidenced that both free DOX and loaded micelles significantly inhibited the spheroids' growth during a week. Nevertheless, the growth of non-treated cells and of cells incubated with non-loaded micelles remained constant, thus suggesting that the cytotoxic effect was mainly due to DOX. This inhibition of cells' growth resulted from induced apoptosis as evidenced by Annexin V apoptosis assays [71].

\section{insert Fig 9.}

Cytotoxicity studies performed on the poly(PHB/PEG/PPG urethane) copolymer or on extracts of the copolymer gel, using the mouse fibroblast L929 cells and MTT assays, indicated a good cell biocompatibility [80,144]. A significantly better cell attachment was observed on the surface of the gel as compared to that on the commercially available PEGPPG-PEG triblock copolymer. The new materials were thought to be promising candidates for injectable drug systems which could be formulated at low temperatures and formed a gel depot in-situ upon subcutaneous injection, or for tissue engineering applications or 3-D cell culture.

\subsubsection{In-vivo efficiency of PHB-based self-assembled systems}

Although cells constitute an efficient tool to assess the toxicity of PHB-based drug carriers, it remains difficult to mimic all events related to cells signaling, cells communication and tissues communication, the way they naturally occur in-vivo. Therefore, it is more interesting to evaluate the biocompatibility and the drug carrier efficiency by using in-vivo models.

The efficiency of PEG- $b$-PHB- $b$-PEG micelles as DDSs was assessed in-vivo on a $\mathrm{SiHa}$ xenograft tumor model in mice. DOX loaded micelles $\left([\mathrm{DOX}]_{0}=6\right.$ and 9 mg. $\mathrm{kg}^{-1}$ ) slowed the growth of tumoral cells during the observation period, while free DOX 
immediately inhibited the proliferation of cells, thus highlighting the prolonged release of loaded micelles (Figure 10). In addition, the concentration of DOX in the blood of mice treated with drug loaded micelles was significantly higher than that of mice treated with free DOX. For example, DOX was detected beyond $4 \mathrm{hr}$ with the use of such DOX loaded miscelles, whereas the half-life of free DOX in the blood of mice is commonly around $10 \mathrm{~min}$ [211]. Remarkably, the size of the tumor was also significantly reduced without any adverse effects on the treated mice [71].

\section{Figure 10.}

The formulation from PEG- $b$-PHB- $b$-PEG copolymers mixed with Pluronic enabled the formation of relatively rigid filamentous micelles which reduced the clearance rate and increased the tumor targeting. The accumulation of the mixed micelles in the tumor of the treated mice was evidenced by fluorescence imaging [79].

The biocompatibility of PHB-based carriers is quite often evaluated in-vitro and invivo during a moderate time. However, it is also important to evaluate the biocompatibility and the behavior of a polymeric self-assembled system during its complete degradation, as discussed in the following section.

\subsection{Biodegradation of PHB-based self-assembled systems}

PHB is a fully biocompatible and biodegradable polymer which degradation product, 3-hydroxybutyric acid, is a normal constituent of blood within concentrations ranging from 0.3 to $1.3 \mathrm{mM}$ [212]. Nevertheless, PHB is not always combined with fully biodegradable moieties; indeed, many polymers cited here, including PEEP, PNIPAAM, PDMAEMA or PEG are not biodegradable. In reported studies, the length of these latter hydrophilic blocks were purposely restricted to $M_{\mathrm{n}} \leq 20000 \mathrm{~g} \cdot \mathrm{mol}^{-1}$ to facilitate easy excretion of the final fragments [70,84], although the renal elimination of PEG blocks was reported with a molar 
mass up to 30000 g.mol ${ }^{-1}[63,213]$. In fact, the literature only reports very scarce data on the biodegradation of synthetic PHB-based drug carriers, as discussed thereafter.

Different degradation pathways of PHB segments can occur; these include in particular hydrolysis or biodegradation by enzymes such as the PHB depolymerize or the more common esterase [209,214]. Most often, the PHB biodegradation requires the contribution of some crystalline phase to induce the enzymatic hydrolysis, a phenomenon known as the crystalline-induced biodegradation [214]. However, Yu and co-workers reported that the biodegradation of fully amorphous PHB in core-shell micelles based on PHB- $b$-PEG$b$-PHB was possible by PHB depolymerase and by esterase from porcine liver [68].

The degradation of synthetic PHB-based self-assembled systems was monitored by different complementary methods such as NMR and fluorescence spectroscopies, $\mathrm{pH}$, and SLS. Yet, SLS analysis of only the nanoparticles remaining after degradation does not For example the direct monitoring of the degradation.

Hydroxybutyrate (HB) oligomers, monomer (dominant), dimer and trimer, are formed during the degradation process of PHB- $b$-PEG- $b$-PHB by PHB depolymerase, as evidenced by NMR spectroscopy analyses [65]. Noteworthy, HB monomer was the major degradation product while HB trimer was formed in the lowest amount. Moreover, after degradation by esterase, only HB monomer and dimer were identified as the major and minor degradation products, respectively, as evidenced by ${ }^{1} \mathrm{H}$ NMR analyses [68]. These results suggested that the degradation behavior was dependent on the enzyme used.

The degradation kinetic profile is monitored through the release of a fluorescent molecule featuring characteristic bands corresponding to the encapsulated and nonencapsulated molecule, respectively. Thus, the intensity of the band corresponding to the pyrene entrapped in a hydrophobic domain has a wavelength of $\lambda 336.6 \mathrm{~nm}$, while the band at $\lambda 333.1 \mathrm{~nm}$ is the distinctive peak of free pyrene in water. The relative ratio of $\mathrm{I}_{(336.6) t} / \mathrm{I}_{(336) 0}$ then enables to follow its release and the degradation of the polymeric matrix as well. Thus, 
the degradation of nanoparticles based on PHB- $b$-PEG- $b$-PHB into HB oligomers of PHB, increased with the PHB depolymerase concentration and decreased with the concentration of the nanoparticles, as monitored by the pyrene fluorescence $[65,66,68]$. These phenomena were rationalized by the available contact surface area relatively to the amount of enzyme. Moreover, the degradation rate depended also on the PHB block length (Figure 11). The initial degradation rate values increased with the PHB block length as the available surface area was increased. Regardless of the nanoparticle and enzyme concentrations, a plateau was reached due to the loss of the enzyme efficiency (itself resulting from the $\mathrm{pH}$ decrease during the PHB degradation), resulting in the incomplete degradation of the PHB segment [65].

The biodegradation of PHB-based nanoparticles depend on several parameters such as the concentration of the nanoparticles, the enzyme concentration, the PHB size, and the surrounding conditions. The degradation of PHB was also correlated with a decrease of the $\mathrm{pH}$ due to the release of hydroxybutyric acid units as followed by $\mathrm{pH}$ measurements (Figure $11)$.

\section{Figure 11.}

\section{Concluding remarks and outlooks}

The use of PHB within DDSs has been widely studied during the past few decades. This polyester presents valuable properties in terms of biocompatibility and biodegradability. Indeed, its degradation product, 3-hydroxybutyric acid, is physiologically present in human organisms and PHB-based self-assembled systems often reveal no acute cytotoxicity.

Historically, PHB has been naturally produced by various bacteria under different growth conditions. Despite its remarkable characteristics, the use of microbial PHB homopolymer remains limited due to its high hydrophobicity and crystallinity. These features induce a poor compatibility of PHB with therapeutic agents and a limited encapsulation efficiency. In addition, the lack of control of the drug release rate makes these natural PHB homopolymer-based materials unsuitable for drug delivery applications. 
Therefore, synthetic PHB, i.e., either chemically modified microbial PHB, or PHB chemically synthesized by ROP of BL, led to the development of highly promising DDSs over the past few years. Indeed, the grafting of molecules of interest into PHB-drug conjugates, the synthesis of PHB by controlled ROP of BL, and the synthesis of amphiphilic copolymers, aimed to tune the physico-chemical properties of these self-assembled systems from the control of the hydrophilic/hydrophobic balance and of the microstructure of the (co)polymer. These recent advances led to the emergence of bespoke self-assembled systems for drug delivery applications. Such PHB-based self-assemblies demonstrated their potential through enhanced water solubility, very low CMC values and high colloidal stability in aqueous medium.

This review presents a comprehensive state-of-the-art view on synthetic PHB-based DDSs. Accounts on the various suitable routes for the chemical modification of PHB into amphiphilic (co)polymers have been addressed. This includes the grafting and the copolymerization carried out from naturally produced PHB, as well as the synthesis through ROP, with precise control of the PHB microstructure. However, the prodrug route certainly remains nowadays under-explored with $\mathrm{PHB}$ in comparison to other polyester-drug conjugates, and the elaboration of PHB-based nanoparticulate systems flanked with a targeting moiety certainly deserves much attention and efforts to achieve the desired sitespecific delivery and to enhance the biodistribution in the cellular compartments. Besides, the ROP approach has benefited from investigations on the catalytic systems used for the polymerization and on the fine-tuning of the polymer stereochemistry. Progress in this field are still on-going and future developments on $\beta$-butyrolactone ring-opening (co)polymerization will also certainly contribute to improve the design of fine-tuned PHBbased copolymer platforms. Therefore, other biocompatible and biodegradable hydrophilic polymers ought to be investigated for original biocompatible and biodegradable PHB-based nanoparticulate systems to unveil innovative performant DDS. 
The physico-chemical characteristics of these synthetic PHB-based self-assembled systems are explored from nanoscale to macroscale. The different methods implemented for the preparation of nano-objects, from solvent evaporation, direct dissolution in water, nanoprecipitation through emulsion-solvent evaporation or dialysis, including the possible use of a surfactant, have shown to significantly impact their morphology, size, and stability. Remarkably, the use of PHB as hydrophobic segments reduced the CMC values of the copolymers compared to the analogous ones containing PLA or PLGA as hydrophobic segment. Highly stable self-assembled systems were thus formed in diluted conditions. Moreover, the CMC of the PHB-based triblock copolymers were found to be nontemperature-sensitive, while triblock copolymers consisting of PLA or PGA as central hydrophobic block are usually thermosensitive. The self-assembly tendency of PHB segment is really strong and independent on temperature changes. The few targeting approaches developed on PHB-based DDSs in order to provide efficient vectors against various cancers cells, are quite relevant. Indeed, the grafting of a peptide such as RGD4C or the grafting of folate on the polymer chain-end led to the development of self-assembled systems with enhanced accumulation in tumoral cells as demonstrated in-vivo. Results reported so far evidence this targeting approach as a promising, although challenging, route. Finally, the degradation behavior and the biological efficiencies of these DDS are demonstrated in-vitro and/or in-vivo in terms of $\mathrm{IC}_{50}$ values and of their response to various stimuli $(\mathrm{pH}$, temperature). However, a limited number of PHB-based self-assembled systems have been investigated in-vitro and/or in-vivo, and these studies should be more extensively carried out. The in-vivo efficiency of nanovector toward cancer cells is often a limiting factor despite the promising in-vitro results. Therefore, efforts should be focused on the transition from in-vitro to in-vivo. Although it is encouraging to see that the development of chemically modified PHB-based self-assemblies affords new perspectives for the improvement of the physicochemical properties of drug delivery carriers, their clinical use is still quite far, yet reasonably 
foreseeable. Whereas there are, to the best of our knowledge, five PHA (co)polymers currently under medical investigation (PHB - namely poly(3-hydroxybutyrate) -, poly(4hydroxybutyrate) (P4HB), $\mathrm{P}(3 \mathrm{HB}-c o-4 \mathrm{HB}), \mathrm{PHBV}$ and poly(3-hydroxyoctanoate-co-3hydroxyhexanoate), only P4HB-based materials have been approved by the FDA for clinical applications as TephaFLEX®-based surgical materials (absorbable monofilament suture and mesh). One major advancement towards clinical trials based on PHB-based biomaterials would most likely be triggered by the FDA approval of PHB.

Given these advances from the past few decades of research, engineered nano-scaled PHB-based materials are thus prone to emerge as a valuable platform for original DDSs.

\section{Acknowledgements}

Financial support from the Fondation pour la Recherche Médicale (FRM) (Ph.D. grant to G.B.), the Centre National de la Recherche Scientifique (CNRS) and the University of Rennes 1 is gratefully acknowledged. 


\section{References}

[1] Chen G, Roy I, Yang C, Prasad PN. Nanochemistry and Nanomedicine for Nanoparticle-based Diagnostics and Therapy. Chem Rev 2016;116:2826-85.

[2] Janib SM, Moses AS, MacKay JA. Imaging and drug delivery using theranostic nanoparticles. Adv Drug Deliv Rev 2010;62:1052-63.

[3] Kamaly N, Yameen B, Wu J, Farokhzad OC. Degradable Controlled-Release Polymers and Polymeric Nanoparticles: Mechanisms of Controlling Drug Release. Chem Rev 2016;116:2602-63.

[4] Ma Y, Huang J, Song S, Chen H, Zhang Z. Cancer-Targeted Nanotheranostics: Recent Advances and Perspectives. Small 2016;12:4936-54.

[5] Min Y, Caster JM, Eblan MJ, Wang AZ. Clinical Translation of Nanomedicine. Chem Rev 2015;115:11147-90.

[6] Barreto JA, O’Malley W, Kubeil M, Graham B, Stephan H, Spiccia L. Nanomaterials: Applications in Cancer Imaging and Therapy. Adv Mater 2011;23:H18-H40.

[7] Doane TL, Burda C. The unique role of nanoparticles in nanomedicine: imaging, drug delivery and therapy. Chem Soc Rev 2012;41:2885-911.

[8] Kamaly N, Xiao Z, Valencia PM, Radovic-Moreno AF, Farokhzad OC. Targeted polymeric therapeutic nanoparticles: design, development and clinical translation. Chem Soc Rev 2012;41:2971-3010.

[9] Lee DE, Koo H, Sun IC, Ryu JH, Kim K, Kwon IC. Multifunctional nanoparticles for multimodal imaging and theragnosis. Chem Soc Rev 2012;41:2656-72

[10] Sun T, Zhang YS, Pang B, Hyun DC, Yang M, Xia Y. Engineered Nanoparticles for Drug Delivery in Cancer Therapy. Angew Chem Int Ed 2014;53:12320-64.

[11] Peng H, Liu X, Wang G, Li M, Bratlie KM, Cochran E, Wang Q. Polymeric multifunctional nanomaterials for theranostics. J Mater Chem 2015;3:6856-70.

[12] Seeta Rama Raju G, Benton L, Pavitra E, Yu JS. Multifunctional nanoparticles: recent progress in cancer therapeutics. Chem Commun 2015;51:13248-59.

[13] Blanco E, Kessinger CW, Sumer BD, Gao J. Multifunctional micellar nanomedicine for cancer therapy. Exp Biol Med 2009;234:123-31.

[14] Khemtong C, Kessinger CW, Gao J. Polymeric nanomedicine for cancer MR imaging and drug delivery. Chem Commun 2009:3497-510.

[15] Rao JP, Geckeler KE. Polymer nanoparticles: Preparation techniques and size-control parameters. Prog Polym Sci 2011;36:887-913.

[16] Hamidi M, Shahbazi MA, Rostamizadeh K. Copolymers: Efficient Carriers for Intelligent Nanoparticulate Drug Targeting and Gene Therapy. Macromol Biosci 2012;12:144-64.

[17] Nicolas J, Mura S, Brambilla D, Mackiewicz N, Couvreur P. Design, functionalization strategies and biomedical applications of targeted biodegradable/biocompatible polymer-based nanocarriers for drug delivery. Chem Soc Rev 2013;42:1147-235.

[18] Musyanovych A, Landfester K. Polymer Micro- and Nanocapsules as Biological Carriers with Multifunctional Properties. Macromol Biosci 2014;14:458-77.

[19] Pecher J, Mecking S. Nanoparticles of Conjugated Polymers. Chem Rev 2010;110:6260-79. 
[20] Mura S, Zouhiri F, Lerondel S, Maksimenko A, Mougin J, Gueutin C, Brambilla D,Caron J,Sliwinski E,LePape A,Desmaele D,Couvreur P. Novel Isoprenoyl Nanoassembled Prodrug for Paclitaxel Delivery. Bioconjug Chem 2013;24:1840-9.

[21] Delplace V, Couvreur P, Nicolas J. Recent trends in the design of anticancer polymer prodrug nanocarriers. Polym Chem 2014;5:1529-44.

[22] Hudlikar MS, Li X, Gagarinov IA, Kolishetti N, Wolfert MA, Boons GJ. Controlled Multi-functionalization Facilitates Targeted Delivery of Nanoparticles to Cancer Cells. Chem Eur J 2016;22:1415-23.

[23] Kumari A, Yadav SK, Yadav SC. Biodegradable polymeric nanoparticles based drug delivery systems. Colloids Surf B 2010;75:1-18.

[24] Pounder RJ, Dove AP. Towards poly(ester) nanoparticles: recent advances in the synthesis of functional poly(ester)s by ring-opening polymerization. Polym Chem 2010;1:260-71.

[25] Cameron DJA, Shaver MP. Aliphatic polyester polymer stars: synthesis, properties and applications in biomedicine and nanotechnology. Chem Soc Rev 2011;40:1761-76.

[26] Cheng J, Teply BA, Sherifi I, Sung J, Luther G, Gu FX, Levy-Nissenbaum E,RadovicMoreno AF,Langer R,Farokhzad OC. Formulation of functionalized PLGA-PEG nanoparticles for in vivo targeted drug delivery. Biomaterials 2007;28:869-76.

[27] Lassalle V, Ferreira ML. PLA Nano- and Microparticles for Drug Delivery: An Overview of the Methods of Preparation. Macromol Biosci 2007;7:767-83.

[28] Saffer EM, Tew GN, Bhatia SR. Poly(lactic acid)-poly(ethylene oxide) Block Copolymers: New Directions in Self-Assembly and Biomedical Applications. Curr Med Chem 2011;18:5676-86.

[29] Oh JK. Polylactide (PLA)-based amphiphilic block copolymers: synthesis, selfassembly, and biomedical applications. Soft Matter 2011;7:5096-108.

[30] Locatelli E, Comes Franchini M. Biodegradable PLGA-b-PEG polymeric nanoparticles: synthesis, properties, and nanomedical applications as drug delivery system. J Nanopart Res 2012;14:1316/1-17.

[31] Li J, Sabliov C. PLA/PLGA nanoparticles for delivery of drugs across the blood-brain barrier. Nanotechnol Rev 2013;2:241-57.

[32] Wei X, Gong C, Gou M, Fu S, Guo Q, Shi S, Luo F, Guo G, Qiu L, Qian Z. Biodegradable poly( $\varepsilon$-caprolactone)-poly(ethylene glycol) copolymers as drug delivery system. Int J Pharm 2009;381:1-18.

[33] Gou M, Wei X, Men K, Wang B, Luo F, Zhao X, Wei Y, Qian Z. PCL/PEG Copolymeric Nanoparticles: Potential Nanoplatforms for Anticancer Agent Delivery. Curr Drug Targets 2011;12:1131-50.

[34] Dash TK, Konkimalla VB. Poly-e-caprolactone based formulations for drug delivery and tissue engineering: A review. J Controlled Release 2012;158:15-33.

[35] Veronese FM, Pasut G. PEGylation, successful approach to drug delivery. Drug Discov Today 2005;10:1451-8.

[36] Pasut G, Veronese FM. PEG conjugates in clinical development or use as anticancer agents: An overview. Adv Drug Deliv Rev 2009;61:1177-88.

[37] Obermeier B, Wurm F, Mangold C, Frey H. Multifunctional Poly(ethylene glycol)s. Angew Chem Int Ed 2011;50:7988-97. 
[38] Cruje C, Chithrani DB. Polyethylene Glycol Functionalized Nanoparticles for Improved Cancer Treatment. Rev Nanosci Nanotechnol 2014;3:20-30.

[39] Suk JS, Xu Q, Kim N, Hanes J, Ensign LM. PEGylation as a strategy for improving nanoparticle-based drug and gene delivery. Adv Drug Deliv Rev 2016;99, Part A:2851.

[40] Kawai F. Microbial degradation of polyethers. Appl Microbiol Biotechnol 2002;58:308.

[41] Bugnicourt L, Ladavière C. Interests of chitosan nanoparticles ionically cross-linked with tripolyphosphate for biomedical applications. Prog Polym Sci 2016;60:1-17.

[42] Alves VD, Torres CAV, Freitas F. Bacterial polymers as materials for the development of micro/nanoparticles. Int J Polym Mater Polym Biomater 2016;65:211-24.

[43] Wu Q, Wang Y, Chen GQ. Medical Application of Microbial Biopolyesters Polyhydroxyalkanoates. Artif Cells Blood Substit Biotechnol 2009;37:1-12.

[44] Laycock B, Halley P, Pratt S, Werker A, Lant P. The chemomechanical properties of microbial polyhydroxyalkanoates. Prog Polym Sci 2014;39:397-442.

[45] Müller HM, Seebach D. Poly(hydroxyalkanoates): A Fifth Class of Physiologically Important Organic Biopolymers? Angew Chem Int Ed 1993;32:477-502.

[46] Sudesh K, Abe H, Doi Y. Synthesis, structure and properties of polyhydroxyalkanoates: biological polyesters. Prog Polym Sci 2000;25:1503-55.

[47] Scholz C. Poly( $\beta$-hydroxyalkanoates) as Potential Biomedical Materials: An Overview. ACS Symp Ser 2001;764:328-34.

[48] Zinn M, Witholt B, Egli T. Occurrence, synthesis and medical application of bacterial polyhydroxyalkanoate. Adv Drug Deliv Rev 2001;53:5-21.

[49] Ojumu TV, Yu J, Solomon BO. Production of Polyhydroxyalkanoates, a bacterial biodegradable polymer. Afr J Biotechnol 2004;3:18-24.

[50] Lenz RW, Marchessault RH. Bacterial Polyesters: Biosynthesis, Biodegradable Plastics and Biotechnology. Biomacromolecules 2005;6:1-8.

[51] Shishatskaya EI. Biomedical Investigations of Biodegradable PHAs. Macromol Symp 2008;269:65-81.

[52] Lu J, Tappel RC, Nomura CT. Mini-Review: Biosynthesis of Poly(hydroxyalkanoates). J Macromol Sci Polym Rev 2009;49:226-48.

[53] Hazer DB, Kılıçay E, Hazer B. Poly(3-hydroxyalkanoate)s: Diversification and biomedical applications: A state of the art review. Mater Sci Eng C 2012;32:637-47.

[54] Taguchi S, Iwata T, Abe H, Doi Y. Poly(hydroxyalkanoate)s. In: Matyjaszewski K, Möller M, editors. Polymer Science: A Comprehensive Reference. Vol. 9. London: Elsevier Ltd; 2012. p. 157-82.

[55] Laycock B, Halley P, Pratt S, Werker A, Lant P. The chemomechanical properties of microbial polyhydroxyalkanoates. Prog Polym Sci 2013;38:536-83.

[56] Nigmatullin R, Thomas P, Lukasiewicz B, Puthussery H, Roy I. Polyhydroxyalkanoates, a family of natural polymers, and their applications in drug delivery. J Chem Technol Biotechnol 2015;90:1209-21.

[57] Li Z, Yang J, Loh XJ. Polyhydroxyalkanoates: opening doors for a sustainable future. NPG Asia Mater 2016;8:e265/1-20. 
[58] Carpentier JF. Discrete Metal Catalysts for Stereoselective Ring-Opening Polymerization of Chiral Racemic $\beta$-Lactones. Macromol Rapid Commun 2010;31:1696-705.

[59] Carpentier JF. Exploitation of a Chain-End-Control Mechanism for the Synthesis of Alternating Copolymers. Angew Chem Int Ed 2010;49:2662-3.

[60] Thomas CM. Stereocontrolled ring-opening polymerization of cyclic esters: synthesis of new polyester microstructures. Chem Soc Rev 2010;39:165-73.

[61] Vert M. Polymeric biomaterials: Strategies of the past vs. strategies of the future. Prog Polym Sci 2007;32:755-61.

[62] Koosha F, Muller RH, Davis SS. Polyhydroxybutyrate as a drug carrier. Crit Rev Ther Drug Carrier Syst 1989;6:117-30.

[63] Yamaoka T, Tabata Y, Ikada Y. Fate of Water-Soluble Polymers Administered via Different Routes. J Pharm Sci 1995;84:349-54.

[64] Li J, Ni X, Li X, Tan NK, Lim CT, Ramakrishna S, Leong KW. Micellization Phenomena of Biodegradable Amphiphilic Triblock Copolymers Consisting of Poly $(\beta-$ hydroxyalkanoic acid) and Poly(ethylene oxide). Langmuir 2005;21:8681-5.

[65] Chen C, Yu CH, Cheng YC, Yu PHF, Cheung MK. Biodegradable nanoparticles of amphiphilic triblock copolymers based on poly(3-hydroxybutyrate) and poly(ethylene glycol) as drug carriers. Biomaterials 2006;27:4804-14.

[66] Chen C, Yu CH, Cheng YC, Yu PHF, Cheung MK. Preparation and characterization of biodegradable nanoparticles based on amphiphilic poly(3-hydroxybutyrate)poly(ethylene glycol)-poly(3-hydroxybutyrate) triblock copolymer. Eur Polym J 2006;42:2211-20.

[67] Li X, Mya KY, Ni X, He C, Leong KW, Li J. Dynamic and Static Light Scattering Studies on Self-Aggregation Behavior of Biodegradable Amphiphilic Poly(ethylene oxide)-Poly[(R)-3-hydroxybutyrate]-Poly(ethylene oxide) Triblock Copolymers in Aqueous Solution. J Phys Chem B 2006;110:5920-6.

[68] Chen C, Cheng YC, Yu CH, Chan SW, Cheung MK, Yu PHF. In vitro cytotoxicity, hemolysis assay, and biodegradation behavior of biodegradable poly(3hydroxybutyrate)-poly(ethylene glycol)-poly(3-hydroxybutyrate) nanoparticles as potential drug carriers. J Biomed Mater Res Part A 2008;87:290-8.

[69] Jeong KH, Kwon SH, Kim YJ. Characterizations and release behavior of poly [(R)-3hydroxy butyrate]-co-methoxy poly(ethylene glycol) with various block ratios. Macromol Res 2008;16:418-23.

[70] Loh XJ, Zhang ZX, Wu YL, Lee TS, Li J. Synthesis of Novel Biodegradable Thermoresponsive Triblock Copolymers Based on Poly[(R)-3-hydroxybutyrate] and Poly(N-isopropylacrylamide) and Their Formation of Thermoresponsive Micelles. Macromolecules 2009;42:194-202.

[71] Kim TH, Mount CW, Gombotz WR, Pun SH. The delivery of doxorubicin to 3-D multicellular spheroids and tumors in a murine xenograft model using tumorpenetrating triblock polymeric micelles. Biomaterials 2010;31:7386-97.

[72] Zhu JL, Liu KL, Zhang Z, Zhang XZ, Li J. Amphiphilic star-block copolymers and supramolecular transformation of nanogel-like micelles to nanovesicles. Chem Commun 2011;47:12849-51. 
[73] Loh XJ, Ong SJ, Tung YT, Choo HT. Dual responsive micelles based on poly[(R)-3hydroxybutyrate] and poly(2-(di-methylamino)ethyl methacrylate) for effective doxorubicin delivery. Polym Chem 2013;4:2564-74.

[74] Chen GQ. A microbial polyhydroxyalkanoates (PHA) based bio- and materials industry. Chem Soc Rev 2009;38:2434-46.

[75] Kwon HS, Jung SG, Kim HY, Parker SA, Batt CA, Kim YR. A multi-functional polyhydroxybutyrate nanoparticle for theranostic applications. J Mater Chem 2014;2:3965-71.

[76] Lee J, Jung SG, Park CS, Kim HY, Batt CA, Kim YR. Tumor-specific hybrid polyhydroxybutyrate nanoparticle: Surface modification of nanoparticle by enzymatically synthesized functional block copolymer. Bioorg Med Chem Lett 2011;21:2941-4.

[77] Chaturvedi K, Ganguly K, Kulkarni AR, Nadagouda MN, Stowbridge J, Rudzinski WE, Aminabhavi TM. Ultra-small fluorescent bile acid conjugated PHB-PEG block copolymeric nanoparticles: synthesis, characterization and cellular uptake. RSC Adv 2013;3:7064-70.

[78] Li J, Li X, Ni X, Leong KW. Synthesis and Characterization of New Biodegradable Amphiphilic Poly(ethylene oxide)-b-poly[(R)-3-hydroxy butyrate]-b-poly(ethylene oxide) Triblock Copolymers. Macromolecules 2003;36:2661-7.

[79] Kim TH, Mount CW, Dulken BW, Ramos J, Fu CJ, Khant HA, Chiu W, Gombotz WR, Pun SH. Filamentous, Mixed Micelles of Triblock Copolymers Enhance Tumor Localization of Indocyanine Green in a Murine Xenograft Model. Mol Pharm 2012;9:135-43.

[80] Loh XJ, Goh SH, Li J. Biodegradable Thermogelling Poly[(R)-3-hydroxybutyrate]Based Block Copolymers: Micellization, Gelation, and Cytotoxicity and Cell Culture Studies. J Phys Chem B 2009;113:11822-30.

[81] Pignatello R, Musumeci T, Impallomeni G, Carnemolla GM, Puglisi G, Ballistreri A. Poly(3-hydroxybutyrate-co- $\varepsilon$-caprolactone) copolymers and poly(3-hydroxybutyrateco-3-hydroxyvalerate-co- $\varepsilon$-caprolactone) terpolymers as novel materials for colloidal drug delivery systems. Eur J Pharm Sci 2009;37:451-62.

[82] Cheng J, Wang J. Syntheses of amphiphilic biodegradable copolymers of poly(ethyl ethylene phosphate) and poly(3-hydroxybutyrate) for drug delivery. Sci China Ser B 2009;52:961-8.

[83] Loh XJ, Cheong WCD, Li J, Ito Y. Novel poly(N-isopropylacrylamide)-poly[(R)-3hydroxybutyrate]-poly(N-isopropylacrylamide) triblock copolymer surface as a culture substrate for human mesenchymal stem cells. Soft Matter 2009;5:2937-46.

[84] Loh XJ, Ong SJ, Tung YT, Choo HT. Incorporation of poly[(R)-3-hydroxybutyrate] into cationic copolymers based on poly(2-(dimethylamino)ethyl methacrylate) to improve gene delivery. Macromol Biosci 2013;13:1092-9.

[85] Barouti G, Liow SS, Dou Q, Ye H, Orione C, Guillaume SM, Loh XJ. New Linear and Star-Shaped Thermogelling Poly([R]-3-hydroxybutyrate) Copolymers. Chem Eur J 2016;22:10501-12.

[86] Liu KL, Zhu Jl, Li J. Elucidating rheological property enhancements in supramolecular hydrogels of short poly[(R,S)-3-hydroxybutyrate]-based amphiphilic triblock 
copolymer and [small alpha]-cyclodextrin for injectable hydrogel applications. Soft Matter 2010;6:2300-11.

[87] Oledzka E, Sliwerska P, Sobczak M, Kraska B, Kamysz W, Nalecz-Jawecki G, Kolodziejski W. Peptide Dendrimer Functionalized with Amphiphilic Triblock Copolymers: Synthesis and Characterization. Macromol Chem Phys 2015;216:136575.

[88] Ajellal N, Thomas CM, Carpentier JF. Functional syndiotactic poly( $\beta$ hydroxyalkanoate)s via stereoselective ring-opening copolymerization of rac- $\beta$ butyrolactone and rac-allyl- $\beta$-butyrolactone. J Polym Sci Part A Polym Chem 2009;47:3177-89.

[89] Ajellal N, Thomas CM, Aubry T, Grohens Y, Carpentier JF. Encapsulation and controlled release of 1-leuprolide from poly([small beta]-hydroxyalkanoate)s: impact of microstructure and chemical functionalities. New J Chem 2011;35:876-80.

[90] Jaffredo CG, Carpentier JF, Guillaume SM. Poly(hydroxyalkanoate) Block or Random Copolymers of $\beta$-Butyrolactone and Benzyl $\beta$-Malolactone: A Matter of Catalytic Tuning. Macromolecules 2013;46:6765-76.

[91] Barouti G, Jarnouen K, Cammas-Marion S, Loyer P, Guillaume SM. Polyhydroxyalkanoate-based amphiphilic diblock copolymers as original biocompatible nanovectors. Polym Chem 2015;6:5414-29.

[92] Barouti G, Guillaume SM. Polyhydroxybutyrate (PHB)-based triblock copolymers: synthesis of hydrophobic PHB/poly(benzyl $\beta$-malolactonate) and amphiphilic $\mathrm{PHB} /$ poly(malic acid) analogues by ring-opening polymerization. Polym Chem 2016;7:4603-8.

[93] Díez-Pascual A, Díez-Vicente A. Poly(3-hydroxybutyrate)/ZnO Bionanocomposites with Improved Mechanical, Barrier and Antibacterial Properties. Int J Mol Sci 2014;15:10950-73.

[94] Lins LC, Bazzo GC, Barreto PLM, Pires ATN. Composite PHB/chitosan microparticles obtained by spray drying: effect of chitosan concentration and crosslinking agents on drug release. J Braz Chem Soc 2014;25:1462-71.

[95] Shakeri F, Shakeri S, Hojjatoleslami M. Preparation and Characterization of Carvacrol Loaded Polyhydroxybutyrate Nanoparticles by Nanoprecipitation and Dialysis Methods. J Food Sci 2014;79:N697-N705.

[96] Pandian SRK, Deepak V, Nellaiah H, Sundar K. PEG-PHB-glutaminase nanoparticle inhibits cancer cell proliferation in vitro through glutamine deprivation. In Vitro Cell Dev Biol Anim 2015;51:372-80.

[97] Bychkova AV, Iordanskii AL, Kovarski AL, Sorokina ON, Kosenko RY, Markin VS, Filatova AG, Gumargalieva KZ, Rogovina SZ, Berlin AA. Magnetic and transport properties of magneto-anisotropic nanocomposites for controlled drug delivery. Nanotechnol Russia 2015;10:325-35.

[98] Chee JW, Amirul AA, Tengku Muhammad TS, Majid MIA, Mansor SM. The influence of copolymer ratio and drug loading level on the biocompatibility of $\mathrm{P}(3 \mathrm{HB}-$ co-4HB) synthesized by Cupriavidus sp. USMAA2-4). Biochem Eng J 2008;38:314-8.

[99] Ying TH, Ishii D, Mahara A, Murakami S, Yamaoka T, Sudesh K, Samian R, Fujita M, Maeda M, Iwata T. Scaffolds from electrospun polyhydroxyalkanoate copolymers: 
Fabrication, characterization, bioabsorption and tissue response. Biomaterials 2008;29:1307-17.

[100] Obata A, Iwata T, Maeda H, Hirata H, Kasuga T. Preparation of poly(3hydroxybutyrate-co-4-hydroxybutyrate)-based composites releasing soluble silica for bone regeneration. J Ceram Soc Jpn 2013;121:753-8.

[101] Yagmurlu MF, Korkusuz F, Gürsel I, Korkusuz P, Örs Ü, Hasirci V. Sulbactamcefoperazone polyhydroxybutyrate-cohydroxyvalerate (PHBV) local antibiotic delivery system: In vivo effectiveness and biocompatibility in the treatment of implant-related experimental osteomyelitis. J Biomed Mater Res Part A 1999;4:494-503.

[102] Grillo R, de Melo NFS, de Lima R, Lourenço RW, Rosa AH, Fraceto LF. Characterization of Atrazine-Loaded Biodegradable Poly(Hydroxybutyrate-CoHydroxyvalerate) Microspheres. J Polym Environ 2010;18:26-32.

[103] Pacheco DP, Amaral MH, Reis RL, Marques AP, Correlo VM. Development of an injectable PHBV microparticles-GG hydrogel hybrid system for regenerative medicine. Int J Pharm 2015;478:398-408.

[104] Hosoda N, Tsujimoto T, Uyama H. Green Composite of Poly(3-hydroxybutyrate-co-3hydroxyhexanoate) Reinforced with Porous Cellulose. ACS Sustain Chem Eng 2014;2:248-53.

[105] Zhang C, Dong Y, Zhao L. Preparation and characterization of novel microparticles based on poly(3-hydroxybutyrate-co-3-hydroxyoctanoate). J Microencapsul 2014;31:915 .

[106] Dong CL, Webb WR, Peng Q, Tang JZ, Forsyth NR, Chen GQ, El Haj AJ. Sustained PDGF-BB release from PHBHHx loaded nanoparticles in 3D hydrogel/stem cell model. J Biomed Mater Res Part A 2015;103:282-8.

[107] Errico C, Bartoli C, Chiellini F, Chiellini E. Poly(hydroxyalkanoates)-Based Polymeric Nanoparticles for Drug Delivery. J Biomed Biotechnol 2009;2009:571702/1-10.

[108] Naveen N, Kumar R, Balaji S, Uma TS, Natrajan TS, Sehgal PK. Synthesis of Nonwoven Nanofibers by Electrospinning - A Promising Biomaterial for Tissue Engineering and Drug Delivery. Adv Eng Mater 2010;12:B380-B7.

[109] Geng Y, Wang S, Qi Q. Expression of Active Recombinant Human Tissue-Type Plasminogen Activator by Using In Vivo Polyhydroxybutyrate Granule Display. Appl Environ Microbiol 2010;76:7226-30.

[110] Pandian SRK, Deepak V, Kalishwaralal K, Gurunathan S. Biologically synthesized fluorescent CdS NPs encapsulated by PHB. Enzyme Microb Technol 2011;48:319-25.

[111] Kim YR, Paik Hj, Ober CK, Coates GW, Batt CA. Enzymatic Surface-Initiated Polymerization: A Novel Approach for the in Situ Solid-Phase Synthesis of Biocompatible Polymer Poly(3-hydroxybutyrate). Biomacromolecules 2004;5:889-94.

[112] Wodzinska J, Snell KD, Rhomberg A, Sinskey AJ, Biemann K, Stubbe J. Polyhydroxybutyrate Synthase: Evidence for Covalent Catalysis. J Am Chem Soc 1996;118:6319-20.

[113] Marchessault RH, Yu GE. Preparation and characterization of low molecular weight poly(3-hydroxybutyrate)s and their block copolymers with poly(oxyethylene)s. Polym Prepr Am Chem Soc Div Polym Chem 1999;40(1):527-8. 
[114] Ravenelle F, Marchessault RH. One-Step Synthesis of Amphiphilic Diblock Copolymers from Bacterial Poly([R]-3-hydroxybutyric acid). Biomacromolecules 2002;3:1057-64.

[115] Hirt TD, Neuenschwander P, Suter UW. Telechelic diols from poly[(R)-3hydroxybutyric acid] and poly\{[(R)-3-hydroxybutyric acid]-co-[(R)-3-hydroxyvaleric acid]\}. Macromol Chem Phys 1996;197:1609-14.

[116] Kim TH, Chen Y, Mount CW, Gombotz WR, Li X, Pun SH. Evaluation of Temperature-Sensitive, Indocyanine Green-Encapsulating Micelles for Noninvasive Near-Infrared Tumor Imaging. Pharm Res 2010;27:1900-13.

[117] Atherton E, Fox H, Harkiss D, Logan CJ, Sheppard RC, Williams BJ. A mild procedure for solid phase peptide synthesis: use of fluorenylmethoxycarbonylaminoacids. Chem Commun 1978:537-9.

[118] Beyerbach A, Farmer PB, Sabbioni G. Biomarkers for Isocyanate Exposure: Synthesis of Isocyanate DNA Adducts. Chem Res Toxicol 2006;19:1611-8.

[119] Mishra PK, Panwar H, Bhargava A, Gorantla VR, Jain SK, Banerjee S, Maudar KK. Isocyanates induces DNA damage, apoptosis, oxidative stress, and inflammation in cultured human lymphocytes. J Biochem Mol Toxicol 2008;22:429-40.

[120] Mishra PK, Bhargava A, Raghuram GV, Gupta S, Tiwari S, Upadhyaya R, Jain SK, Maudar KK. Inflammatory response to isocyanates and onset of genomic instability in cultured human lung fibroblasts. Genet Mol Res 2009;8:129-43.

[121] Xiao CS, Wang YC, Du JZ, Chen XS, Wang J. Kinetics and Mechanism of 2-Ethoxy2-oxo-1,3,2-dioxaphospholane Polymerization Initiated by Stannous Octoate. Macromolecules 2006;39:6825-31.

[122] Amgoune A, Thomas CM, Ilinca S, Roisnel T, Carpentier JF. Highly Active, Productive, and Syndiospecific Yttrium Initiators for the Polymerization of Racemic $\beta$ Butyrolactone. Angew Chem Int Ed 2006;45:2782-4.

[123] Kramer JW, Treitler DS, Dunn EW, Castro PM, Roisnel T, Thomas CM, Coates GW. Polymerization of Enantiopure Monomers Using Syndiospecific Catalysts: A New Approach To Sequence Control in Polymer Synthesis. J Am Chem Soc 2009;131:16042-4.

[124] Jaffredo CG, Chapurina Y, Guillaume SM, Carpentier JF. From Syndiotactic Homopolymers to Chemically Tunable Alternating Copolymers: Highly Active Yttrium Complexes for Stereoselective Ring-Opening Polymerization of $\beta$ Malolactonates. Angew Chem Int Ed 2014;53:2687-91.

[125] Jaffredo CG, Chapurina Y, Kirillov E, Carpentier JF, Guillaume SM. Highly Stereocontrolled Ring-Opening Polymerization of Racemic Alkyl $\beta$-Malolactonates Mediated by Yttrium [Amino-alkoxy-bis(phenolate)] Complexes. Chem Eur J 2016;22:7629-41.

[126] Chamberlain BM, Cheng M, Moore DR, Ovitt TM, Lobkovsky EB, Coates GW. Polymerization of Lactide with Zinc and Magnesium $\beta$-Diiminate Complexes: Stereocontrol and Mechanism. J Am Chem Soc 2001;123:3229-38.

[127] Nederberg F, Connor EF, Möller M, Glauser T, Hedrick JL. New Paradigms for Organic Catalysts: The First Organocatalytic Living Polymerization. Angew Chem Int Ed 2001;40:2712-5. 
[128] Jaffredo CG, Carpentier JF, Guillaume SM. Controlled ROP of $\beta$-Butyrolactone Simply Mediated by Amidine, Guanidine, and Phosphazene Organocatalysts. Macromol Rapid Commun 2012;33:1938-44.

[129] Jaffredo CG, Carpentier JF, Guillaume SM. Organocatalyzed controlled ROP of $\square-$ lactones towards poly(hydroxyalkanoate)s: from $\square$-butyrolactone to benzyl $\square$ malolactone polymers. Polym Chem 2013;4:3837-50.

[130] Couffin A, Martin-Vaca B, Bourissou D, Navarro C. Selective O-acyl ring-opening of [small beta]-butyrolactone catalyzed by trifluoromethane sulfonic acid: application to the preparation of well-defined block copolymers. Polym Chem 2014;5:161-8.

[131] Alexis F, Pridgen EM, Langer R, Farokhzad OC. Nanoparticle Technologies for Cancer Therapy. In: Schäfer-Korting M, editor. Drug Delivery. Heidelberg: Springer; 2010. p. 55-86.

[132] Shi J, Votruba AR, Farokhzad OC, Langer R. Nanotechnology in Drug Delivery and Tissue Engineering: From Discovery to Applications. Nano Lett 2010;10:3223-30.

[133] Wang AZ, Langer R, Farokhzad OC. Nanoparticle Delivery of Cancer Drugs. Annu Rev Med 2012;63:185-98.

[134] Tong R, Langer R. Nanomedicines Targeting the Tumor Microenvironment. Cancer J 2015;21:314-21.

[135] Konstantinos A. Pegylated Poly(Lactide) and Poly(Lactide-Co-Glycolide) Nanoparticles: Preparation, Properties and Possible Applications in Drug Delivery. Curr Drug Deliv 2004;1:321-33.

[136] Sahoo SK, Labhasetwar V. Biodegradable PLGA/PLA nanoparticles for anticancer therapy. In: Amiji M, editor.Nanotechnology for Cancer Therapy. Boca Raton: CRC Press LLC; 2007. p. 243-50.

[137] Dinarvand R, Sepehri N, Manoochehri S, Rouhani H, Atyabi F. Polylactide-coglycolide nanoparticles for controlled delivery of anticancer agents. Int $\mathbf{J}$ Nanomed 2011;6:877-95.

[138] Andrieux K, Couvreur P. Polyalkylcyanoacrylate nanoparticles for delivery of drugs across the blood-brain barrier. Wiley Interdiscip Rev Nanomed Nanobiotechnol 2009;1:463-74.

[139] Graf A, McDowell A, Rades T. Poly(alkycyanoacrylate) nanoparticles for enhanced delivery of therapeutics - is there real potential? Expert Opin Drug Deliv 2009;6:37187.

[140] Nicolas J, Couvreur P. Synthesis of poly(alkyl cyanoacrylate)-based colloidal nanomedicines. Wiley Interdiscip Rev Nanomed Nanobiotechnol 2009;1:111-27.

[141] Althuri A, Mathew J, Sindhu R, Banerjee R, Pandey A, Binod P. Microbial synthesis of poly-3-hydroxybutyrate and its application as targeted drug delivery vehicle. Bioresour Technol 2013;145:290-6.

[142] Kolahchi AR, Kontopoulou M. Chain extended poly(3-hydroxybutyrate) with improved rheological properties and thermal stability, through reactive modification in the melt state. Polym Degrad Stab 2015;121:222-9.

[143] Liu KL, Goh SH, Li J. Threading $\alpha$-Cyclodextrin through Poly[(R,S)-3hydroxybutyrate] in Poly[(R,S)-3-hydroxybutyrate]-Poly(ethylene glycol)-Poly[(R,S)3-hydroxybutyrate] Triblock Copolymers: Formation of Block-Selected Polypseudorotaxanes. Macromolecules 2008;41:6027-34. 
[144] Loh XJ, Goh SH, Li J. New Biodegradable Thermogelling Copolymers Having Very Low Gelation Concentrations. Biomacromolecules 2007;8:585-93.

[145] Sonam, Chaudhary H, Arora V, Kholi K, Kumar V. Effect of Physicochemical Properties of Biodegradable Polymers on Nano Drug Delivery. Polym Rev 2013;53:546-67.

[146] Gaur U, Sahoo SK, De TK, Ghosh PC, Maitra A, Ghosh PK. Biodistribution of fluoresceinated dextran using novel nanoparticles evading reticuloendothelial system. Int J Pharm 2000;202:1-10.

[147] Moghimi SM, Hunter AC, Murray JC. Long-Circulating and Target-Specific Nanoparticles: Theory to Practice. Pharmacol Rev 2001;53:283-318.

[148] Gaumet M, Vargas A, Gurny R, Delie F. Nanoparticles for drug delivery: The need for precision in reporting particle size parameters. Eur J Pharm Biopharm 2008;69:1-9.

[149] Kataoka K, Harada A, Nagasaki Y. Block copolymer micelles for drug delivery: design, characterization and biological significance. Adv Drug Deliv Rev 2001;47:11331.

[150] Mai Y, Eisenberg A. Self-assembly of block copolymers. Chem Soc Rev 2012;41:5969-85.

[151] Mora-Huertas CE, Fessi H, Elaissari A. Polymer-based nanocapsules for drug delivery. Int J Pharm 2010;385:113-42.

[152] Grabnar PA, Kristl J. The manufacturing techniques of drug-loaded polymeric nanoparticles from preformed polymers. J Microencapsul 2011;28:323-35.

[153] Chen S, Cheng SX, Zhuo RX. Self-Assembly Strategy for the Preparation of PolymerBased Nanoparticles for Drug and Gene Delivery. Macromol Biosci 2011;11:576-89.

[154] Nicolai T, Colombani O, Chassenieux C. Dynamic polymeric micelles versus frozen nanoparticles formed by block copolymers. Soft Matter 2010;6:3111-8.

[155] Johnson BK, Prud'homme RK. Mechanism for Rapid Self-Assembly of Block Copolymer Nanoparticles. Phys Rev Lett 2003;91:118302/1-4.

[156] Jeong B, Bae YH, Lee DS, Kim SW. Biodegradable block copolymers as injectable drug-delivery systems. Nature 1997;388:860-2.

[157] Jeong B, Bae YH, Kim SW. Biodegradable thermosensitive micelles of PEG-PLGAPEG triblock copolymers. Colloids Surf B 1999;16:185-93.

[158] Kissel T, Li Y, Unger F. ABA-triblock copolymers from biodegradable polyester Ablocks and hydrophilic poly(ethylene oxide) B-blocks as a candidate for in situ forming hydrogel delivery systems for proteins. Adv Drug Deliv Rev 2002;54:99-134.

[159] Mao G, Sukumaran S, Beaucage G, Saboungi ML, Thiyagarajan P. PEO-PPO-PEO Block Copolymer Micelles in Aqueous Electrolyte Solutions: Effect of Carbonate Anions and Temperature on the Micellar Structure and Interaction. Macromolecules 2001;34:552-8.

[160] Jain S, Bates FS. On the Origins of Morphological Complexity in Block Copolymer Surfactants. Science 2003;300:460-4.

[161] Rajagopal K, Mahmud A, Christian DA, Pajerowski JD, Brown AEX, Loverde SM, Discher DE. Curvature-Coupled Hydration of Semicrystalline Polymer Amphiphiles Yields flexible Worm Micelles but Favors Rigid Vesicles: Polycaprolactone-Based Block Copolymers. Macromolecules 2010;43:9736-46. 
[162] Zhang Q, Ko NR, Oh JK. Recent advances in stimuli-responsive degradable block copolymer micelles: synthesis and controlled drug delivery applications. Chem Commun 2012;48:7542-52.

[163] Yu J, Chu X, Hou Y. Stimuli-responsive cancer therapy based on nanoparticles. Chem Commun 2014;50:11614-30.

[164] Karimi M, Ghasemi A, Sahandi Zangabad P, Rahighi R, Moosavi Basri SM, Mirshekari H, Amiri M, Shafaei Pishabad Z, Aslani A, Bozorgomid M, Ghosh D, Beyzavi A, Vaseghi A, Aref AR, Haghani L, Bahrami S, Hamblin MR. Smart micro/nanoparticles in stimulus-responsive drug/gene delivery systems. Chem Soc Rev 2016;45:1457-501.

[165] Tong R, Cheng J. Anticancer polymeric nanomedicines. Polym Rev 2007;47:345-81.

[166] Cheng W, Gu L, Ren W, Liu Y. Stimuli-responsive polymers for anti-cancer drug delivery. Mater Sci Eng C 2014;45:600-8.

[167] Liu F, Urban MW. Recent advances and challenges in designing stimuli-responsive polymers. Prog Polym Sci 2010;35:3-23.

[168] Stuart MAC, Huck WTS, Genzer J, Muller M, Ober C, Stamm M, Sukhorukov GB, Szleifer I, Tsukruk VV, Urban M, Winnik F, Zauscher S, Luzinov I, Minko S. Emerging applications of stimuli-responsive polymer materials. Nat Mater 2010;9:10113.

[169] Cabane E, Zhang X, Langowska K, Palivan CG, Meier W. Stimuli-Responsive Polymers and Their Applications in Nanomedicine. Biointerphases 2012;7:1-27.

[170] Hoffman AS. Stimuli-responsive polymers: Biomedical applications and challenges for clinical translation. Adv Drug Deliv Rev 2013;65:10-6.

[171] Schattling P, Jochum FD, Theato P. Multi-stimuli responsive polymers - the all-in-one talents. Polym Chem 2014;5:25-36.

[172] Motokawa R, Morishita K, Koizumi S, Nakahira T, Annaka M. Thermosensitive Diblock Copolymer of Poly(N-isopropylacrylamide) and Poly(ethylene glycol) in Water: Polymer Preparation and Solution Behavior. Macromolecules 2005;38:574860 .

[173] Kim YC, Kil DS, Kim JC. Synthesis and phase separation of poly(N-isopropyl acrylamide-co-methoxy polyethyleneglycol monomethacrylate). J Appl Polym Sci 2006;101:1833-41.

[174] Cho SH, Jhon MS, Yuk SH, Lee HB. Temperature-induced phase transition of poly(N,N-dimethylaminoethyl methacrylate-co-acrylamide). J Polym Sci Part B Polym Phys 1997;35:595-8.

[175] Lee RS, Lin CH, Aljuffali IA, Hu KY, Fang JY. Passive targeting of thermosensitive diblock copolymer micelles to the lungs: synthesis and characterization of poly $(\mathrm{N}$ isopropylacrylamide)-block-poly( $\varepsilon$-caprolactone). J Nanobiotechnol 2015;13:42/1-12.

[176] Mishra AK, Vishwakarma NK, Patel VK, Biswas CS, Paira TK, Mandal TK, Maiti P, Ray B. Synthesis, characterization, and solution behavior of well-defined double hydrophilic linear amphiphilic poly ( $\mathrm{N}$-isopropylacrylamide)-b-poly ( $\varepsilon$-caprolactone)b-poly (N-isopropylacrylamide) triblock copolymers. Colloid Polym Sci 2014;292:1405-18. 
[177] Chang C, Wei H, Quan CY, Li YY, Liu J, Wang ZC, Cheng SX, Zhang XZ, Zhuo RX. Fabrication of thermosensitive PCL-PNIPAAm-PCL triblock copolymeric micelles for drug delivery. J Polym Sci Part A Polym Chem 2008;46:3048-57.

[178] Lee YS. Self-Assembly and Nanotechnology: A Force Balance Approach. New York: John Wiley \& Sons Inc; 2007. p. 183-219.

[179] Gao W, Chan JM, Farokhzad OC. pH-Responsive Nanoparticles for Drug Delivery. Mol Pharm 2010;7:1913-20.

[180] Legrand P, Benoit JP, Briançon S, Fattal E, Fessi H, Passirani C. Sphéroiides et formes vectorisées. (in French). In: Wehrié P, editor. Pharmacie Galénique: Formulation et Technologie pharmaceutique. Parais: Maloine; 2007. p. 221-50.

[181] Nakamura T, Hitomi S, Watanabe S, Shimizu Y, Jamshidi K, Hyon SH, Ikada Y. Bioabsorption of polylactides with different molecular properties. J Biomed Mater Res 1989;23:1115-30.

[182] Cai H, Dave V, Gross RA, McCarthy SP. Effects of physical aging, crystallinity, and orientation on the enzymatic degradation of poly(lactic acid). J Polym Sci Part B Polym Phys 1996;34:2701-8.

[183] Hurrell S, Cameron RE. The effect of initial polymer morphology on the degradation and drug release from polyglycolide. Biomaterials 2002;23:2401-9.

[184] Moon HJ, Ko DY, Park MH, Joo MK, Jeong B. Temperature-responsive compounds as in situ gelling biomedical materials. Chem Soc Rev 2012;41:4860-83.

[185] Buenger D, Topuz F, Groll J. Hydrogels in sensing applications. Prog Polym Sci 2012;37:1678-719.

[186] Vashist A, Vashist A, Gupta YK, Ahmad S. Recent advances in hydrogel based drug delivery systems for the human body. J Mater Chem 2014;2:147-66.

[187] Sivaram AJ, Rajitha P, Maya S, Jayakumar R, Sabitha M. Nanogels for delivery, imaging and therapy. Wiley Interdiscip Rev Nanomed Nanobiotechnol 2015;7:509-33.

[188] Caló E, Khutoryanskiy VV. Biomedical applications of hydrogels: A review of patents and commercial products. Eur Polym J 2015;65:252-67.

[189] Wu YL, Chen X, Wang W, Loh XJ. Engineering Bioresponsive Hydrogels toward Healthcare Applications. Macromol Chem Phys 2016;217:175-88.

[190] Liow SS, Dou Q, Kai D, Karim AA, Zhang K, Xu F, Loh XY. Thermogels: In Situ Gelling Biomaterial. ACS Biomater Sci Eng 2016;2:295-316.

[191] Langer R. New methods of drug delivery. Science 1990;249:1527-33.

[192] Fredenberg S, Wahlgren M, Reslow M, Axelsson A. The mechanisms of drug release in poly(lactic-co-glycolic acid)-based drug delivery systems-A review. Int J Pharm 2011;415:34-52.

[193] Bussemer T, Otto I, Bodmeier R. Pulsatile Drug-Delivery Systems. Crit Rev Ther Drug Carrier Syst 2001;18:433-58.

[194] Sharma G, Sharma AR, Nam JS, Doss GPC, Lee SS, Chakraborty C. Nanoparticle based insulin delivery system: the next generation efficient therapy for Type 1 diabetes. J Nanobiotechnol 2015;13:74/1-13.

[195] Jenkins AD. Book Review: Contemporary polymer chemistry (3rd edition). HR Allcock, FW Lampe and JE Mark. Pearson Education, Inc (Pearson/Prentice Hall), Upper Saddle River, NJ, USA, 2003. Polym Int 2004;53:1395-5. 
[196] Loh XJ, Wu YL, Seow WTJ, Norimzan MNI, Zhang ZX, Xu FJ. Micellization and phase transition behavior of thermosensitive poly(N-isopropylacrylamide)-poly( $\varepsilon$ caprolactone)-poly(N-isopropylacrylamide) triblock copolymers. Polymer 2008;49:5084-94.

[197] Xu XD, Wei H, Zhang XZ, Cheng SX, Zhuo RX. Fabrication and characterization of a novel composite PNIPAAm hydrogel for controlled drug release. J Biomed Mater Res Part A 2007;81:418-26.

[198] Yamamoto Y, Nagasaki Y, Kato Y, Sugiyama Y, Kataoka K. Long-circulating poly(ethylene glycol)-poly(d,l-lactide) block copolymer micelles with modulated surface charge. J Controlled Release 2001;77:27-38.

[199] Canelas DA, Herlihy KP, DeSimone JM. Top-down particle fabrication: control of size and shape for diagnostic imaging and drug delivery. Wiley Interdiscip Rev Nanomed Nanobiotechnol 2009;1:391-404.

[200] Longmire MR, Ogawa M, Choyke PL, Kobayashi H. Biologically Optimized Nanosized Molecules and Particles: More than Just Size. Bioconjug Chem 2011;22:993-1000.

[201] Gref R, Minamitake Y, Peracchia M, Trubetskoy V, Torchilin V, Langer R. Biodegradable long-circulating polymeric nanospheres. Science 1994;263:1600-3.

[202] Jones MC, Leroux JC. Polymeric micelles - a new generation of colloidal drug carriers. Eur J Pharm Biopharm 1999;48:101-11.

[203] Suh J, Choy KL, Lai SK, Suk JS, Tang BC, Prabhu S, Hanes J. PEGylation of nanoparticles improves their cytoplasmic transport. Int J Nanomed 2007;2:735-41.

[204] Sudimack J, Lee RJ. Targeted drug delivery via the folate receptor. Adv Drug Deliv Rev 2000;41:147-62.

[205] Elsaesser A, Howard CV. Toxicology of nanoparticles. Adv Drug Deliv Rev 2012;64:129-37.

[206] Ronzani C, Safar R, Diab R, Chevrier J, Paoli J, Abdel-Wahhab MA, Le Faou A, Rihn $\mathrm{BH}$, Joubert $\mathrm{O}$. Viability and gene expression responses to polymeric nanoparticles in human and rat cells. Cell Biol Toxicol 2014;30:137-46.

[207] Sutherland R. Cell and environment interactions in tumor microregions: the multicell spheroid model. Science 1988;240:177-84.

[208] Hall MD, Martin C, Ferguson DJP, Phillips RM, Hambley TW, Callaghan R. Comparative efficacy of novel platinum(IV) compounds with established chemotherapeutic drugs in solid tumour models. Biochem Pharmacol 2004;67:17-30.

[209] Goodman TT, Ng CP, Pun SH. 3-D Tissue Culture Systems for the Evaluation and Optimization of Nanoparticle-Based Drug Carriers. Bioconjug Chem 2008;19:1951-9.

[210] Bryce NS, Zhang JZ, Whan RM, Yamamoto N, Hambley TW. Accumulation of an anthraquinone and its platinum complexes in cancer cell spheroids: the effect of charge on drug distribution in solid tumour models. Chem Commun 2009:2673-5.

[211] Chytil P, Etrych T, Koňák Č, Šírová M, Mrkvan T, Bouček J, Říhová B, Ulbrich K. New HPMA copolymer-based drug carriers with covalently bound hydrophobic substituents for solid tumour targeting. J Controlled Release 2008;127:121-30.

[212] Bonartsev AP, Bonartseva GA, Iordanskii AL, Zaikov GE, Artsis MI. Polymers in medicine: microbial poly(3-hydroxybutyrate): synthesis, properties, applications. Polym Res J 2013;7:37-69. 
[213] Yamaoka T, Tabata Y, Ikada Y. Distribution and Tissue Uptake of Poly(ethylene glycol) with Different Molecular Weights after Intravenous Administration to Mice. J Pharm Sci 1994;83:601-6.

[214] Wang Y, Inagawa Y, Osanai Y, Kasuya KI, Saito T, Matsumura S, Doi Y, Inoue Y. Enzymatic Hydrolysis of Chemosynthesized Atactic Poly(3-hydroxybutyrate) by Poly(3-hydroxyalkanoate) Depolymerase from Acidovorax Sp. TP4 and Ralstonia pickettii T1. Biomacromolecules 2002;3:894-8. 


\section{Figures and Schemes captions}

Fig 1. (a) DLS and (b) field emission-scanning electron microscopy analyses of native PHB nanoparticles versus surface functionalized hybrid PHB nanoparticles using RGD4C fused PHA synthase. Scale bar is $100 \mathrm{~nm}$. [76], Copyright 2011. Reproduced with permission from Elsevier Ltd.

Fig 2. Plots of the I337/I334 ratio of the pyrene excitation spectra in water as a function of the copolymer concentration at different temperatures for $\mathrm{PEG}_{5000}-b-\mathrm{PHB}_{3800}-b-\mathrm{PEG}_{5000}$. [64]. Copyright 2016. Reproduced with permission from American Chemical Society.

Fig 3. Cryo-TEM images of (A) PEG- $b$-PPG- $b$-PEG micelles, (B) PEG- $b$-PPG- $b$-PEG/PF$127(7: 3, w / w)$ micelles, and (C) PF-127 micelles. Micelles were equilibrated at $37{ }^{\circ} \mathrm{C}$ before flash-freezing in liquid ethane. Scale bar in inset of panel C is $20 \mathrm{~nm}$. [79], Copyright 2016. Reproduced with permission from American Chemical Society.

Fig 4. Schematic representation of (a) the self-assembly and TEM image of adamantyl-PHB$b$-sPEG (10-3.1) micelles (scale bar $=100 \mathrm{~nm}$ ); (b) the self-assembly of adamantyl-PHB- $b$ sPEG/DM- $\beta$-CD complexes and TEM of adamantyl-PHB- $b$-sPEG $\left(M_{\mathrm{n}, \mathrm{PEG}}=10000, M_{\mathrm{n}, \mathrm{PHB}}=\right.$ 3100g. $\left.\mathrm{mol}^{-1}\right) / \mathrm{DM}-\beta-\mathrm{CD}$ aggregate (scale bar $=0.5 \mathrm{~mm}$ ). [72], Copyright 2016. Reproduced with permission from Royal Society of Chemistry.

Fig 5. (a) Proposed thermoresponsive behavior of PNIPAAM- $b$-PHB- $b$-PNIPAAM triblock copolymers; (b) TEM micrographs of the PNIPAAM $20300-b$-PHB $1460-b$-PNIPAAM 20300 micelles prepared at 25 and $35^{\circ} \mathrm{C}$; (c) Particle size distribution of PNIPAAM $20300-b$-PHB $1460^{-}$ $b$-PNIPAAM 20300 micelles (solution concentration $=50 \mathrm{mg} \cdot \mathrm{L}^{-1}$ at 25 and $35^{\circ} \mathrm{C}$ ) measured by DLS; (d) Schematic relation between the proposed structure of the micelle aggregates and the TEM-observed structures. [70], Copyright 2008. Reproduced with permission from American Chemical Society. 
Fig 6. (a) Graphics showing the gel transition of poly(PHB/PEG/PPG urethane)s (Poly(PEG/PPG/PHB urethane)s are denoted EPH, E for PEG, P for PPG and H for PHB; $\mathrm{EPH} 2: 5 \mathrm{wt} \%$ in $\mathrm{H}_{2} \mathrm{O}$ ) with increasing temperature. The transition from a clear sol to a gel and further to a turbid sol is observed in the graphics. (b) Sol-gel phase diagrams of poly(PHB/PEG/PPG urethane)s in aqueous solutions in comparison with $\mathrm{EG}_{100} \mathrm{PG}_{65} \mathrm{EG}_{100}$ triblock copolymer $\left(\boldsymbol{\Delta}, \mathrm{EPH} 1 ; \mathbf{\square}, \mathrm{EH} 2 ; \diamond, \mathrm{EPH} 3 ; \times, \mathrm{EPH} 5 ; *, \mathrm{EG}_{100} \mathrm{PG}_{65} \mathrm{EG}_{100}\right)$. [80], Copyright 2009. Reproduced with permission from American Chemical Society.

Fig 7. Effect of the temperature on the drug release profile of micelles based on PDMAEMA$b$-PHB- $b$-PDMAEMA, showing (a) a continuous uninterrupted drug release at 20 and $37{ }^{\circ} \mathrm{C}$, and (b) the effect of a temperature change midway of the drug release experiment. [73], Copyright 2013. Reproduced with permission from Royal Society of Chemistry.

Fig 8. DNA replication measured by the BrdU incorporation in HepaRG proliferating cells (left charts) and apoptosis level evaluated via the caspase 3 activity (right charts) in HepaRG progenitor cells incubated with nanoparticles based on $\mathrm{PMLA}_{800}-b-\mathrm{PHB}_{7300}$ and $\mathrm{PMLA}_{3300}-b-$ PHB $_{3100 .}$ Statistical analyses: *,$p<0.05$ ( $p, p$-value); **, $p<0.01$. [91], Copyright 2015. Reproduced with permission from Royal Society of Chemistry.

Fig 9. Penetration of DOX and micelle-encapsulated DOX in SiHa multicellular spheroids: (a) DOX fluorescence in representative sections from SiHa MCS treated for 30 min with unloaded micelles, free DOX, physical mixtures of free DOX with unloaded micelles, and DOX-loaded micelles; (b) Quantification of mean fluorescence intensity normalized by area. (* indicates a statistically significant difference from free DOX using the student's t-test, $\mathrm{p}<$ 0.05 , respectively, number of experiments $=10-25)$; (c) Penetration distance of DOX from spheroid periphery; (d) Representative fluorescence images of sections from untreated SiHa MCS and MCS treated with fluorescein-labeled micelles for $30 \mathrm{~min}$. [71], Copyright 2010. Reproduced with permission from Elsevier. 
Fig 10. Evaluation of in-vivo antitumor activity of free DOX and DOX-loaded PEG- $b$-PHB- $b$ PEG micelles: (a) Tumor reduction study in SiHa xenograft mice after single intratumoral injection of $5 \%$ glucose, empty micelle, free DOX and DOX-micelle (dose: 5 mg. $\mathrm{kg}^{-1}$ ); (b) Growth inhibition of subcutaneous $\mathrm{SiHa}$ tumors induced by multiple intravenous injections of $5 \%$ glucose, empty micelles, free DOX, DOX-loaded micelle $\left(6 \mathrm{mg} . \mathrm{kg}^{-1}\right.$ or 9 mg.kg-1 for each dose); (c) Body weights of treated mice; (d) Fluorescence intensity of DOX in blood plasma at $4 \mathrm{~h}$ post-injection of free DOX and DOX-loaded micelles (dose: $5 \mathrm{mg} . \mathrm{kg}^{-1}$, intra-venous single injection) $(*$ and $* *$ indicate a statistically significant difference from empty PEG- $b$-PHB- $b$-PEG micelle and free DOX, respectively, using the student's t-test, $p<$ 0.05, number of experiment $=3-5$ ). [71], Copyright 2010. Reproduced with permission from Elsevier.

Fig 11. Relative $\mathrm{I}_{(336.6) t} / \mathrm{I}_{(336.6) 0}$ fluorescence ratio and $\mathrm{pH}$ values as a function of the biodegradation time for $\mathrm{PHB}_{90}-b-\mathrm{PEG}_{91}-b-\mathrm{PHB}_{90}$, where $\mathrm{Y}$ presents $\mathrm{I}_{336.6}$ and $\mathrm{pH}$ values, and the subscripts " 0 ", " $t$ " and " $N$ " represent the time $t=0, t=t$ and $t=e n d$, respectively. Initial degradation rate $\left(\mathrm{V}_{0}\right)$ as a function of time is presented in the inset. [65], Copyright 2006. Reproduced with permission from Elsevier.

Scheme 1. Two-step synthesis of $\alpha, \omega$-diDOCA telechelic PHB- $b$-PEG copolymer [77].

Scheme 2. Three-step synthesis of PEG- $b$-PHB- $b$-PEG copolymer from microbial PHB [78].

Scheme 3. Two-step synthesis of fluorescein-conjugated PEG- $b$-PHB- $b$-PEG copolymer [71].

Scheme 4. Three-step synthesis of Alexa Fluor 488-conjugated PEG- $b$-PHB- $b$-PEG copolymer [79].

Scheme 5. Synthesis of poly(PEG/PPG/PHB urethane) random copolymer [80].

Scheme 6. ROP of EEP using PHB diol as macroinitiator for the synthesis of PEEP- $b$-PHB- $b$ PEEP copolymer [82]. 
Scheme 7. a) Synthesis of PHB-diBr macroinitiator; b) synthesis of PNIPAAM- $b$-PHB- $b$ PNIPAAM copolymer by the ATRP of NIPAAM using PHB-diBr as macroinitiator [70,83]; c) synthesis of PDMAEMA- $b$-PHB- $b$-PDMAEMA copolymer by the ATRP of NIPAAM using PHB-diBr as macroinitiator [73,84].

Scheme 8. Synthesis of multi-arm PHB- $b$-PNIPAAM- $b$-(PPEGMEMA-co-PPPGMA) [85].

Scheme 9. Three-step synthesis of adamantyl-PHB- $b$-sPEG conjugate [72].

Scheme 10. ROP of $r a c$-BL using PEG diol as macroinitiator for the synthesis of PHB- $b$ PEG- $b$-PHB copolymer [65,66].

Scheme 11. ROP of $r a c-B L$ using a anionic PEG macroinitiator for the synthesis of PHB- $b$ PEG- $b$-PHB copolymer [86].

Scheme 12. Synthesis peptide dendrimer-PHB- $b$-PEG- $b$-PHB conjugate [87].

Scheme 13. Synthesis of PHB-co-PHB ${ }^{\mathrm{Allyl}}$ and $\mathrm{PHB}-c o-\mathrm{PHB}^{\mathrm{diOH}}$ with different tacticities $[88,89]$.

Scheme 14. Synthesis of PHB- $b$-PMLA amphiphilic copolymer [91].

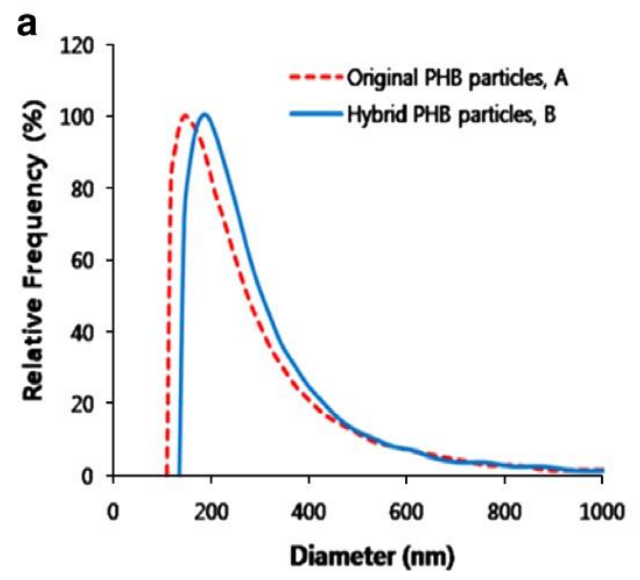

b

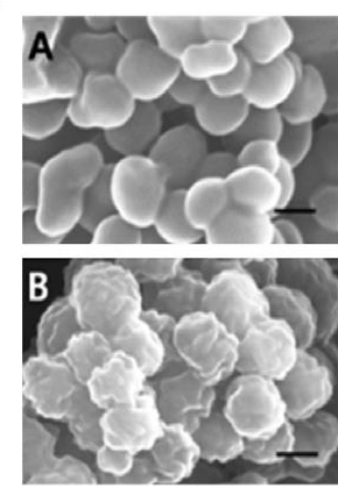

Figure 1. 


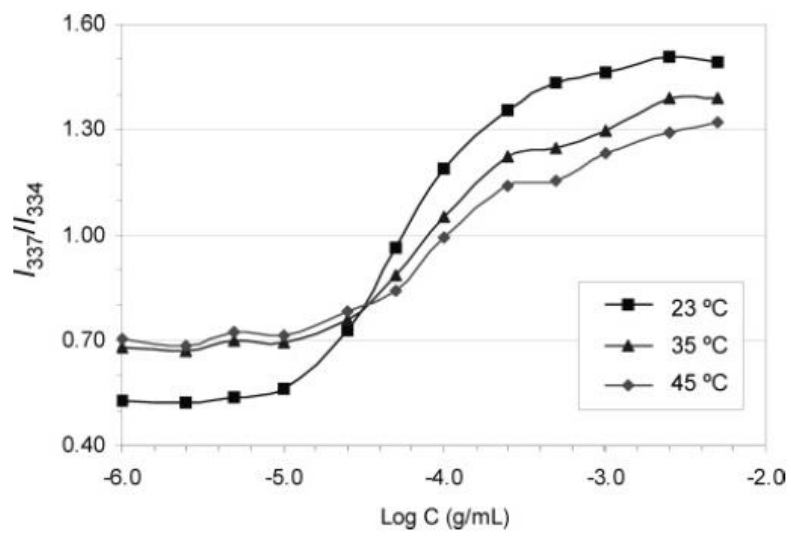

Figure 2. 

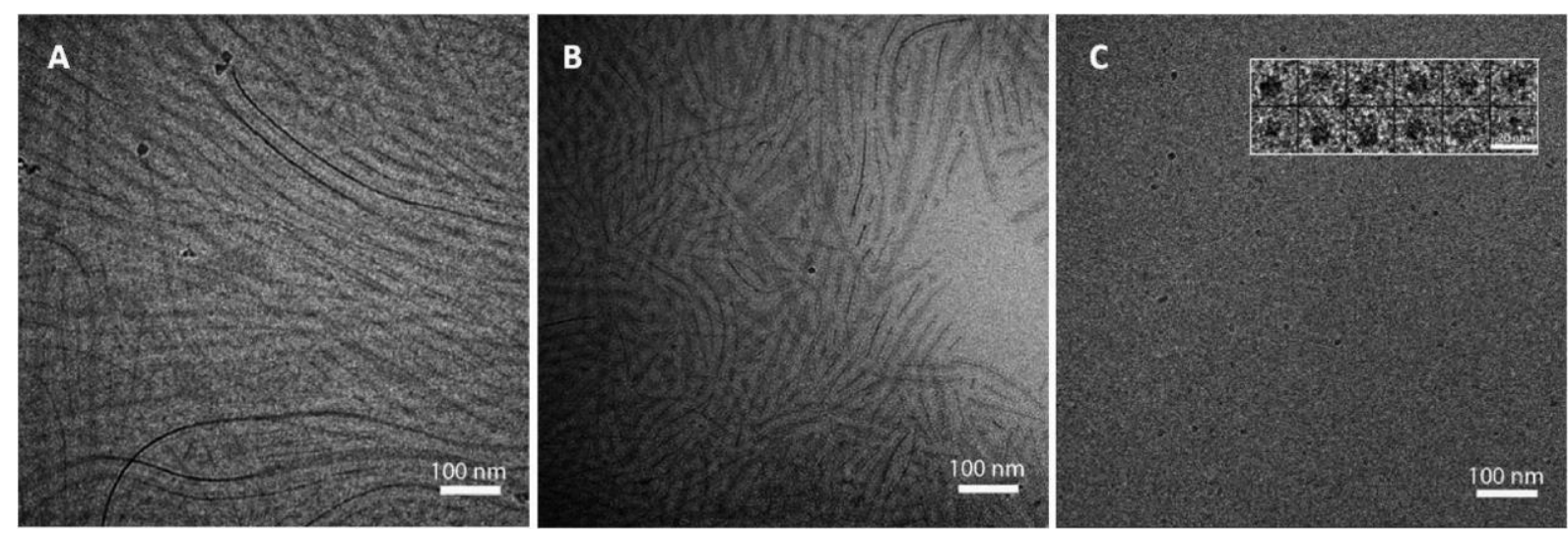

Figure 3. 


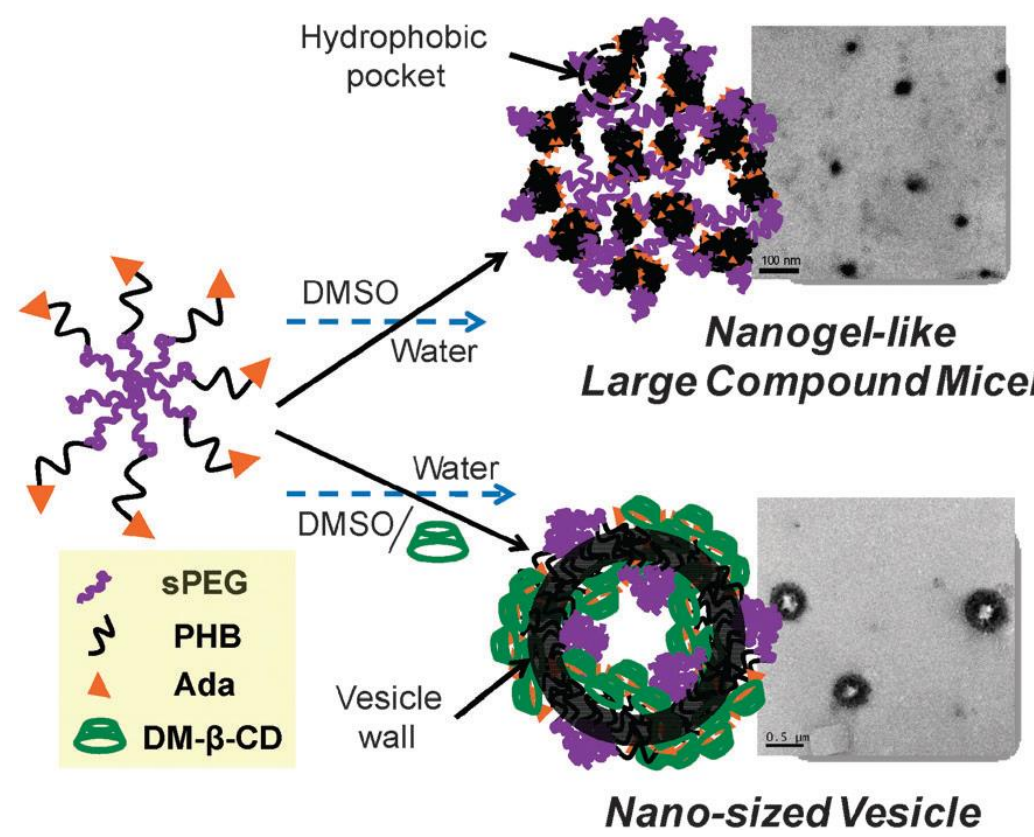

(a)

(b)

Figure 4. 
(a)
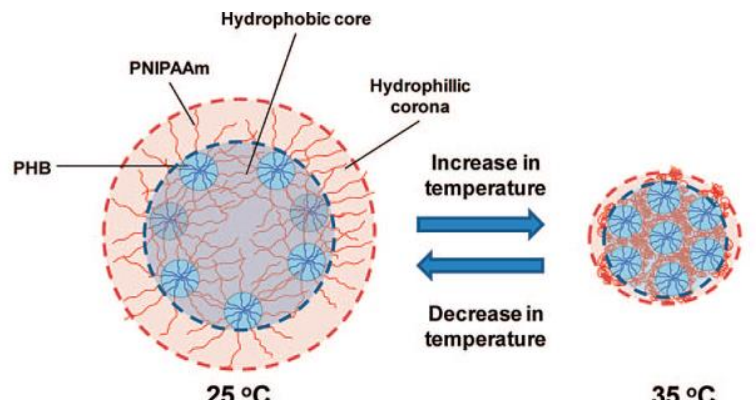

(b)

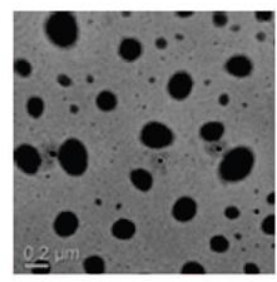

$35^{\circ} \mathrm{C}$

(c)

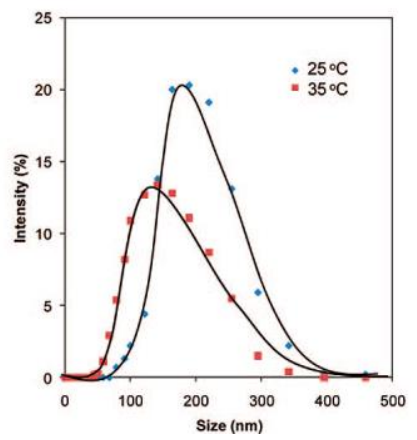

(d)
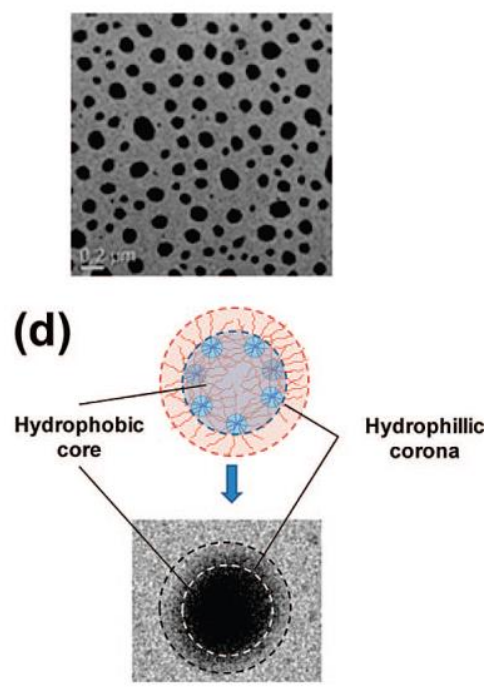

Figure 5. 
(a)

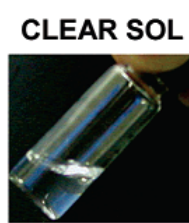

$5^{\circ} \mathrm{C}$

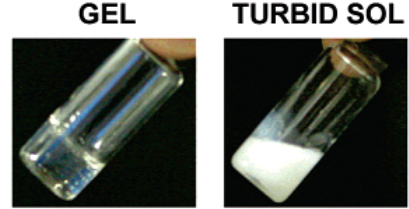

$75^{\circ} \mathrm{C}$

(b)

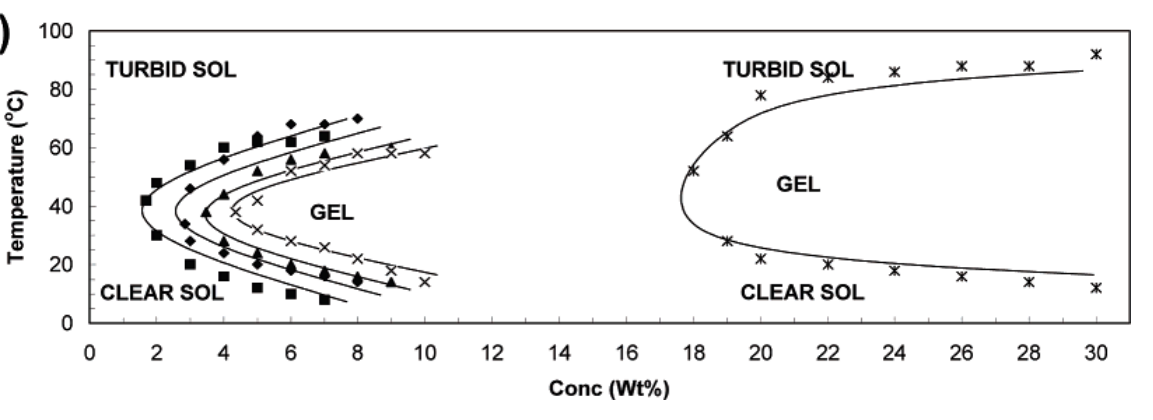

Figure 6. 
(a)

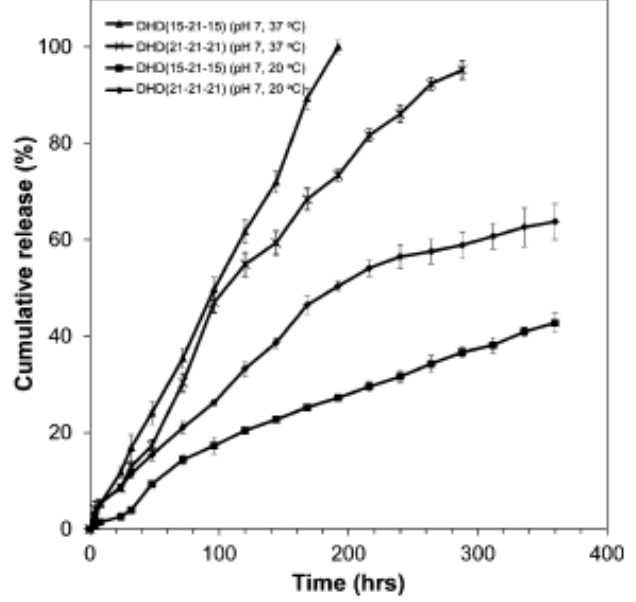

(b)

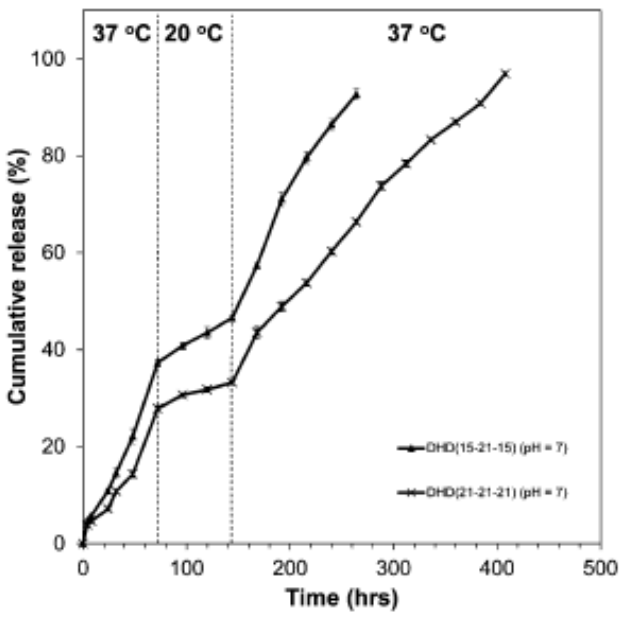

Figure 7. 

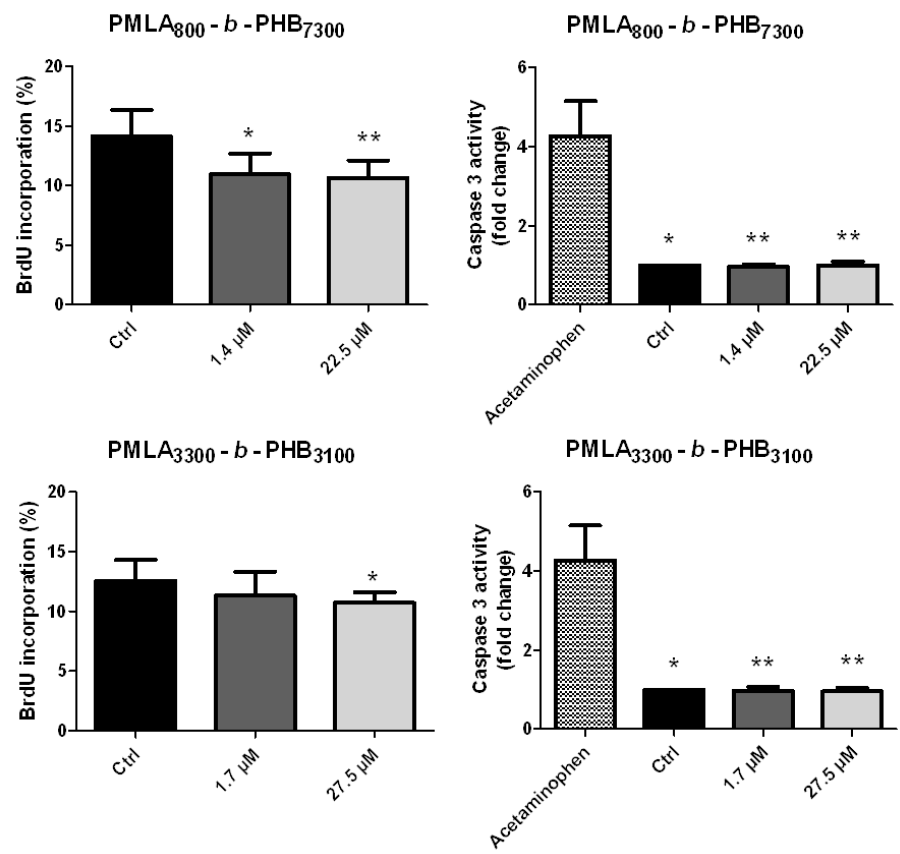

Figure 8. 

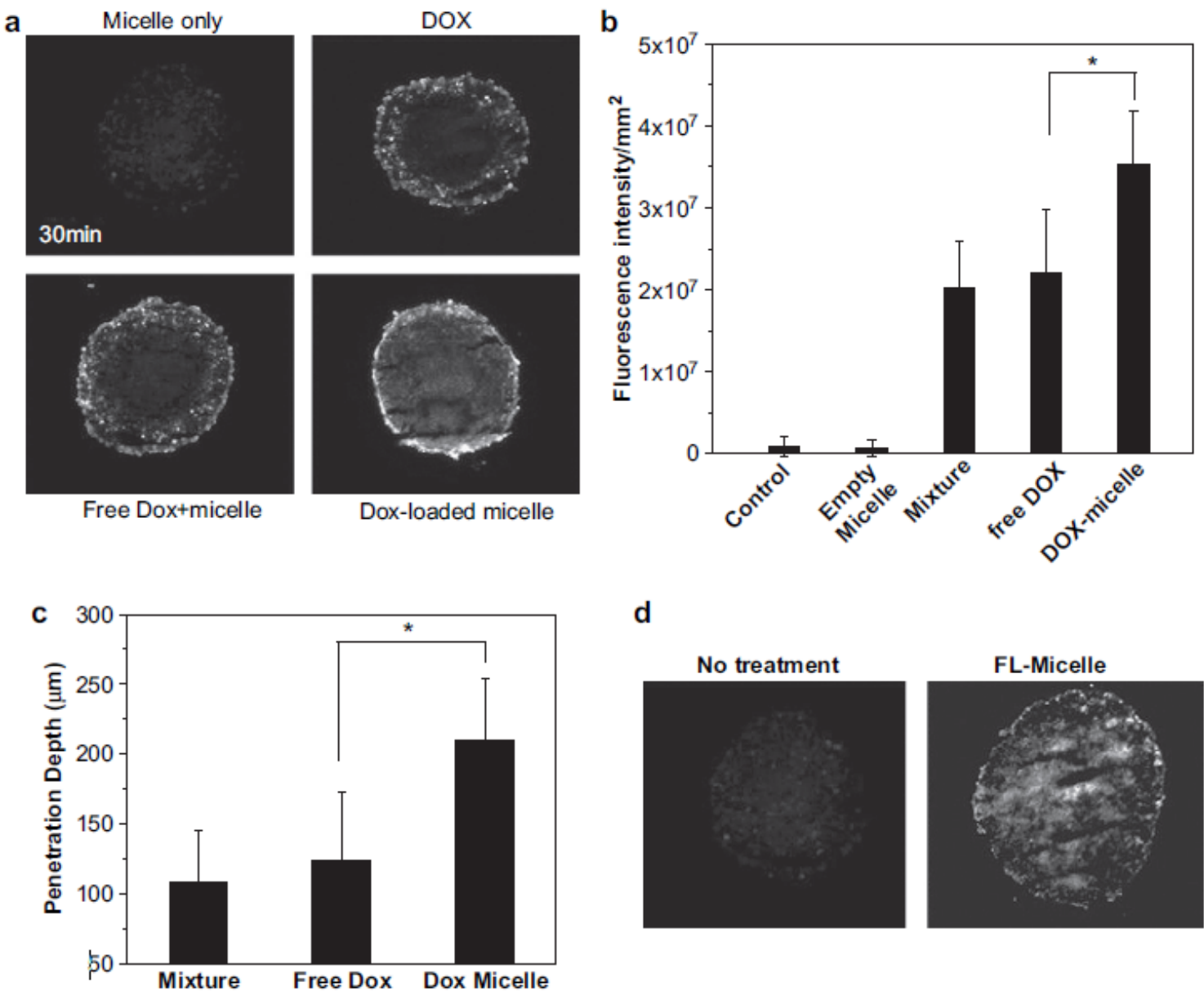

d
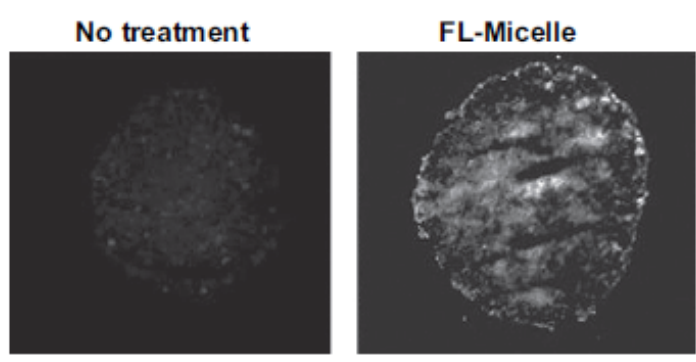

Figure 9. 

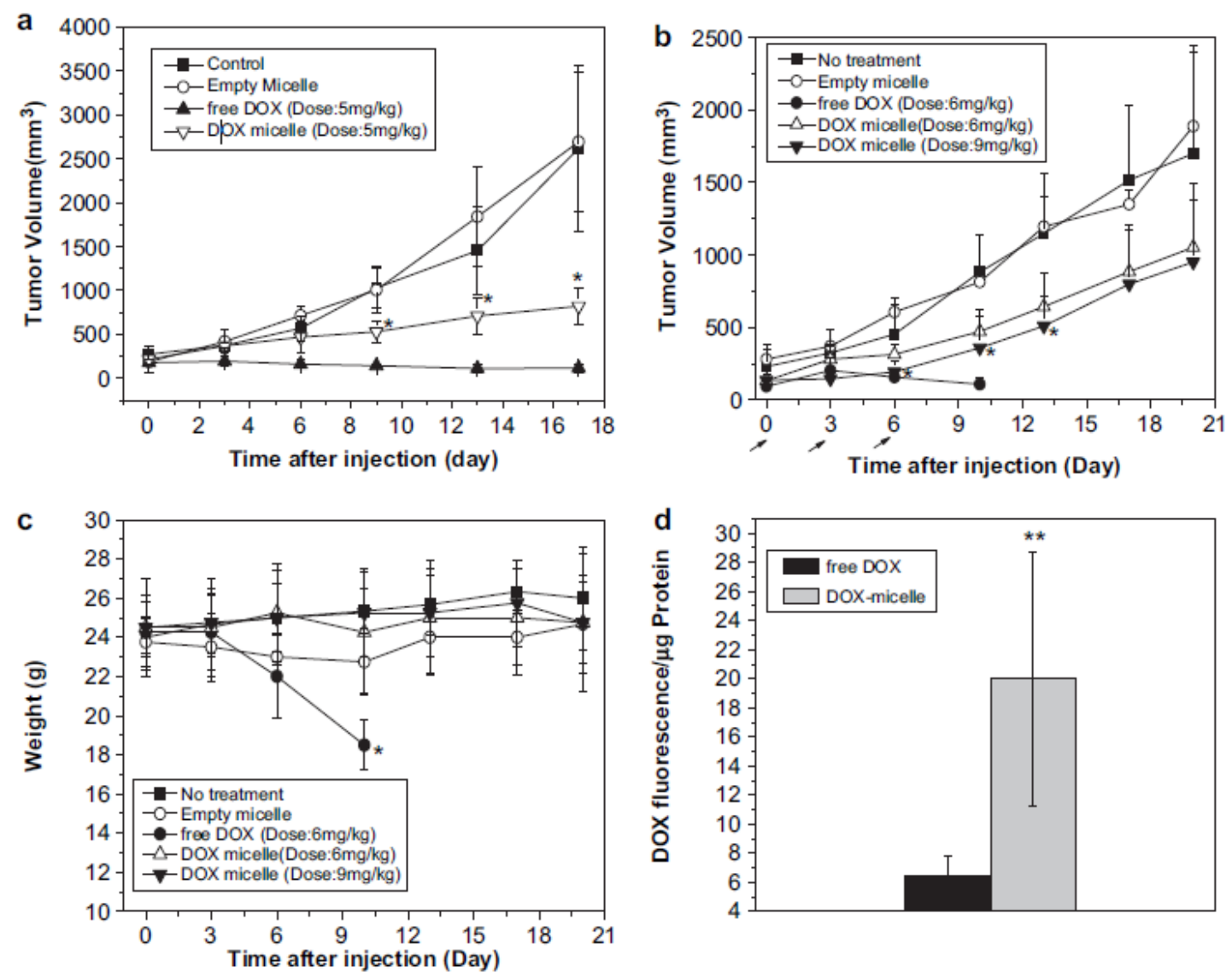

Figure 10. 


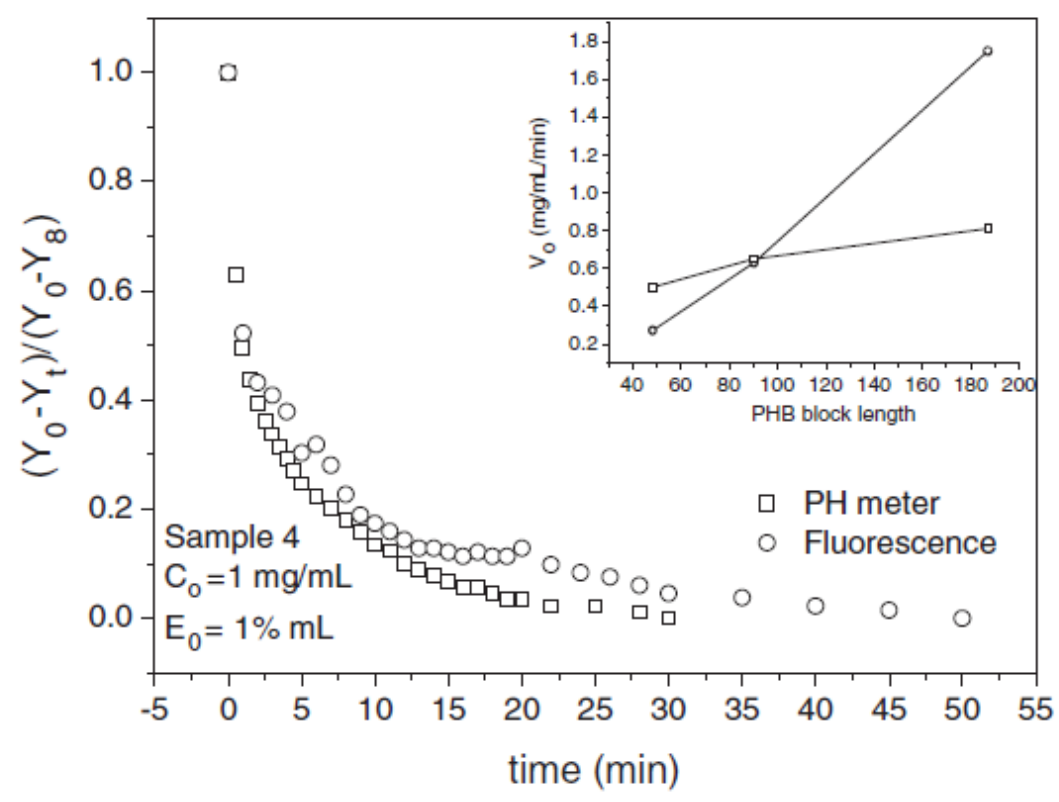

Figure 11. 


$$
\text { bacterial PHB }
$$

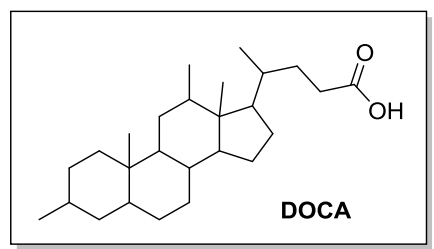

\section{Scheme 1.}

$$
\text { crude }
$$
a) Dissolution $\mathrm{CHCl}_{3}$

$$
\text { b) Filtration }
$$

c) Precipitation Petroleum spirit$$
\begin{gathered}
\text { crude } \\
\text { bacterial PHB }
\end{gathered}
$$

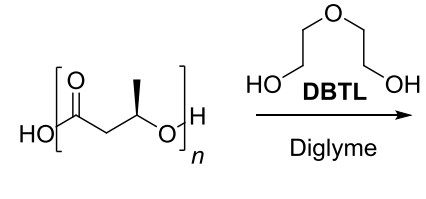

purified bacterial PHB<smiles>COC(C)CC(=O)OCCOCCO</smiles>

short-chain PHB diol

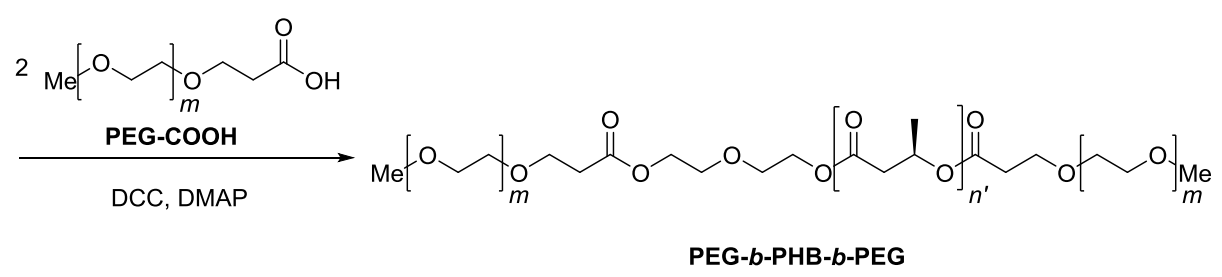

\section{Scheme 2.}

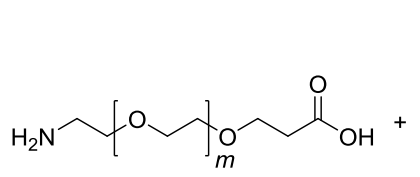

$\mathrm{H}_{2}$ N-PEG-COOH

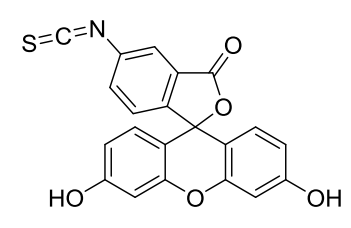

Fluorescein 5(6)-isothiocyanate

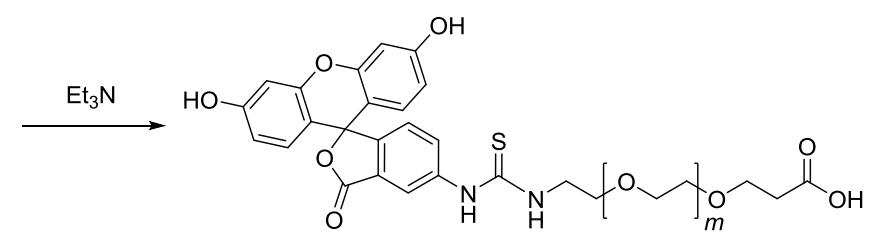

Fluorescein-PEG-COOH

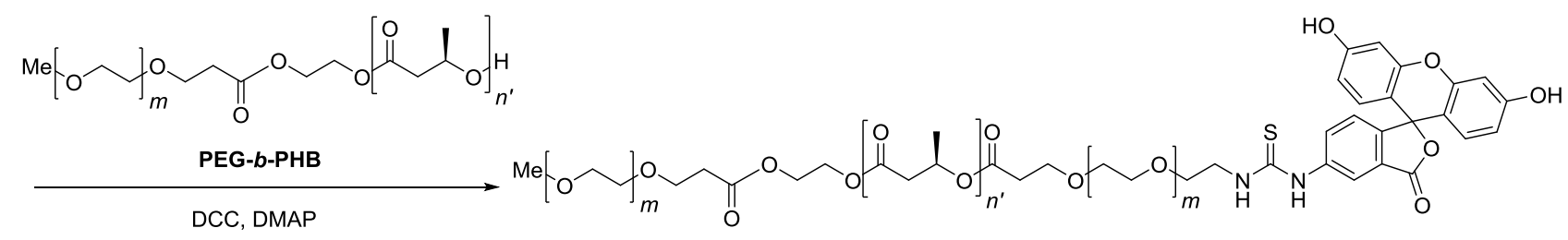

Fluorescein-conjugated PEG-b-PHB-b-PEG

\section{Scheme 3.}




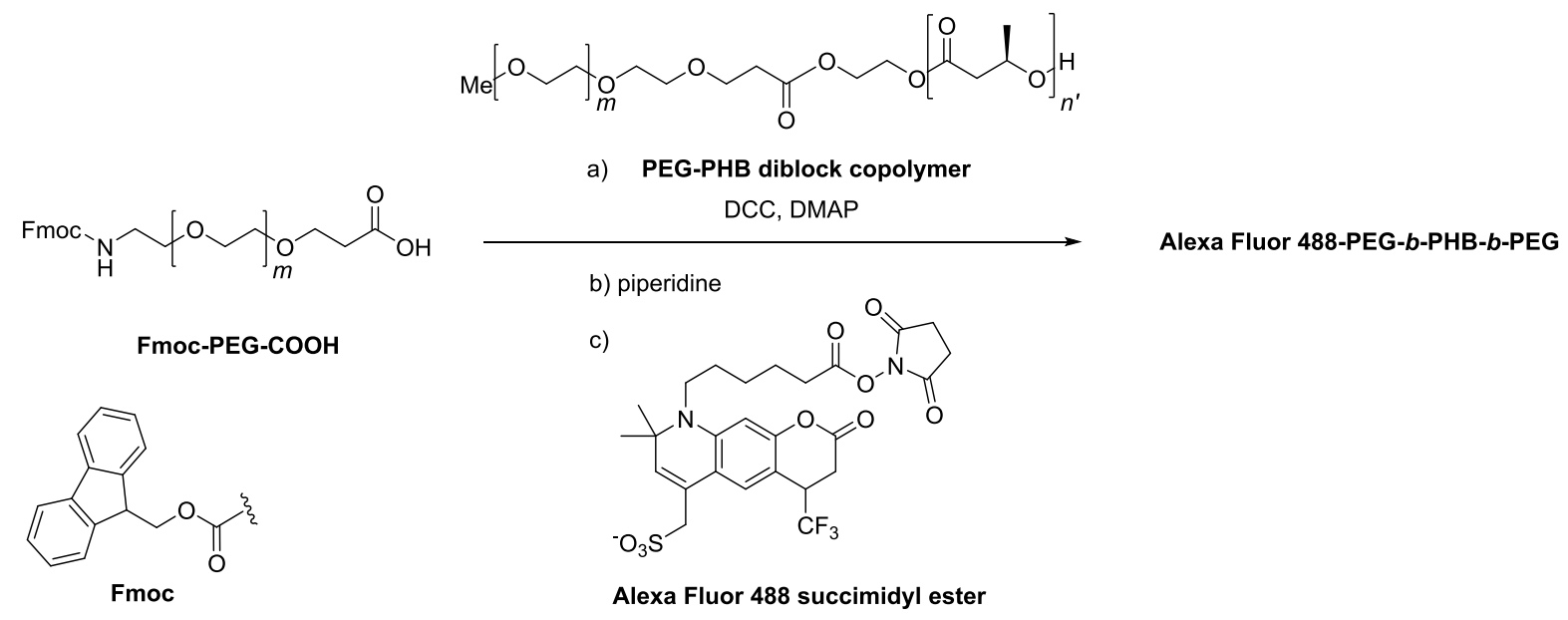

Scheme 4.

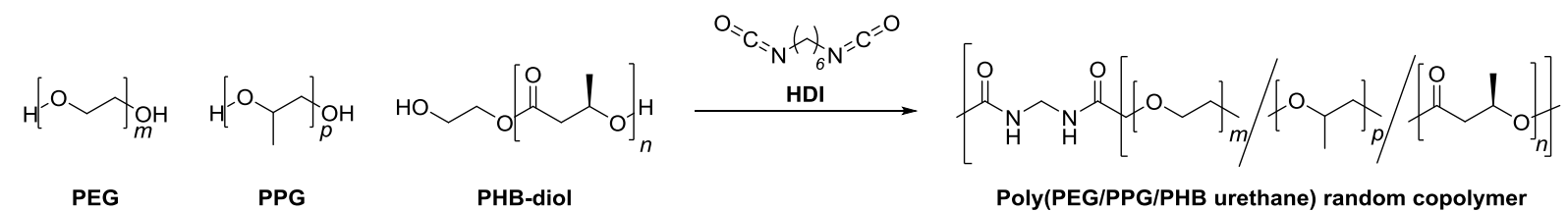

Scheme 5.

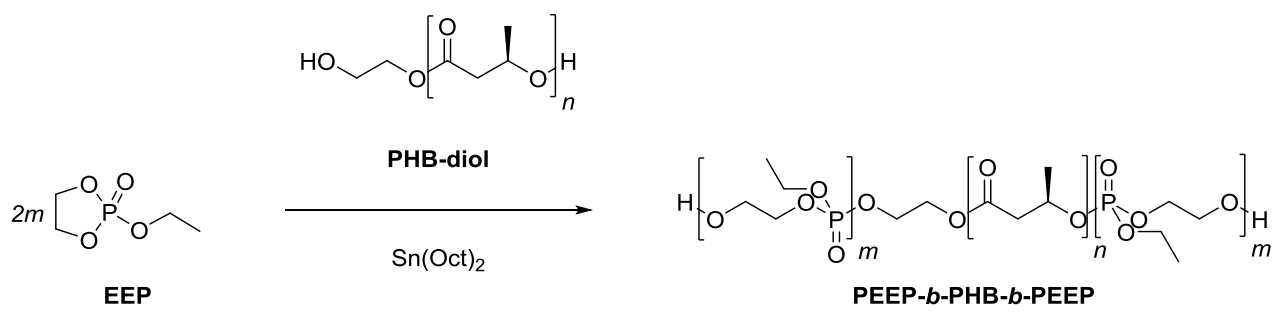

Scheme 6. 
<smiles>C[Ga](C)CC(=O)OCCO</smiles>

PHB-diol

b)<smiles>C=CC(=O)NC(C)CC</smiles>

NIPAAM

c)<smiles>C=CC(=O)OCCNC(C)C(=O)c1ccccc1</smiles>
DMAEMA<smiles>CCN(CC)CC</smiles>

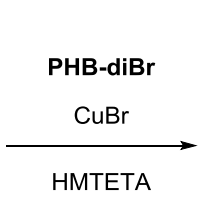

HMTETA

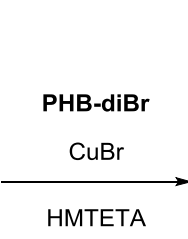

HMTETA
${ }_{\mathrm{Br}}^{\mathrm{B}} \mathrm{O}_{\mathrm{O}}^{\mathrm{O}} \mathrm{H}_{\mathrm{O}}^{\mathrm{O}} \mathrm{H}_{\mathrm{H}}^{\mathrm{O}} \mathrm{X}^{\mathrm{Br}}$

PHB-diBr

PNIPAAM- $b$-PHB- $b$-PNIPAAM<smiles>CC(CC(C)C(=O)OCCOC(=O)C(C)(C)CC(C)(C)C(=O)OCCN(C)C)OC(=O)C(C)(C)CC(C)(C)C(=O)OCCN(C)C</smiles>

PDMAEMA-b-PHB-b-PDMAEMA

Scheme 7. 

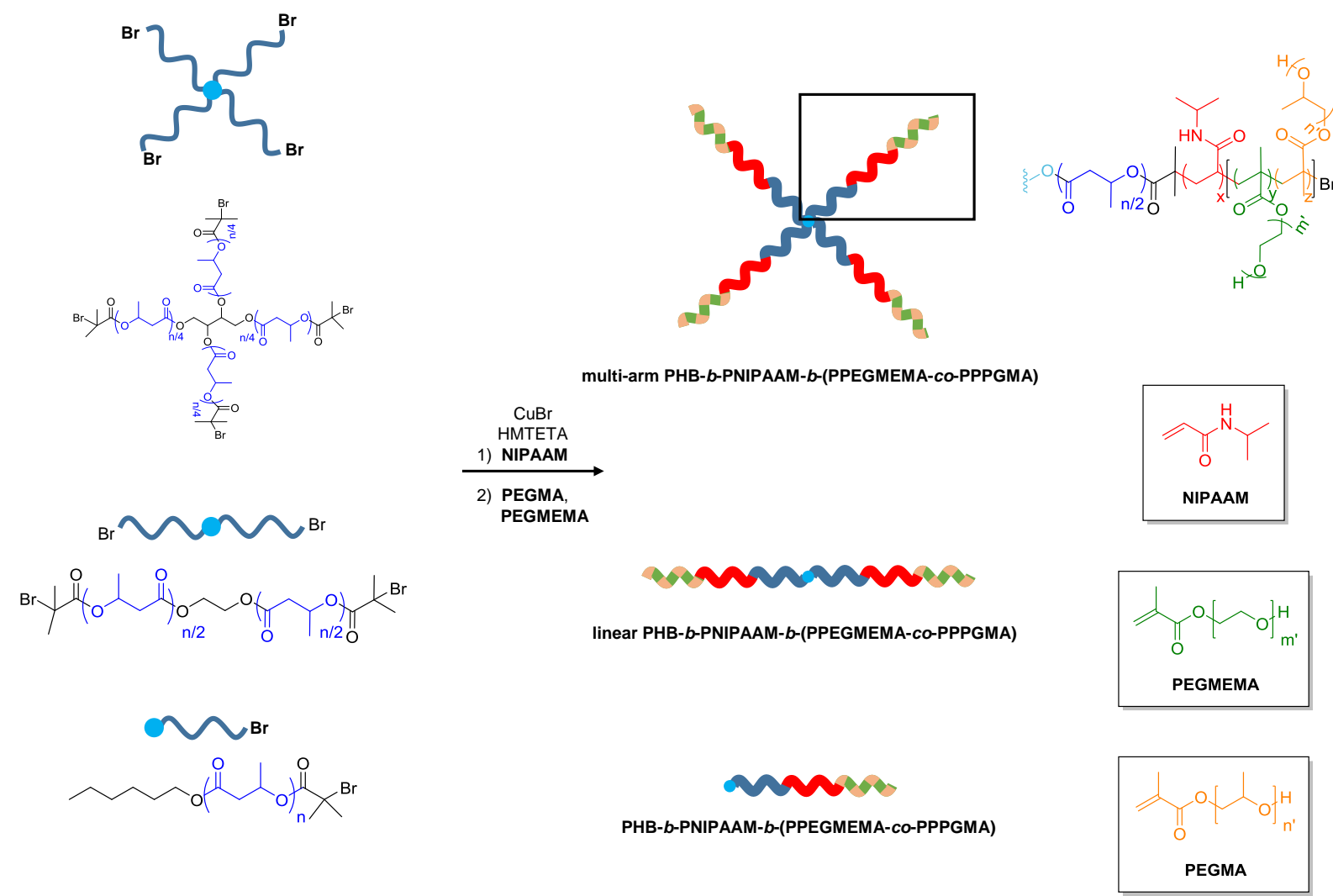

Scheme 8. 

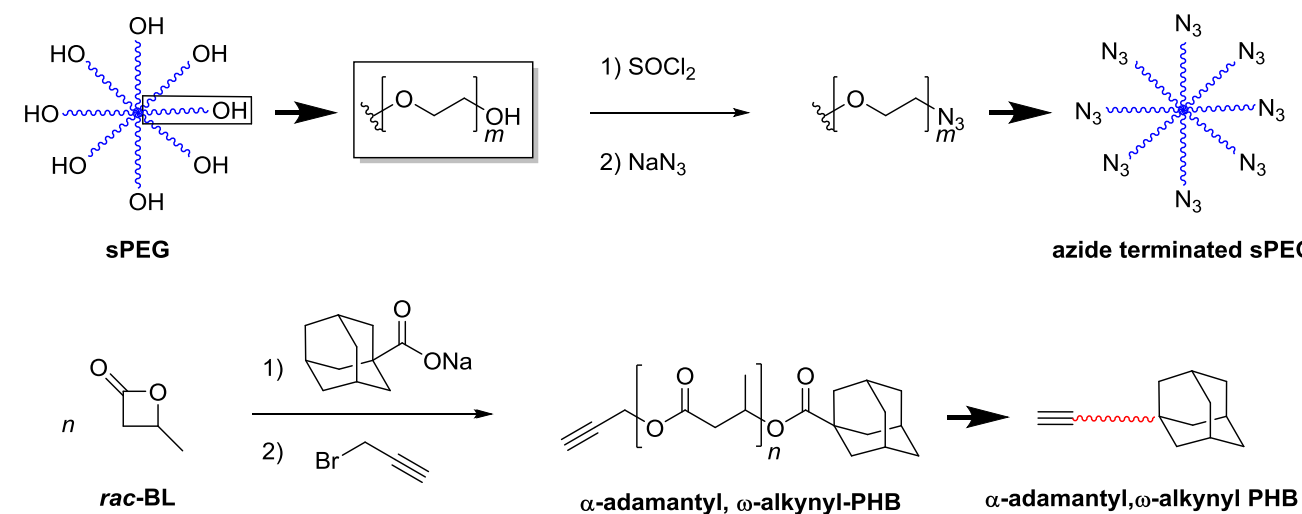

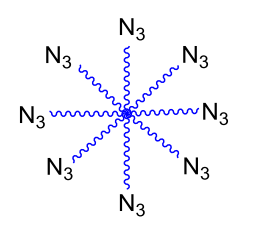

azide terminated sPEG $\alpha$-adamantyl, $\omega$-alkynyl PHB

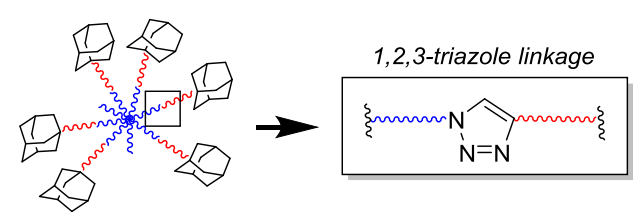

sPEG-b-PHB-adamantyl

\section{Scheme 9.}

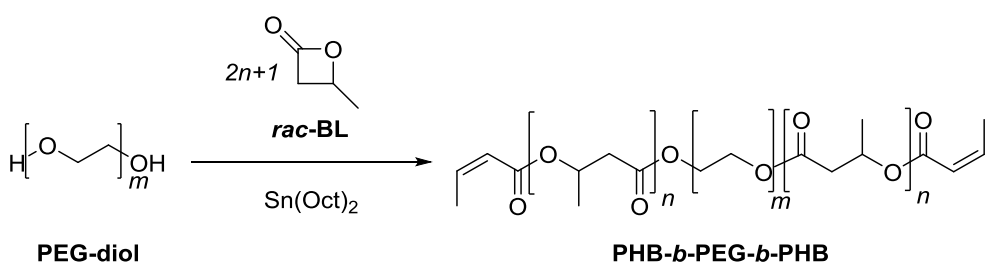

Scheme 10. 


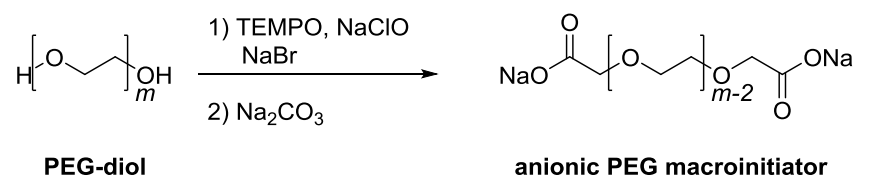
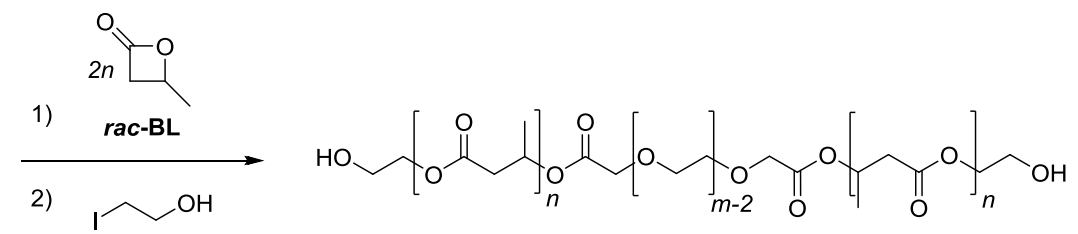

PHB-b-PEG-b-PHB

Scheme 11. 

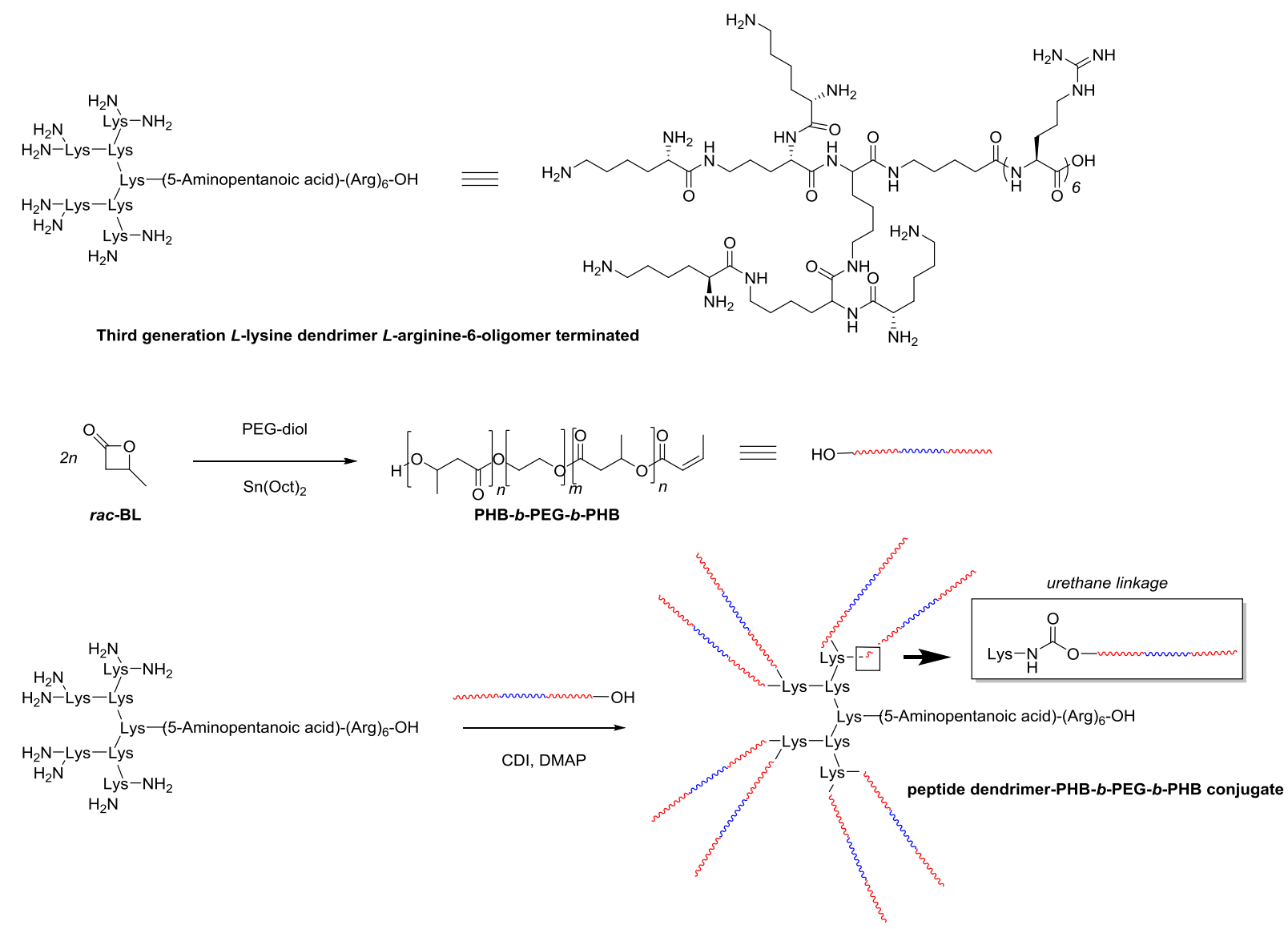

\section{Scheme 12.}


rac-BL<smiles>C/C=C\CC1CC(=O)O1</smiles>

rac-BL

rac-BL ${ }^{\text {allyl }}$

${ }_{n}$

$R$-BL

$R$-BLallyl<smiles>C=CC[C@H]1C[C@@H](O)C1=O</smiles>

$\mathrm{H}_{0}^{\mathrm{O}}$

PHB-co-PHB allyl
Zn $\beta$-diimidate
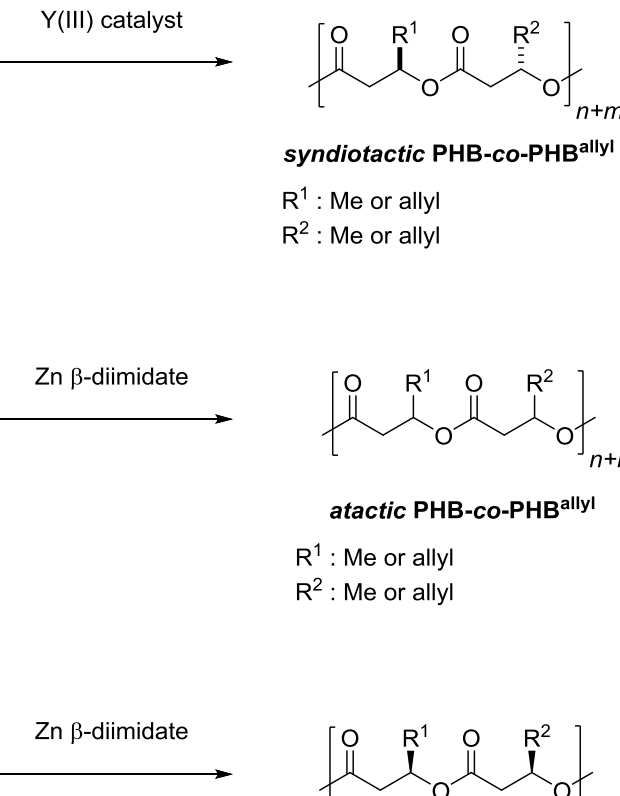

syndiotactic PHB-co-PHB allyl

$\mathrm{R}^{1}:$ Me or allyl

$\mathrm{R}^{2}:$ Me or allyl

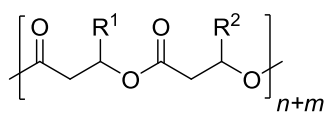

atactic PHB-co-PHB allyl

$\mathrm{R}^{1}$ : Me or allyl

$\mathrm{R}^{2}:$ Me or allyl

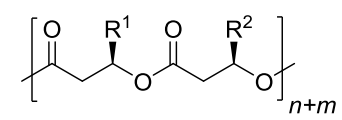

isotactic $\mathrm{PHB}-c 0-\mathrm{PHB}^{\text {allyI }}$

$\mathrm{R}^{1}:$ Me or allyl

$\mathrm{R}^{2}$ : Me or allyl

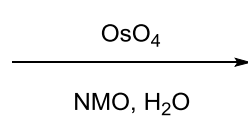<smiles></smiles>

PHB-Co-PHB ${ }^{\text {diOH }}$

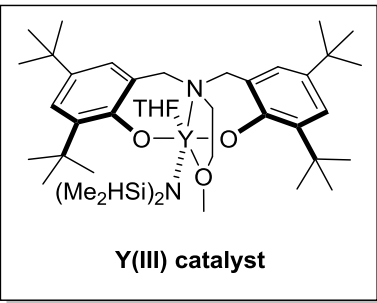

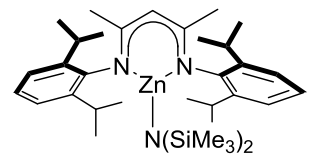

Zn $\beta$-diimidate

Scheme 13. 

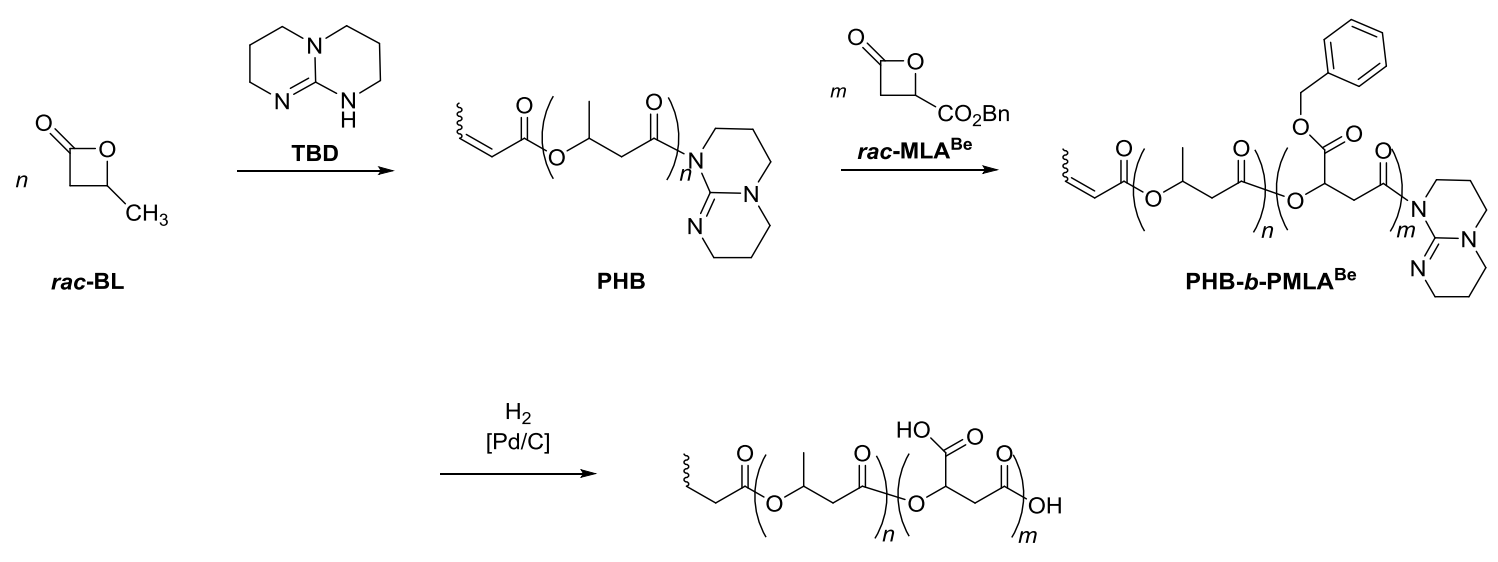

PHB-b-PMLA

Scheme 14. 
Table 1. Characteristics of PHB-based copolymers prepared from synthetic routes.

\begin{tabular}{|c|c|c|c|c|c|c|c|}
\hline \multirow{2}{*}{ PHB (co)polymer } & \multirow{2}{*}{$\begin{array}{l}\text { Natural } \\
\text { or } \\
\text { Synthet } \\
\text { ic PHB }\end{array}$} & \multirow{2}{*}{$\begin{array}{l}\text { PHB (co)polymer } \\
M_{\mathbf{n} ;} ; \bigoplus_{M} \\
\left(\text { g.mol }^{\square 1}\right)\end{array}$} & \multicolumn{2}{|l|}{$\begin{array}{l}\text { Molar mass } \\
\left(\text { g. mol }{ }^{01}\right)\end{array}$} & \multirow{2}{*}{$\begin{array}{l}\text { PHB } \\
\text { content } \\
(\mathbf{w t} \%)\end{array}$} & \multirow{2}{*}{$\begin{array}{l}\text { Thermal } \\
\text { Properties } \\
\left({ }^{\circ} \mathrm{C}\right)\end{array}$} & \multirow{2}{*}{ Ref. } \\
\hline & & & PHB & $\begin{array}{l}\text { Other } \\
\text { segment }\end{array}$ & & & \\
\hline \multicolumn{8}{|c|}{ 2.1. Chemically modified bacterial PHB-based (co)polymers } \\
\hline \multicolumn{8}{|c|}{ 2.1.1. Bacterial PHB homopolymers chemically modified into PHB-conjugates } \\
\hline AG-PHB & nat & - & - & - & - & - & [75] \\
\hline RGD4C-PHB & nat & - & - & - & - & - & [76] \\
\hline \multicolumn{8}{|c|}{ 2.1.2. Chemically modified bacterial PHB/PEG-based copolymers } \\
\hline DOCA-PHB- $b$-PEG-DOCA & nat & - & - & 4000 & - & - & [77] \\
\hline PHB-co-PEG & nat & $\begin{array}{l}\text { 5600-9900 (SEC); } \\
-\end{array}$ & $3500-5000$ & $750-5000$ & $41-87$ & - & [69] \\
\hline PEG- $b$-PHB- $b$-PEG & nat & $\begin{array}{l}\text { 4500-13 400 (SEC vs } \\
\text { PEG); 1.04-1.21 }\end{array}$ & $500-5500$ & $1800-4750$ & $7-59$ & $T_{\mathrm{m}}=54,147$ & {$[64,67,78]$} \\
\hline PEG- $b$-PHB- $b$-PEG & nat & $\begin{array}{l}12700 \text { (SEC vs PEG); } \\
1.13\end{array}$ & 2500 & 4900 & 51 & - & {$[71]$} \\
\hline Fluorescein-PEG- $b$-PHB- $b$-PEG & nat & - & - & - & - & - & [71] \\
\hline PEG- $b$-PHB- $b$-PEG & nat & $\begin{array}{l}13800 \text { (SEC vs PEG); } \\
1.20\end{array}$ & 2300 & 4900 & 48 & - & [79] \\
\hline Alexa Fluor 488-PEG- $b$-PHB- $b$-PEG & nat & - & - & - & - & - & [79] \\
\hline poly(PEG/PPG/PHB urethane) & nat & $\begin{array}{l}42500-50600 \quad \text { (SEC vs } \\
\text { PEG); } 1.37-1.56\end{array}$ & 1100 & $\begin{array}{l}\text { PEG : } 1900 \\
\text { PPG : } 2200\end{array}$ & $2-8$ & - & {$[80]$} \\
\hline \multicolumn{8}{|c|}{ 2.1.3. Other chemically modified bacterial PHB-based copolymers } \\
\hline PHB-co-PCL & nat & 4600-25 900 (SEC vs PS); & $400000\left(M_{\mathrm{w}}\right)$ & $120000\left(M_{\mathrm{w}}\right)$ & $28-81$ & - & [81] \\
\hline
\end{tabular}




\begin{tabular}{|c|c|c|c|c|c|c|c|}
\hline & & $1.31-1.72$ & & & & & \\
\hline PHBV-co-PCL & nat & $\begin{array}{l}13600-17300 \quad \text { (SEC } \quad \text { vs } \\
\text { PS }) ; 1.35-1.56\end{array}$ & $\begin{array}{l}\text { PHBV : } \\
177000\left(M_{\mathrm{w}}\right)\end{array}$ & $120000\left(M_{\mathrm{w}}\right)$ & $33-36$ & - & {$[81]$} \\
\hline PEEP- $b$-PHB- $b$-PEEP & nat & $\begin{array}{l}3400-15600 \quad\left({ }^{1} \mathrm{H} \quad \mathrm{NMR}\right) \\
1.47-2.23\end{array}$ & $900-4050$ & $1200-5800$ & $19-62$ & - & {$[82]$} \\
\hline PNIPAAM- $b$-PHB- $b$-PNIPAAM & nat & $\begin{array}{l}3800-37700 \text { (SEC vs PS); } \\
1.09-1.50\end{array}$ & 1700 & $1000-18000$ & $5-45$ & - & {$[70,83]$} \\
\hline PDMAEMA- $b$-PHB- $b$-PDMAEMA & nat & $\begin{array}{l}5200-24000 \quad\left({ }^{1} \mathrm{H} \quad \mathrm{NMR}\right) ; \\
1.23-1.35\end{array}$ & 2100 & $1600-11000$ & $9-41$ & - & {$[73,84]$} \\
\hline $\begin{array}{l}\text { PHB- } b \text {-PNIPAAM- } b \text {-(PPEGMEMA- } \\
c o \text {-PPPGMA) }\end{array}$ & nat & $\begin{array}{l}17 \text { 300-26 } 300 \quad \text { (SEC vs } \\
\text { PMMA) }\end{array}$ & $1400-2500$ & $14800-24900$ & $6-11$ & $\begin{array}{l}T_{\mathrm{m}}=35-38 \\
135-150 \\
T_{\mathrm{d}}=255-325 \\
325-445\end{array}$ & [85] \\
\hline
\end{tabular}

\subsection{PHB-based copolymers prepared from ROP of $\boldsymbol{\beta}$-butyrolactone}

\subsubsection{PHB/PEG-based copolymers from ROP of BL}

\begin{tabular}{|c|c|c|c|c|c|c|c|}
\hline adamantyl-PHB- $b$-sPEG & synth & $\begin{array}{l}20600-36800\left({ }^{1} \mathrm{H} \text { NMR }\right) \text {; } \\
1.30-1.41\end{array}$ & $1600-3100$ & $9500-19900$ & $34-64$ & - & {$[72]$} \\
\hline PHB- $b$-PEG- $b$-PHB & synth & $\begin{array}{l}\text { 5300-67 } 400\left({ }^{1} \mathrm{H} \text { NMR }\right) \text {; } \\
-\end{array}$ & $650-31700$ & 4000 & $25-94$ & $\begin{array}{l}T_{\mathrm{g}}=-43,-24 \\
T_{\mathrm{m}}=35,60\end{array}$ & {$[65,66]$} \\
\hline PHB- $b$-PEG- $b$-PHB & synth & $\begin{array}{l}4500 \text { (SEC vs PEG); } \\
1.07\end{array}$ & 860 & 1800 & 19 & - & [86] \\
\hline Peptide dendrimer-PHB- $b$-PEG- $b$-PHB & synth & $\begin{array}{l}1000-4900 \text { (SEC vs PS); } \\
1.48-2.26\end{array}$ & $200-2200$ & 600 & $40-88$ & $\begin{array}{l}T_{\mathrm{g}}=-26,-24 \\
T_{\mathrm{m}}=60,150\end{array}$ & [87] \\
\hline \multicolumn{8}{|c|}{ 2.2.2. PHB/PHA-based copolymers from ROP of BL } \\
\hline PHB-co-PHB ${ }^{\text {Allyl }}$ & synth & $\begin{array}{l}9200-61100 \text { (SEC vs PS); } \\
1.24-1.62\end{array}$ & - & - & 89 & $\begin{array}{l}T_{\mathrm{g}}=-10 \\
T_{\mathrm{m}}=113\end{array}$ & {$[88,89]$} \\
\hline PHB-co-PHB ${ }^{\mathrm{diOH}}$ & synth & $11200-69600$ (SEC vs & - & - & 89 & $T_{\mathrm{g}}=-2$ & {$[88,89]$} \\
\hline
\end{tabular}




\begin{tabular}{|c|c|c|c|c|c|c|c|}
\hline & & PS); $1.28-1.76$ & & & & $T_{\mathrm{m}}=130$ & \\
\hline PHB- $b$-PMLA ${ }^{\text {Be }}$ & synth & $\begin{array}{l}8200-18800 \quad\left({ }^{1} \mathrm{H} \quad \mathrm{NMR}\right) ; \\
1.16-1.28\end{array}$ & $1700-7300$ & $1700-17300$ & $9-73$ & $T_{\mathrm{g}}=2,38$ & {$[90,91]$} \\
\hline PHB- $b$-PMLA & synth & $\begin{array}{l}8100-10200\left({ }^{1} \mathrm{H} \text { NMR }\right) ; \\
\text { - }\end{array}$ & $1700-7300$ & $800-8500$ & $17-90$ & $T_{\mathrm{g}}=-6,+19$ & [91] \\
\hline PMLA $^{\mathrm{Be}}-b$-PHB- $b$-PMLA ${ }^{\mathrm{Be}}$ & synth & $\begin{array}{l}3300-11500\left({ }^{1} \mathrm{H} \quad \mathrm{NMR}\right) \\
1.30-1.41\end{array}$ & $1100-6500$ & $400-5200$ & $16-75$ & $T_{\mathrm{g}}=1,26$ & [92] \\
\hline PMLA- $b$-PHB- $b$-PMLA & synth & $\begin{array}{l}2800-7100\left({ }^{1} \mathrm{H} \text { NMR }\right) ; \\
-\end{array}$ & $1100-6600$ & $200-2600$ & $17-86$ & - & {$[92]$} \\
\hline
\end{tabular}


Table 2. Preparation methods and characteristics of PHB-based self-assembled systems.

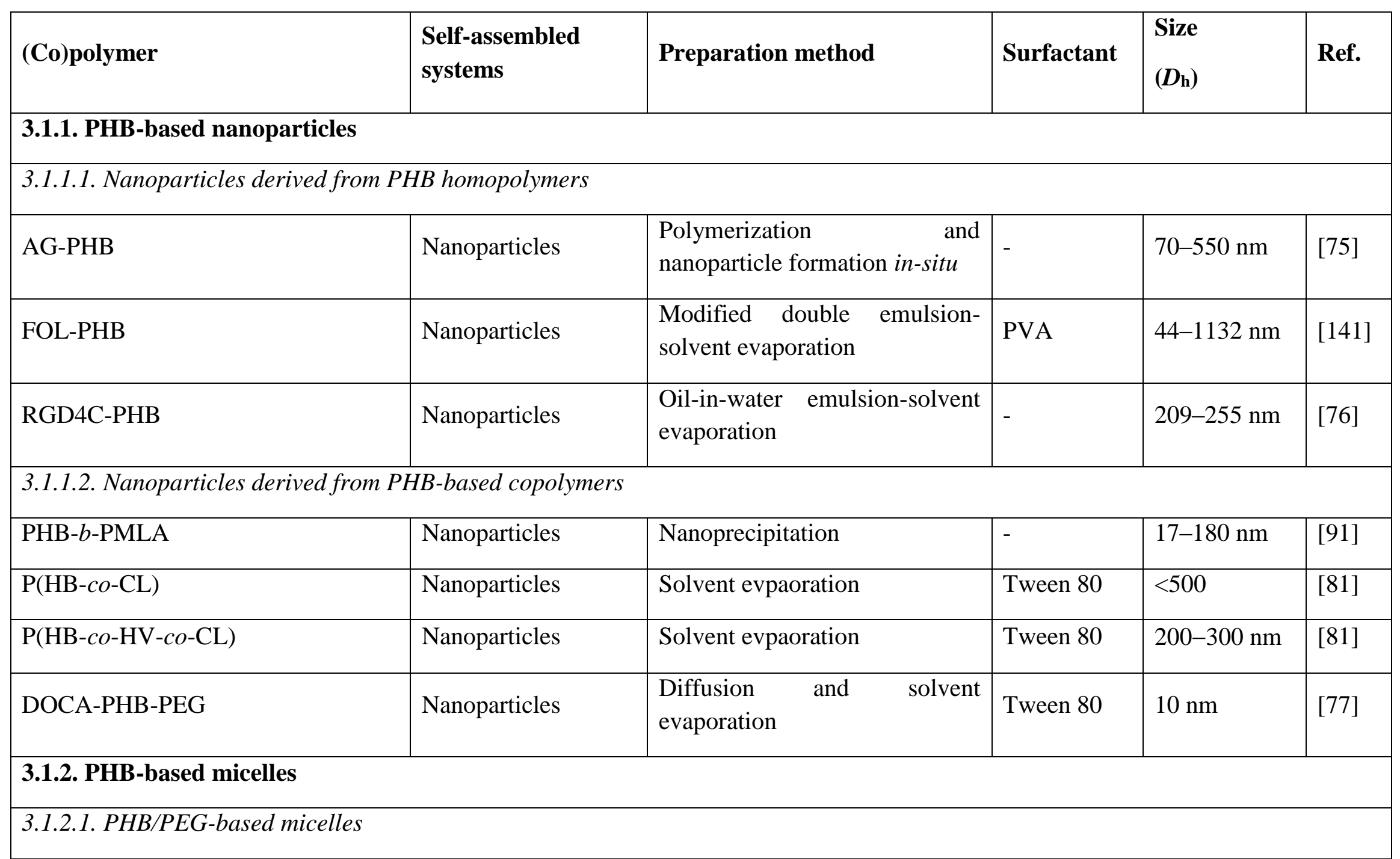




\begin{tabular}{|c|c|c|c|c|c|}
\hline PHB-co-PEG & Micelles & - & - & $61-109$ & [69] \\
\hline PEG- $b$-PHB- $b$-PEG & Micelles & Direct dissolution in water & - & $27-48 \mathrm{~nm}$ & [64] \\
\hline PEG- $b$-PHB- $b$-PEG & Micelles & Direct dissolution in water & - & $64-86 \mathrm{~nm}$ & [67] \\
\hline PEG- $b$-PHB- $b$-PEG & Micelles & Solvent evaporation & - & $37 \mathrm{~nm}$ & [71] \\
\hline PEG- $b$-PHB- $b$-PEG & Filamentous micelles & Solvent evaporation & PF-127 & $5 \mathrm{~nm}$ & [79] \\
\hline PHB- $b$-PEG- $b$-PHB & Micelles & $\begin{array}{l}\text { Precipitation-solvent } \\
\text { evaporation (ultrasound) }\end{array}$ & - & $73-89 \mathrm{~nm}$ & [68] \\
\hline PHB- $b$-PEG- $b$-PHB & Micelles & $\begin{array}{l}\text { Precipitation-solvent } \\
\text { evaporation (ultrasound) }\end{array}$ & - & $20-127 \mathrm{~nm}$ & {$[65]$} \\
\hline PHB- $b$-PEG- $b$-PHB & Micelles & $\begin{array}{l}\text { Precipitation-solvent } \\
\text { evaporation (ultrasound) }\end{array}$ & - & $20-130 \mathrm{~nm}$ & [66] \\
\hline adamantyl-PHB- $b$-sPEG & Micelles & Dialysis & - & $154-264 \mathrm{~nm}$ & [72] \\
\hline adamantyl-PHB- $b$-sPEG/DM- $\beta \square \mathrm{CD}$ & Vesicles & Dialysis & - & $200-500 \mathrm{~nm}$ & [72] \\
\hline \multicolumn{6}{|c|}{ 3.1.2.2. PHB-based stimuli-responsive micelles } \\
\hline PNIPAAM- $b$-PHB- $b$-PNIPAAM & Micelles & Dissolution in water & & $140-844 \mathrm{~nm}$ & [70] \\
\hline Poly(PEG/PPG/PHB urethane)s & Micelles & Solubilization & - & not reported & [80] \\
\hline PDMAEMA- $b$-PHB- $b$-PDMAEMA & Micelles & Solvent evaporation & - & $\begin{array}{l}10-20 \mathrm{~nm}, \\
\text { aggregates }\end{array}$ & [73] \\
\hline
\end{tabular}




\begin{tabular}{|c|c|c|c|c|c|}
\hline PEEP- $b$-PHB- $b$-PEEP & Micelles & Dialysis & - & $30-70 \mathrm{~nm}$ & {$[82]$} \\
\hline \multicolumn{6}{|l|}{ 3.1.3. PHB-based microparticles } \\
\hline $\mathrm{P}(\mathrm{HB}-c o-\mathrm{CL})$ & Microparticles & Solvent evaporation & Tween 80 & $2.5-3 \mu \mathrm{m}$ & {$[81]$} \\
\hline $\begin{array}{l}\mathrm{P}\left(\mathrm{HB}-c o-\mathrm{HB}^{\text {allyl }}\right) \\
\mathrm{P}\left(\mathrm{HB}-c o-\mathrm{HB}^{\mathrm{diOH}}\right)\end{array}$ & Microparticles & $\begin{array}{l}\text { Coprecipitation } \\
\text { Solvent evaporation }\end{array}$ & PVA & $10-100 \mu \mathrm{m}$ & [89] \\
\hline \multicolumn{6}{|l|}{ 3.1.4. PHB-based hydrogels } \\
\hline TAM(PHB- $b$-DCP- $b$-PHB $)_{3}$ & Hydrogels & $\begin{array}{ll}\text { Reactive } & \text { extrusion } \\
\text { modification of PHB } & \end{array}$ & - & - & [142] \\
\hline PHB- $b$-PEG- $b$-PHB $/ \beta-\mathrm{CD}$ & Hydrogels & $\begin{array}{l}\text { Vortexing and ultrasonicating } \\
\text { the bulk copolymer in a } \\
\text { saturated a-CD solution }\end{array}$ & - & - & [143] \\
\hline poly(PHB/PPG/PEG urethane) & Hydrogels & $\begin{array}{l}\text { Reversible sol-gel transition in } \\
\text { aqueous solution }\end{array}$ & - & - & [144] \\
\hline $\begin{array}{l}\text { PHB- } b \text {-PNIPAAM- } b \text {-(PPEGMEMA- } \\
c o \text {-PPPGMA) }\end{array}$ & Hydrogels & $\begin{array}{l}\text { Direct dissolution in aqueous } \\
\text { solution }\end{array}$ & - & - & {$[85]$} \\
\hline
\end{tabular}


Table 3. Characteristics of encapsulation and drug release from PHB-based self-assembled systems.

\begin{tabular}{|c|c|c|c|c|c|}
\hline PHB (co)polymer & $\begin{array}{l}\text { Encapsulated } \\
\text { molecule }\end{array}$ & $\begin{array}{l}\text { DLC } \\
\text { DLE }\end{array}$ & $\begin{array}{l}\text { Drug release } \\
\text { kinetic profile }\end{array}$ & Application & Ref. \\
\hline \multicolumn{6}{|c|}{ 3.2.1. PHB-based nanoparticles } \\
\hline \multicolumn{6}{|c|}{ PHB homopolymer nanoparticles } \\
\hline AG-PHB & Nile red & - & - & Colon cancer & [75] \\
\hline FOL-PHB & Arsenic trioxide & $\begin{array}{l}40 \mathrm{mg} \cdot \mathrm{g}^{-1} \\
94 \%\end{array}$ & $\begin{array}{l}\text { Burst release and then } \\
\text { sustained release }\end{array}$ & Colon cancer & [141] \\
\hline RGD4C-PHB & Nile Red & - & - & Breast cancer & [76] \\
\hline \multicolumn{6}{|c|}{ PHB copolymers nanoparticles } \\
\hline PHB- $b$-PMLA & Did oil & - & - & Cancer & {$[91]$} \\
\hline $\mathrm{P}(\mathrm{HB}-c o-\mathrm{HV}-c o-\mathrm{CL})$ & Calcein & $\begin{array}{l}\text { ca. } 1 \% \\
<20 \%\end{array}$ & $\begin{array}{l}\text { Burst effect }(20 \% \\
\text { released in } 15 \mathrm{~min}) \text { and } \\
100 \% \text { released in } c a . \\
3.5 \mathrm{~d}\end{array}$ & Drug carriers & [81] \\
\hline $\mathrm{P}(\mathrm{HB}-c o-\mathrm{HV}-c o-\mathrm{CL})$ & Oil Red O & $\begin{array}{l}\text { ca. } 1 \% \\
<20 \%\end{array}$ & $\begin{array}{l}\text { Linear release kinetic } \\
\text { preceded by a lag time } \\
\text { of } 6-8 \mathrm{~h}\end{array}$ & Drug carriers & [81] \\
\hline DOCA-PHB- $b$-PEG & FITC-Inulin & - & - & Colon cancer & {$[77]$} \\
\hline
\end{tabular}




\begin{tabular}{|c|c|c|c|c|c|}
\hline \multicolumn{6}{|l|}{ 3.2.2.1. PHB/PEG-based micelles } \\
\hline PEG- $b$-PHB- $b$-PEG & DOX & $\begin{array}{l}- \\
64 \%\end{array}$ & $30 \%$ released in $4 \mathrm{~d}$ & $\begin{array}{l}\text { Cancer therapy } \\
\text { (Xenograft tumor) }\end{array}$ & [71] \\
\hline PHB- $b$-PEG- $b$-PHB & Pyrene & $\begin{array}{l}1.4-6.7 \mathrm{mg} \cdot \mathrm{g}^{-1} \\
14-61 \%\end{array}$ & $\begin{array}{l}\text { Second order } \\
\text { exponential decay }\end{array}$ & & [65] \\
\hline PHB-co-PEG & Griseofulvin & $\begin{array}{l}\text { not reported } \\
14-67 \%\end{array}$ & $\begin{array}{l}\text { Burst effect followed } \\
\text { by sunstained release } \\
\text { during } 48 \mathrm{~h}\end{array}$ & Drug delivery & [69] \\
\hline \multicolumn{6}{|l|}{ 3.2.2.2. Other PHB-based micelles } \\
\hline PNIPAAM- $b$-PHB- $b$-PNIPAAM & pyrene & - & - & $\begin{array}{l}\text { Chemotherapeutics } \\
\text { applications }\end{array}$ & [70] \\
\hline PDMAEMA- $b$-PHB- $b$-PDMAEMA & DOX & $31-38 \%$ & $\begin{array}{l}13 \mathrm{~d}, \mathrm{pH} 7,37^{\circ} \mathrm{C} \\
>20 \mathrm{~d}, \mathrm{pH} 7,20^{\circ} \mathrm{C}\end{array}$ & $\begin{array}{l}\text { Chemotherapeutics } \\
\text { applications }\end{array}$ & [73] \\
\hline PEEP- $b$-PHB- $b$-PEEP & Paclitaxel & $\begin{array}{l}0.01-5 \% \\
1-46 \%\end{array}$ & $70 \%$ released $25 \mathrm{~d}$ & Drug delivery & [82] \\
\hline \multicolumn{6}{|l|}{ 3.2.3. PHB-based microparticles } \\
\hline $\mathrm{P}(\mathrm{HB}-c o-\mathrm{CL})$ & Calcein & $\begin{array}{l}2-9 \% \\
100 \%\end{array}$ & $\begin{array}{l}\text { Burst effect followed } \\
\text { by a sustained release }\end{array}$ & Drug carriers & [81] \\
\hline $\mathrm{P}(\mathrm{HB}-c o-\mathrm{CL})$ & Oil Red O & $1-6 \%$ & $\begin{array}{ll}\text { No burst } & \text { effect, } \\
\text { sustained } & \text { release }\end{array}$ & Drug carriers & [81] \\
\hline
\end{tabular}




\begin{tabular}{|c|c|c|c|c|c|}
\hline & & $10-57 \%$ & $\begin{array}{l}\text { highly depending on } \\
\text { the polymer molar } \\
\text { mass and crystallinity }\end{array}$ & & \\
\hline $\begin{array}{l}\mathrm{P}\left(\mathrm{HB}-c o-\mathrm{HB}^{\text {allyl }}\right) \\
\mathrm{P}\left(\mathrm{HB}-c o-\mathrm{HB}^{\mathrm{diOH}}\right)\end{array}$ & L-Leuprolide & $\begin{array}{l}- \\
94 \%\end{array}$ & $\begin{array}{l}\text { Release dependent on } \\
\text { the PHB microstrcuture }\end{array}$ & Drug delivery & [89] \\
\hline
\end{tabular}

